\author{
UNIVERSIDADE DE SÃO PAULO \\ FACULDADE DE MEDICINA DE RIBEIRÃO PRETO
}

PRISCILA COLAVITE PAPASSIDERO

Análise da perfusão cerebral através de SPECT em pacientes com dor lombar crônica secundária à hérnia de disco antes e após o tratamento com Gabapentina.

Ribeirão Preto 


\section{Análise da perfusão cerebral através de SPECT em pacientes com dor lombar crônica secundária à hérnia de disco antes e após o tratamento com Gabapentina.}

Dissertação apresentada ao Programa de PósGraduação da Faculdade de Medicina de Ribeirão Preto da Universidade de São Paulo para obtenção do título de Mestre em Ciências.

Área de concentração: Neurologia.

Subárea: Neurologia Clínica

Orientadora:

Profa. Dra. Fabíola Dach ${ }^{1}$

Colaboração:

Prof. Dr. Lauro Wichert Ana²

1. Docente do Departamento de Neurociências e Ciências do Comportamento da Faculdade de Medicina de Ribeirão Preto da Universidade de São Paulo; Neurologista responsável pelo Ambulatório de Cefaleias e Algias Craniofaciais do Hospital das Clínicas da Faculdade de Medicina de Ribeirão Preto.

2. Docente Coordenador e Supervisor da Seção de Medicina Nuclear, Departamento de Clínica Médica do Hospital das Clínicas da Faculdade de Medicina de Ribeirão Preto da Universidade de São Paulo. 
Autorizo a reprodução e divulgação total ou parcial deste trabalho, por qualquer meio convencional ou eletrônico, para fins de estudo e pesquisa, desde que citada a fonte.

Ficha Catalográfica

Papassidero, Priscila Colavite

Análise da perfusão cerebral através de SPECT em pacientes com dor lombar crônica secundária à hérnia de disco antes e após o tratamento com Gabapentina.

Ribeirão Preto, 2019.

104 f.: il.; $30 \mathrm{~cm}$.

Dissertação de mestrado apresentada à Faculdade de Medicina de Ribeirão Preto / USP

Área de concentração: Neurologia

Orientadora: Dach, Fabíola

1. Dor crônica. 2. Gabapentina. 3. SPECT. 4. Córtex cingulado. 5. Córtex pré-frontal dorsolateral. 


\section{FOLHA DE APROVAÇÃO}

Nome: Papassidero, Priscila Colavite

Título: Análise da perfusão cerebral através de SPECT em pacientes com dor lombar crônica secundária à hérnia de disco antes e após o tratamento com Gabapentina.

Dissertação apresentada ao Programa de PósGraduação da Faculdade de Medicina de Ribeirão Preto da Universidade de São Paulo para obtenção do título de Mestre em Ciências.

Aprovada em:

Banca examinadora:

Prof.Dr.

Instituição: Julgamento:

Prof.Dr.

Instituição: Julgamento:

Prof.Dr. Instituição: Julgamento: 


\section{DEDICATÓRIA}

Dedico este trabalho ao meu esposo e grande amor da minha vida Eduardo, que há 16 anos caminha ao meu lado vibrando com minhas vitórias, apoiando minhas ideias e cuidando da nossa família. Dedico também ao meu filho, João Eduardo, que com seu amor mais genuíno, seu sorriso cativante e seu abraço intenso me mostrou um amor que até então eu desconhecia. Amo vocês. 


\section{AGRADECIMENTOS}

À Deus, por me proporcionar saúde, determinação, sabedoria e capacidade para realizar todos os meus objetivos.

Ao meu esposo Eduardo, por todo apoio, compreensão e paciência durante esta jornada. Sem seu suporte nada disso seria possível. Obrigada por me amar e cuidar de mim por todos esses anos.

Ao meu filho João Eduardo, cujo amor incondicional me inspira a almejar voos cada vez mais altos. Obrigada por me escolher para ser sua mãe.

Aos meus pais João e Silvia, por serem exemplo de esforço e honestidade que pautam minha jornada. Seu apoio e incentivo durante toda minha vida acadêmica foram fundamentais para que eu chegasse até aqui.

À minha irmã Gabriela, por me ensinar tanto sobre a vida com sua serenidade.

À minha avó Wanda, que em meus tempos de infância ensinou-me as primeiras palavras e foi grande incentivadora de meus estudos durante toda a vida.

À Prof. Dra. Fabíola Dach, por aceitar ser minha orientadora, pela paciência, por todos seus ensinamentos e por ser exemplo a ser seguido em sua brilhante jornada profissional. Obrigada por sua contribuição ímpar em minha formação acadêmica e profissional, desde a residência médica até a pós-graduação.

Ao Prof. Dr. Lauro Wichert-Ana, pela cooperação fundamental para que este projeto pudesse se desenvolver de forma tão harmônica. Obrigada por compartilhar sua sabedoria conosco e não medir esforços para o bom andamento desta pesquisa. 
À Prof. Dra. Érica Negrini Lia, pela oportunidade de trabalho em conjunto, desde a discussão de ideias até a coleta de dados, cujo papel foi determinante para que eu pudesse ingressar neste projeto. Obrigada por toda contribuição ao longo da jornada.

Ao físico médico Leonardo Alexandre Santos, por sua atuação primordial no processamento dos dados e imagens das SPECTs, obrigada por abrilhantar este trabalho com toda sua expertise.

Aos nossos pacientes e voluntários, por confiarem e depositarem suas esperanças de melhora em nossa pesquisa, sem a participação de vocês essa conquista não seria possível. É por vocês que prosseguimos em nossa missão.

À equipe da Unidade de Pesquisa Clínica, pela parceria no andamento deste trabalho que foi imprescindível para o sucesso do mesmo.

À equipe da Medicina Nuclear, por acolher nossos pacientes e tornar mais leve sua jornada de contribuição com nossa pesquisa.

Aos professores das disciplinas de pós-graduação que colaboraram de alguma forma para a construção deste trabalho, com seus ensinamentos teóricos e práticos e sua experiência acadêmica. 


\section{EPÍGRAFE}

"Minha ideia do sábio estoico moderno é alguém que transforma medo em prudência, dor em informação, erros em começos e desejos em realizações".

Nassim Nicholas Taleb 


\section{RESUMO}

\section{PAPASSIDERO, P.C. Análise da perfusão cerebral através de SPECT em pacientes com dor lombar crônica secundária à hérnia de disco antes e após o tratamento com}

Gabapentina. 2019. 104f. Dissertação (Mestrado) em Neurologia - Faculdade de Medicina, Universidade de São Paulo, Ribeirão Preto, 2019.

Dor lombar crônica (DLC) é causa de incapacidade para o trabalho e prejuízo econômico para a sociedade. Quando decorre do comprometimento de estruturas do sistema nervoso (dor neuropática), seu manejo é difícil e exige expertise do profissional que a acompanha. A gabapentina emerge nesse cenário como uma possibilidade terapêutica eficaz, estando indicada em diversas diretrizes para o tratamento de dor neuropática como medicação de primeira linha. Este estudo propõe analisar qual o padrão de perfusão cerebral de pacientes com dor lombar crônica secundária à hérnia discal e avaliar se há mudanças nesse padrão após o tratamento com gabapentina utilizando SPECT cerebral. Baseamos a comparação na medida da intensidade da dor pela Escala Visual Numérica (EVN) antes e após o tratamento, além de sua correlação com aspectos biopsicossociais que estão envolvidos na dor crônica (ansiedade, depressão, catastrofização e qualidade de vida). Foram selecionados 13 pacientes portadores de dor crônica secundária à hérnia discal lombar, com média de idade de 41 anos e intensidade de dor de 5,92 pontos medida pela EVN. Os resultados mostraram que portadores de DLC possuem aumento da perfusão cerebral no córtex pré-frontal dorsolateral, lobo occipital direito e córtex cingulado posterior em relação aos voluntários saudáveis. Após o uso da gabapentina, houve hiperperfusão no lobo límbico bilateral e hipoperfusão na substância cinzenta periaquedutal em comparação aos voluntários saudáveis. Entre os pacientes que não apresentaram melhora clínica com o uso da gabapentina houve hipoperfusão biparietal em comparação aos voluntários saudáveis e hiperperfusão no cíngulo anterior esquerdo em comparação à imagem de SPECT antes do uso da gabapentina. Não houve correlação estatística significativa entre o uso da gabapentina e melhora de sintomas associados à dor como depressão, ansiedade, catastrofização e percepção de qualidade de vida.

Palavras-chave: 1. Dor lombar crônica. 2. Gabapentina. 3. SPECT. 4. Córtex cingulado. 5. Córtex pré-frontal dorsolateral. 


\begin{abstract}
PAPASSIDERO, P.C. Analysis of cerebral perfusion through SPECT in patients with low back pain due to disc herniation before and after treatment with gabapentin. 2019. 104f. Dissertação (Mestrado) em Neurologia - Faculdade de Medicina, Universidade de São Paulo, Ribeirão Preto, 2019.

Chronic low back pain (LBP) is a cause of disability for work and economic harm to society. When it is due to the compromise of structures of the nervous system (neuropathic pain), its handling is difficult and requires the expertise of the professional who accompanies it. Gabapentin emerges in this scenario as an effective therapeutic possibility and is indicated in several guidelines for the treatment of neuropathic pain as first-line medication. This study proposes to analyze the pattern of cerebral perfusion of patients with chronic low back pain secondary to the herniated disc and to evaluate if there are changes in this pattern after the treatment with gabapentin using cerebral SPECT. We base the comparison in the pain intensity measurement by the Visual Numerical Scale (VNS) before and after the treatment, in addition to its correlation with biopsychosocial aspects that are involved in chronic pain (anxiety, depression, catastrophization and quality of life). We selected 13 patients with chronic pain due to lumbar disc herniation, with a mean age of 41 years and pain intensity of 5.92 points measured by VNS. The results showed that LBP patients had increased cerebral perfusion in the dorsolateral prefrontal cortex, right occipital lobe and posterior cingulate cortex compared to healthy volunteers. After gabapentin use, there was hyperperfusion in the bilateral limbic lobe and hypoperfusion in periaqueductal gray matter compared to healthy volunteers. Among patients who did not show clinical improvement with gabapentin, there was biparietal hypoperfusion compared to healthy volunteers and hyperperfusion in the left anterior cingulate cortex compared to SPECT before gabapentin. There was no significant statistical correlation between the use of gabapentin and improvement of symptoms associated with pain such as depression, anxiety, catastrophization and perception of quality of life.
\end{abstract}

Key words: 1. Chronic low back pain. 2. Gabapentin. 3. SPECT. 4. Cingulate cortex. 5. Dorsolateral prefrontal cortex. 


\section{LISTA DE FIGURAS}

Figura 1- Níveis de acurácia no diagnóstico da dor neuropática ....................................19

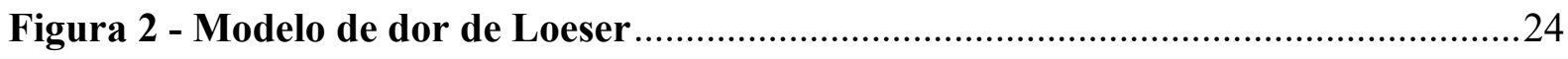

Figura 3 - Alterações do FSCr em pacientes com dor lombar crônica, antes do uso da gabapentina, em relação a voluntários saudáveis.

Figura 4 - Alterações do FSCr em 13 pacientes com dor lombar crônica após o uso de gabapentina

Figura 5 - Alterações do FSCr em pacientes sem melhora clínica com gabapentina, em relação aos controles saudáveis

Figura 6 - Comparação do FSCr pós versus pré tratamento com gabapentina, no grupo de 7 pacientes que não apresentaram melhora clínica 


\section{LISTA DE TABELAS}

Tabela 1- Características demográficas dos participantes

Tabela 2 - Regiões cerebrais com alterações significativas do FSCr nos pacientes com dor lombar crônica antes do uso da gabapentina, em comparação a voluntários saudáveis 47

Tabela 3 - Diferença perfusional individual antes e depois da gabapentina

Tabela 4 - Comparação do grupo de 13 pacientes com dor lombar crônica, antes e depois do uso da gabapentina - Áreas de hiper e hipoperfusão. 50

Tabela 5 - Análise individual das diferenças no FSCr entre pacientes com e sem melhora com a gabapentina comparativamente aos controles saudáveis - Áreas de hiper e hipoperfusão

Tabela 6 - Comparação entre o grupo de pacientes sem melhora clínica com a gabapentina e o banco de dados de voluntários saudáveis - área de hipoperfusão .54

Tabela 7 - Comparação entre grupos. Diferenças do FSCr antes e depois do uso da gabapentina, analisados separadamente nos grupos com e sem melhora clínica. 


\section{LISTA DE GRÁFICOS}

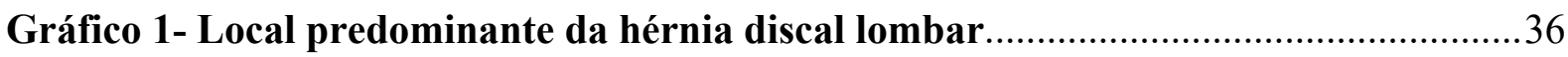

Gráfico 2 - Eventos adversos relacionados ao uso da gabapentina ................................ 38

Gráfico 3 - Melhora clínica de acordo com a dose utilizada de gabapentina ..................39

Gráfico 4 - Presença de sintomas de ansiedade de acordo com a escala HADS-A...........40

Gráfico 5 - Presença de sintomas de depressão de acordo com a escala HADS-D ...........41

Gráfico 6 - Comparação entre melhora clínica e sintomas de depressão e ansiedade .....42

Gráfico 7 - Comparação entre a pontuação da escala EPCD na visita inicial e na visita de finalização.

Gráfico 8 - Comparação da qualidade de vida medida através do WHOQOL-bref antes

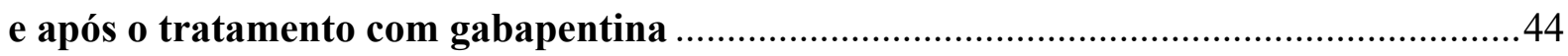

Gráfico 9 - Presença de sonolência entre os participantes antes e após o tratamento .....45 


\section{LISTA DE ABREVIATURAS}

AINEs - Anti-inflamatórios não-esteroidais

ASL - Arterial Spin Labelling

AVC - Acidente vascular cerebral

CCA - Córtex cingulado anterior

CCApg - Córtex cingulado anterior pré-genual

CCP - Córtex cingulado posterior

CI - Córtex insular

CPF - Córtex pré-frontal

CPFDL - Córtex pré-frontal dorsolateral

CRF - Case report form

DLC - Dor lombar crônica

DMN - Default mode network

DN4 - Douleur neurophatique en 4 questions

DNPT - Ambulatório de dor neuropática

ECG - Eletrocardiograma

EPCD - Escala de pensamentos catastróficos em dor da PRSS

ESE - Escala de sonolência de Epworth

EVA - Escala visual analógica

EVN - Escala visual numérica

FSCr - Fluxo sanguíneo cerebral regional

GABA - Ácido gama amino butírico

HADS - Escala hospitalar de ansiedade e depressão

HCFMRP-USP - Hospital das Clínicas da Faculdade de Medicina de Ribeirão Preto da Universidade de São Paulo

IASP - International Association for the Study of Pain

JOABPEQ - Japanese orthopedic association back pain evaluation questionnaire

M1 - Córtex motor primário

NeuPSIG - Grupo Especial de Interesse em Dor Neuropática da IASP

NMDA - N-metil D-aspartato

PET - Tomografia por emissão de pósitrons

PKC - Proteína quinase C 
PRSS - Catastrophizing scale of the pain-related self-statements scale

PSQI - Escala de qualidade de sono de Pittsburgh

RM - Ressonância magnética

RMf - Ressonância magnética funcional

S1 - Córtex somatossensorial primário

S2 - Córtex somatossensorial secundário

SCP - Substância cinzenta periaquedutal

SF-36 - Medical outcomes short-form health survey

SNC - Sistema nervoso central

SPECT-Single-photon emission computed tomography

Tc-ECD - Tecnécio-etilenodicisteína

TCLE - Termo de consentimento livre e esclarecido

TGO - Transaminase glutâmica oxalacética

UPC - Unidade de pesquisa clínica

WHOQOL - Grupo de qualidade de vida da Organização Mundial de Saúde

WHOQOL-bref - Escala de qualidade de vida da Organização Mundial de Saúde, versão abreviada 


\section{SUMÁRIO}

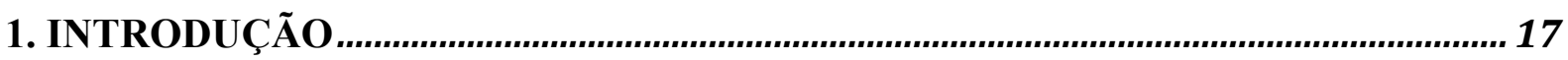

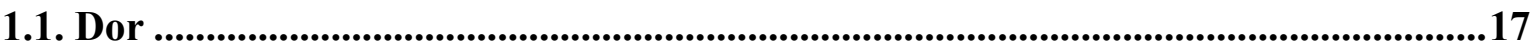

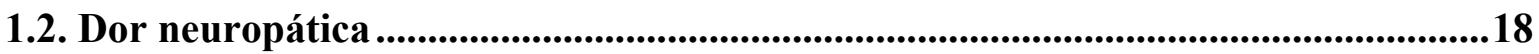

1.3. Dor lombar baixa e hérnia discal lombar..................................................................20

1.4. Uso da gabapentina no tratamento da dor neuropática .......................................22

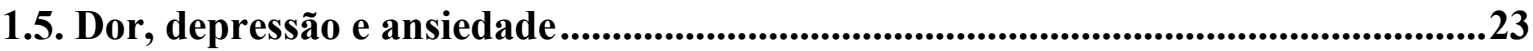

1.6. Dor e catastrofização .................................................................................................................23

1.7. Dor e qualidade de vida .................................................................................................25

1.8. Dor e distúrbios do sono .....................................................................................................26

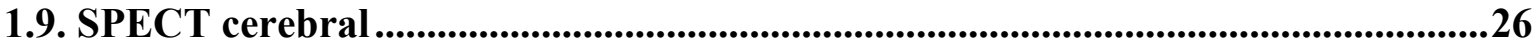

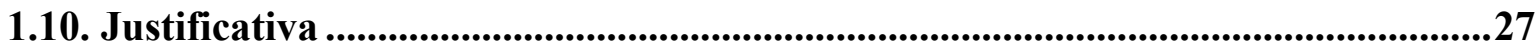

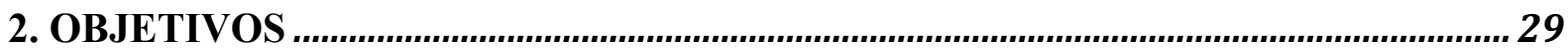

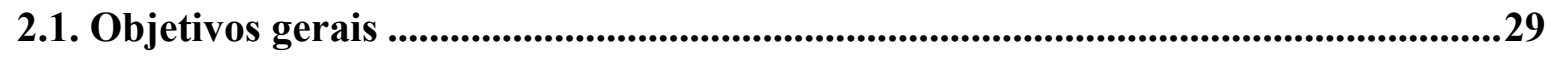

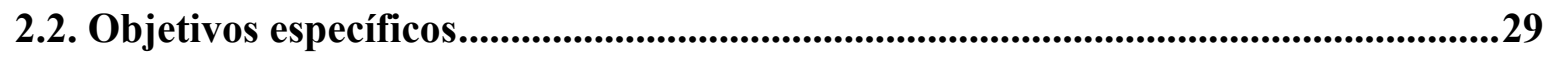

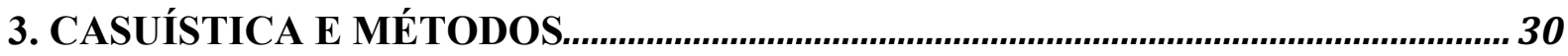

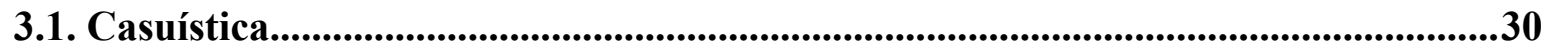

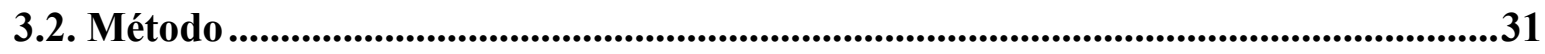

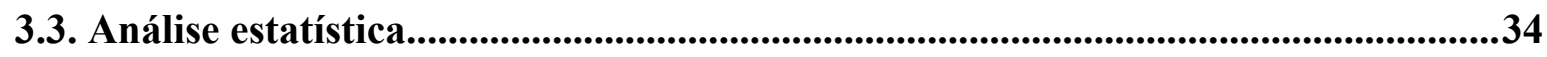

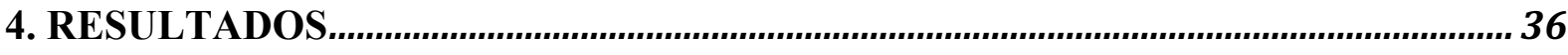

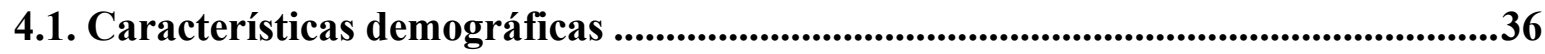

4.2. Avaliação da dor .......................................................................................................................38

4.3. Avaliação de depressão e ansiedade.................................................................................39

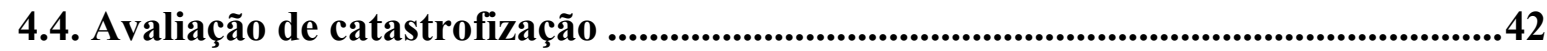

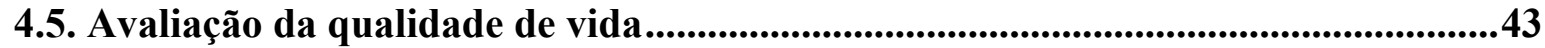


4.7. Avaliação do fluxo sanguíneo cerebral regional (FSCr)

4.7.1 Comparação entre grupos. Diferenças no FSCr entre pacientes com dor lombar crônica, antes do uso da gabapentina, versus voluntários saudáveis.

4.7.2 Comparação individual e entre grupos. Diferenças no FSCr do grupo de 13

pacientes com dor lombar crônica, antes e depois do uso da gabapentina.

4.7.3 Comparação individual e entre grupos. Diferenças do FSCr entre pacientes com melhora $(n=6)$ e sem melhora $(n=7)$ da DLC após o uso da gabapentina, comparativamente aos voluntários saudáveis

4.7.4 Comparação entre grupos. Diferenças do FSCr antes e depois do uso da gabapentina, analisados separadamente nos grupos com e sem melhora clínica.

5. DISCUSSÃO

6. CONCLUSÃO

REFERÊNCIAS BIBLIOGRÁFICAS

APÊNDICE A - Aprovação do CEP 82

APÊNDICE B - Termo de Consentimento Livre e Esclarecido......................................... 88

APÊNDICE C - Case Report Form (CRF) .............................................................. 92

APÊNDICE D - Correlação entre alterações individuais do FSCr com escala EVN ...... 96

ANEXO A - ESCALA VISUAL NUMÉRICA (EVN)............................................... 97

ANEXO B - Douleur Neurophatique en 4 Questions (DN4).............................................. 98

ANEXO C - Escala Hospitalar de Ansiedade e Depressão (HAD) ................................... 99

ANEXO D - Escala de Pensamentos Catastróficos Sobre Dor (EPCD) ...........................100

ANEXO E - Instrumento Abreviado de Avaliação da Qualidade de Vida......................101

(WHOQOL-bref)

ANEXO F - Escala de Sonolência de Epworth............................................................104 


\section{INTRODUÇÃO}

\subsection{Dor}

De acordo com a definição proposta pela IASP (International Association for the Study of Pain), a dor é conceituada como uma experiência sensorial e emocional desagradável associada ou relacionada a um dano real ou potencial dos tecidos, ou descrita em termos de tal dano.

A dor é considerada subjetiva, tendo em vista que cada indivíduo define o que é dor de acordo com experiências prévias e com influências socioculturais (1). É um fenômeno complexo, que envolve aspectos sensitivo-discriminativos, emocionais, cognitivo-avaliativos e respostas comportamentais (2).

Podemos classificar a dor temporalmente em aguda ou crônica. A dor aguda tem um caráter transitório, cuja duração varia de segundos a semanas, e tem um papel de alerta para lesão em tecidos ou órgãos, podendo ser causada por inflamações, infecções, traumas, entre outras causas. Entretanto, em alguns casos a dor pode se prolongar por um tempo maior do que o habitual para a cicatrização do tecido lesionado, perdendo seu papel de alerta e tornando-se um sintoma sem propósito definido, cuja duração pode variar de meses à muitos anos; neste caso é denominada crônica ou persistente (3).

Do ponto de vista neuroanatômico, a dor pode ser classificada em nociceptiva, neuropática ou mista. A dor nociceptiva decorre da ativação de receptores periféricos (nociceptores ou terminações nervosas livres) por estímulos ambientais, sejam eles mecânicos, químicos ou térmicos. O estímulo gera um potencial de ação que é transmitido pelas fibras amielínicas do tipo $\mathrm{C}$ ou fibras mielinizadas A-delta até atingirem o Sistema Nervoso Central (SNC), onde a resposta é interpretada como dor. Entretanto, dor é muito mais do que nocicepção. Ao longo do caminho até o SNC, outras estruturas são ativadas, gerando respostas neuroendócrinas, autonômicas, neuroimunitárias e psíquicas. Fibras descendentes projetam-se para a formação reticular do tronco encefálico, especialmente sobre a substância cinzenta periaquedutal (SCP), ativando mecanismos endógenos de supressão da dor (4). Alterações sobre o apetite, sono, humor e medo culminam em um comportamento doloroso (Figura 2) (57).

A repercussão que o estímulo nociceptivo traz a cada indivíduo envolve fatores genéticos, ambientais, raciais, culturais, religiosos, filosóficos, entre outros, que podem atenuar ou 
amplificar a resposta dolorosa de acordo com experiências pregressas e estado mental de tal indivíduo. A resposta emocional negativa gerada pela dor é o sofrimento (8). Entender o quão impactante a dor é na vida de um indivíduo pode se tornar um desafio. Diversos métodos tentam transformar tal sensação subjetiva em uma forma objetiva de mensuração. A importância da dor foi destacada pela Sociedade Americana de Dor em 1995 ao declará-la como $5^{\circ}$ sinal vital (9).

Diversas escalas e questionários podem ser usadas para avaliar a dor de forma unidimensional (somente a intensidade da dor) ou multidimensional (impacto sobre atividades diárias, qualidade de vida, aspectos psicológicos relacionados à dor, qualidade do sono). Dentre aquelas que avaliam a dor de forma unidimensional, a escala visual numérica (EVN) é uma das mais utilizadas, e consiste em uma régua dividida em onze partes, de modo que a nota 0 (zero) significa que o paciente não sente nenhuma dor e a nota 10 significa dor em seu grau máximo (ANEXO A). É uma escala simples, de fácil aplicação à beira leito, que pode ser utilizada por qualquer profissional da saúde com boa confiabilidade e validade (10). Essa tradução da dor em um número, por mais simplista que pareça, pode ser uma ferramenta útil para auxiliar na conduta médica, avaliar a resposta a um tratamento proposto e acompanhar a evolução e o desfecho de uma patologia (11).

\subsection{Dor neuropática}

A dor neuropática é definida como dor que surge como consequência direta de uma lesão ou doença que afeta o sistema somatossensitivo (12). Sua prevalência varia entre $6-8 \%$ da população geral, gerando alto impacto socioeconômico e incapacidade (13).

Este tipo de dor pode ser manifestado em diversas doenças neurológicas que afetem tanto o sistema nervoso central quanto periférico, como neuropatia diabética, neuralgia pósherpética, dor pós-operatória, dor pós-AVC, radiculopatia e esclerose múltipla. Apesar de mecanismos etiológicos distintos, os pacientes que desenvolvem dor neuropática apresentam características clínicas comuns: dor em uma área com perda total ou parcial da sensibilidade tátil; utilização de descritores como dor em "queimação, pontadas, agulhadas, choques"; aumento da dor após estimulação repetitiva e dor persistente após cessação do estímulo; e dor desencadeada por estímulo não nocivo (alodinia). A presença de sinais e sintomas positivos e 
negativos no território doloroso deve levantar a possibilidade de dor neuropática, apesar de não serem específicos dela (14).

A dor neuropática é mais comum em mulheres, principalmente acima dos 50 anos de idade, e tem como causa mais comum as hérnias discais cervicais e lombares (15). Este tipo de dor tem uma maior propensão para se tornar crônica e, em geral, é pouco responsiva aos analgésicos comumente utilizados para dor $(16,17)$.

Se a história clínica sugere presença de lesão ou doença neurológica e a dor assume uma localização neuroanatomicamente plausível, podemos considerar que este paciente tem uma dor neuropática possível. Se há presença de alterações ao exame neurológico como perda de sensibilidade, alteração de reflexos osteotendíneos profundos ou perda da força muscular, este paciente passa a ser considerado como portador de dor neuropática provável. A dor neuropática pode ser considerada definitiva se há evidências de lesão ou doença que afete o sistema somatossensitivo comprovada por exame complementar objetivo (estudo neurofisiológico, biópsia de pele, microscopia confocal da córnea, ressonância magnética). A Figura 1 abaixo mostra os níveis de acurácia do diagnóstico da dor neuropática (18).

Figura 1- Níveis de acurácia no diagnóstico da dor neuropática

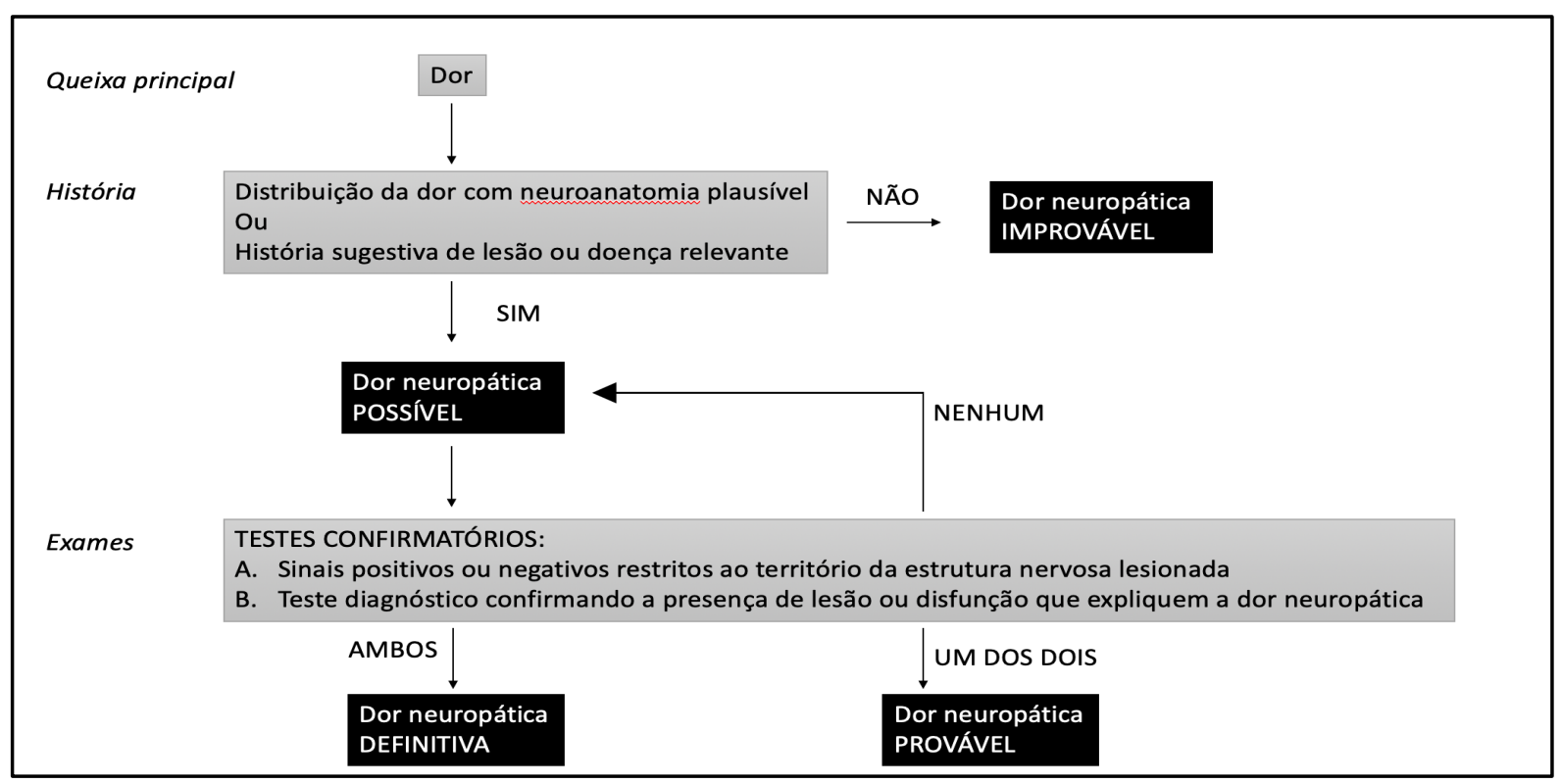

Treede et al., 2008 (12)

A escala Douleur Neurophatique en 4 Questions (DN4) é um instrumento de rastreio para caracterização de dor neuropática (ANEXO B). Foi originalmente desenvolvida e validada na França, sendo um questionário de aplicação pelo clínico (19). É constituída por dez itens, sendo 
que sete deles estão relacionados com as características da dor referidas pelo doente, através de termos descritivos, e os três itens restantes resultam do exame físico, e procuram identificar a presença de regiões de hipoestesia tátil ou dolorosa ou de alodinia mecânica. O escore total é calculado pela soma dos 10 itens, cada um valendo 1 ponto. Uma pontuação maior ou igual a 4 sugere dor neuropática. Esta escala foi validada em português por Santos et al. em 2010, e tem demonstrado excelentes propriedades no rastreio/identificação de dor associada a lesões do sistema nervoso central ou periférico, com boa especificidade (90\%) e sensibilidade (83\%) (20).

\subsection{Dor lombar baixa e hérnia discal lombar}

A dor lombar baixa é definida pela presença de dor e/ou desconforto abaixo da margem costal e acima das dobras glúteas inferiores, na presença ou não de dor referida em membros inferiores (21). Estima-se que mais $70 \%$ dos indivíduos de países industrializados experimentarão ao menos um episódio de dor lombar baixa ao longo da vida. A grande maioria dos episódios são agudos e autolimitados, entretanto a dor lombar baixa é considerada crônica quando sua duração ultrapassa 12 semanas (22). Quando crônica, a dor lombar é um dos principais motivos de incapacidade para o trabalho, e sua prevalência é estimada em $9,4 \%$ da população geral (23).

A fisiopatogenia da lombalgia crônica envolve mecanismos complexos e heterogêneos, em que componentes de dor nociceptiva e neuropática se sobrepõem. A dor nociceptiva é proveniente da ativação de nociceptores presentes em ligamentos, articulações, músculos, fáscia e tendões secundários à inflamação tecidual e ao estresse biomecânico. Já a dor neuropática decorre de lesão que afeta diretamente as raízes nervosas, como a presença de material do núcleo pulposo de um disco intervertebral roto que comprime a raiz em questão (22). A lombalgia crônica pode ser assim considerada uma síndrome dolorosa mista $(1,24)$, entretanto os componentes neuropáticos da dor ainda são sub-diagnosticados por boa parte dos clínicos e, em consequência disso, inadequadamente tratados.

Radiculopatia é a perda objetiva da função sensitiva e/ou motora em consequência de dano à raiz do nervo e pode ocorrer com ou sem dor associada (25). O Grupo Especial de Interesse em Dor Neuropática da IASP (NeuPSIG) define radiculopatia dolorosa quando o diagnóstico for baseado na presença de sinais sensoriais além de alterações motoras (12). 
Quando assume características típicas de radiculopatia, a dor neuropática por compressão de uma raiz lombar pode ser chamada de ciática. Em 1934, Mixter e Barr estabeleceram que a principal causa da ciática é a compressão de uma raiz nervosa lombar pelo material de um disco intervertebral roto, chegando a corresponder à $85 \%$ dos casos (26). A ciática pode ser evocada por manobras provocadoras como o teste de Lasègue (elevação passiva do membro inferior provocando dor lombar entre 30 à 70 graus) ou manobra de Valsalva, confirmando a suspeita de ruptura do ânulo fibroso do disco intervertebral (27).

Avaliação complementar através de exames de neuroimagem, especialmente Ressonância Magnética (RM), podem ser úteis na interpretação de um diagnóstico diferencial em pacientes com lombalgia neuropática, se mostrando a técnica de exame não invasiva mais apropriada para este diagnóstico (28). Os resultados devem ser avaliados com cautela, dentro de um contexto clínico adequado, na presença de sinais e sintomas que sugiram radiculopatia, já que há uma alta prevalência de discopatias degenerativas assintomáticas em idosos que não implicam necessariamente em dor neuropática $(29,30)$.

A dor neuropática crônica secundária à radiculopatia por hérnia discal lombar é causa de alto impacto negativo sobre qualidade de vida, perda de dias de trabalho e sobrecarga econômica aos serviços de saúde pública, planos de saúde, empregadores e famílias $(23,31)$. Além disso, estes pacientes estão mais sujeitos à desenvolverem comorbidades psicológicas como depressão, ansiedade, catastrofização, somatização, o que certamente contribui para maior incapacidade ao trabalho e maior prejuízo socioeconômico (32).

Diversos guidelines abordam o aspecto multimodal no tratamento da dor lombar baixa, envolvendo estratégias farmacológicas e não farmacológicas. Entretanto, nem todos contemplam a abordagem da dor lombar neuropática, já que esta não responde às terapias convencionais com uso de anti-inflamatórios não-esteroidais (AINEs) e corticosteroides. Por outro lado, poucas diretrizes para o tratamento da dor neuropática avaliaram especificamente a lombalgia crônica, e muitas vezes evidências de tratamentos com drogas estudadas para outras condições são extrapoladas para o tratamento desta patologia (22). 


\subsection{Uso da gabapentina no tratamento da dor neuropática}

A gabapentina e a pregabalina são duas drogas anticonvulsivantes da classe dos ligantes do canal de cálcio alfa-2-delta que são frequentemente usados no tratamento da dor neuropática, sendo considerados medicamentos de primeira linha para esta condição (33).

Estudos recentes têm demonstrado a eficácia da gabapentina na melhora de diversos tipos de dor neuropática $(34,35)$, além de apresentar melhor perfil de segurança, pois não interfere com enzimas microssomais hepáticas, é de fácil monitoramento e apresenta baixo índice de interações medicamentosas (36). Um estudo em portadores de dor neuropática por lesão da medula espinhal mostrou que a gabapentina também foi capaz de melhorar condições comórbidas à dor crônica como depressão, ansiedade, distúrbio do sono, além de uma melhor impressão geral de qualidade de vida (37).

O mecanismo de ação analgésico da gabapentina é complexo e inclui inibição da transmissão do impulso nervoso em neurônios do gânglio da raiz dorsal e do corno dorsal da medula espinhal. Além disso, modula outros alvos, como receptores NMDA (N-metil Daspartato), PKC (proteína quinase C) e citocinas. A gabapentina também parece atuar na circuitaria inibitória descendente noradrenérgica, contribuindo com a redução da hipersensibilidade associada à dor neuropática (36).

Os efeitos adversos mais comuns esperados com o uso da gabapentina são náuseas e vômitos, sonolência/sedação, distúrbios de memória e concentração, constipação intestinal, tonturas, fadiga e cefaleia (38). Eventos adversos sérios não foram mais comuns do que com uso de placebo (35). A fim de minimizar a ocorrência destes efeitos, é sugerido o início do tratamento com doses baixas e titulação lenta, e manutenção da droga por médio à longo prazo.

O gabapentinoides se mostraram efetivos no tratamento de diversas condições de dor neuropática (33), mas seu maior benefício parece estar relacionado aos casos de neuralgia pósherpética e neuropatia diabética dolorosa, quando comparados ao placebo (35). Há uma carência de ensaios clínicos randomizados que avaliem sua efetividade para a dor lombar crônica neuropática, e não parece haver evidências suficientes para recomendar ou refutar seu uso nesses casos $(28,39)$. A maioria dos estudos são não-randomizados, e o uso off-label dessa classe de medicamentos é crescente (38). 


\subsection{Dor, depressão e ansiedade}

Os transtornos depressivos são, após a insônia, a segunda comorbidade mais frequente em pacientes com dor. Sintomas de depressão maior ocorrem entre 1,5\% a 57\% dos pacientes com dor crônica e a distimia, em 4,3\% a 48,6\% (41). Esses números são bastante expressivos quando consideramos a prevalência de transtorno depressivo na população geral entre 5-8\% (40). O estresse psicológico, a depressão e a somatização parecem ser fatores contribuintes para a cronificação da dor (41) .

Dentre os pacientes que sofrem de dor lombar crônica, parece haver um risco 6,2 vezes maior de desenvolver transtorno depressivo do que naqueles livres de dor. Não há exatamente uma relação entre depressão e intensidade da dor, mas sim uma maior interferência nas atividades cotidianas e no número de sítios dolorosos. Pacientes portadores de dor lombar crônica e depressão, quando comparados àqueles sem sintomas depressivos, tendem a ser mais jovens, com predomínio do sexo feminino e solteiros (42).

A Escala Hospitalar de Ansiedade e Depressão (HADS) (ANEXO C) é um instrumento de alta sensibilidade, e sua utilização por profisssionais na área de dor pode ser de extrema utilidade, discriminando os pacientes que necessitam de uma avaliação psiquiátrica mais específica. A mesma possui 14 itens, dos quais 7 buscam avaliar ansiedade e os outros 7 avaliam sintomas de depressão. Cada item pode ser pontuado de 0 a 3, com pontuação máxima de 21 . Foram adotados os pontos de corte postulados por Zigmond e Snaith, sendo HADS-ansiedade (HADS-A): 0 a 8 sem ansiedade; $\geq 9$ com ansiedade e HADS-depressão (HADS-D): 0 a 8 sem depressão; $\geq 9$ com depressão (43). Em 2006 essa escala foi validada em português por Castro, para pacientes portadores de dor crônica (44).

A ocorrência de sintomas psicológicos deve ser investigada dentre os portadores de dor lombar crônica e tratada quando presente, visto auxiliar na melhora da percepção de incapacidade e reversão do processo de cronificação da dor.

\subsection{Dor e catastrofização}

Pensamentos catastróficos são definidos como processos mentais direcionados à uma exagerada orientação negativa com relação a um estímulo nocivo (45). A presença de crenças negativas sobre a dor leva os pacientes a imaginar o pior resultado possível, ocasionando medo 
da atividade e evitação que, por sua vez, causa desuso e consequente sofrimento, reforçando a avaliação negativa original em um ciclo deletério. Loeser propõe um "modelo multifacetado da dor” (Figura 2) que envolve 4 domínios de fenômenos da dor: 1. a detecção de dano tecidual (nocicepção), 2. o reconhecimento da estimulação nociceptiva pelo SNC (dor), 3. a resposta afetiva negativa à dor (sofrimento), e 4. o que uma pessoa faz ou diz que leva o observador a inferir que o paciente está sofrendo de um estímulo nocivo (comportamento doloroso) (46).

Os pacientes mais catastrofizadores tendem a ter uma experiência aumentada de dor, levando a um comportamento doloroso, em que o paciente passa a apresentar preocupação excessiva ou busca incessante de ajuda para o seu sintoma (47). Está associada também a um comportamento de doença, em que há maior frequência e duração de internações hospitalares, visitas mais frequentes a profissionais de saúde e maior abuso de medicamentos vendidos sem receita médica (45). Além disso, a catastrofização tem sido associada a maiores índices de incapacidade, mesmo quando se controlam comorbidades como depressão, ansiedade, gravidade da doença e intensidade da dor, além de menor resposta aos tratamentos propostos (48).

Figura 2 - Modelo de dor de Loeser

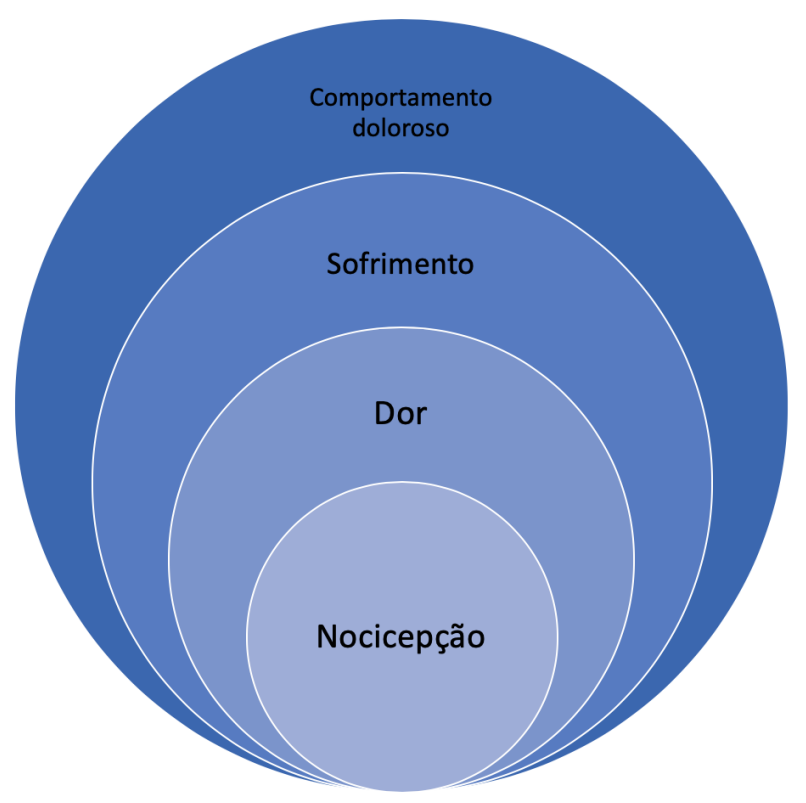

Diller L., 1989 (46) 
A Escala de Auto Declarações Relacionadas à Dor (PRSS) é composta por duas escalas (estratégias de enfrentamento e catastrofização), desenvolvidas com base nos conceitos do sistema cognitivo e pensamentos automáticos (49). Dentro dela, encontramos a Escala de Pensamentos Catastróficos Sobre Dor (EPCD) (ANEXO D), que está validada para o português, sendo composta de 9 itens escalonados em uma escala Likert que varia de 0 a 5 pontos associados às palavras quase nunca e quase sempre nas extremidades (50). O escore total é a soma dos itens dividido pelo número de itens respondidos, sendo que o escore mínimo pode ser 0 e o máximo 5. Não há pontos de corte. Escores mais elevados indicam maior presença de pensamentos catastróficos.

\subsection{Dor e qualidade de vida}

A qualidade de vida é definida pelo Grupo de Qualidade de Vida da Organização Mundial de Saúde (WHOQOL) como a percepção do indivíduo de sua posição na vida, no contexto da cultura e sistemas de valores em que vive, e em relação aos seus objetivos, expectativas, padrões e preocupações. É uma avaliação subjetiva, baseada no cenário social, cultural e ambiental de cada um (51).

Existem fortes evidências que correlacionam presença de dor com piores escores de qualidade de vida, gerando prejuízo físico, social e emocional, o que enfatiza a abordagem biopsicossocial como parte do tratamento de quadros dolorosos crônicos (52).

A dor neuropática, principalmente, tem alto impacto negativo sobre a qualidade de vida do paciente, afetando seu bem estar social e psicológico, além de aumentar gastos com auxílio médico (53). O Instrumento Abreviado de Avaliação da Qualidade de Vida da Organização Mundial de Saúde consta de 26 questões divididas em quatro domínios: físico, psicológico, relações sociais e meio ambiente, e demonstrou avaliar adequadamente os âmbitos relevantes para a qualidade de vida em um grande número de culturas em todo o mundo (ANEXO E) (54). Os escores são pontuados utilizando o programa estatístico SPSS. Está validado para o português desde 2000 e parece ser uma ferramenta adequada para mensurar a qualidade de vida dos portadores de dor crônica (55). 


\subsection{Dor e distúrbios do sono}

Dor lombar crônica e distúrbios do sono são duas patologias frequentes na população em geral (56) e podem se apresentar como doenças comórbidas em uma relação de reciprocidade, onde tanto a presença de dor crônica predispõe ao surgimento de distúrbios do sono, quanto a presença de privação de sono e/ou má qualidade do sono pode aumentar a percepção dolorosa do paciente (57) e reduzir sua capacidade de enfrentamento da dor (58).

Alterações do sono podem acometer 50 à $70 \%$ do pacientes portadores de dor crônica não-oncológica $(59,60)$, podendo incluir aumento da latência para iniciar o sono, dificuldade em manter o sono, despertar precoce e sono fragmentado. Todos estes distúrbios têm alto impacto negativo sobre a qualidade de vida dos pacientes, como piora da ansiedade, depressão e distúrbios de atenção e memória $(61,62)$.

Um estudo caso-controle realizado com 198 indivíduos mostrou que há correlação positiva entre a intensidade do impacto da dor lombar crônica na vida diária e a gravidade dos distúrbios do sono (63). Utilizando a escala de qualidade de sono de Pittsburgh (PSQI), foi demonstrado que há comprometimento na qualidade do sono dentre os portadores de dor lombar crônica, sendo observado maior prejuízo na latência do sono, qualidade subjetiva do sono e duração do sono (58).

A escala de sonolência de Epworth (ESE) (ANEXO F) é um questionário simples que pede ao paciente que avalie em uma escala de 0 a 3 as chances de que cochile em oito situações diferentes, variando desde situações altamente soporíferas ("deitado para descansar no período da tarde, quando as circunstâncias permitem") até muito menos soporíferos ("sentado e conversando com alguém"). A pontuação da ESE pode variar de 0 a 24 , sendo que escores acima de 10 sugerem sonolência diurna excessiva, o que pode representar um reflexo da má qualidade do sono noturno. Além disso, sonolência diurna é um evento adverso esperado com o uso da gabapentina, e essa escala pode auxiliar na monitorização deste sintoma (64).

\subsection{SPECT cerebral}

Técnicas de neuroimagem funcional, como Tomografia por Emissão de Fóton Único (SPECT-Single-photon emission computed tomography) e Arterial Spin Labelling (ASL), avaliam o fluxo sanguíneo cerebral regional (FSCr) e podem ser usadas para obter informações 
task-free de acordo com a atividade cerebral em curso, podendo refletir características espontâneas da dor crônica, como em pacientes com DLC (65). A ativação de certas áreas cerebrais em resposta à dor tem sido consistentemente demonstrada em vários estudos anteriores, sendo os mais importantes o córtex somatossensorial primário e secundário ( $\mathrm{S} 1$ e S2), o córtex insular (CI), o córtex cingulado anterior (CCA), o tálamo e o córtex pré-frontal (CPF), que constituem a "matriz da dor".

Esses estudos de neuroimagem funcional têm sido empregados para compreender o mecanismo de ação e o local de atuação de medicamentos que agem no sistema nervoso central. Neste sentido, o emprego da SPECT utilizando a ${ }^{99 \mathrm{~m}}$ Tc-etilenodicisteína ( $\left.{ }^{99 \mathrm{~m}} \mathrm{Tc}-\mathrm{ECD}\right)$ tem sido utilizado para avaliar a distribuição de fármacos no cérebro. Estudos anteriores relatam o uso da SPECT para avaliar o efeito da lamotrigina no fluxo sanguíneo cerebral de pacientes com epilepsia idiopática generalizada, e sugerem que o fármaco diminui a perfusão nas áreas córtico-tálamo-límbico, córtex órbito-frontal e tronco cerebral (66). A SPECT também permitiu sugerir que as propriedades ansiolíticas do canabidiol em voluntários sadios são mediadas pela ação nas áreas límbica e paralímbica do cérebro (67). O grupo de estudo da Faculdade de Medicina de Ribeirão Preto USP, envolvido neste projeto, utilizou a SPECT cerebral para estudar os sítios de ação centrais da oxcarbazepina, correlacionando as imagens obtidas com a farmacocinética da droga (publicação em andamento).

Em 2014 Nakamura e colaboradores avaliaram o FSCr de pacientes portadores de lombalgia crônica inespecífica através de SPECT cerebral, e encontraram uma disfunção do CPF que poderia levar ao aparecimento de um comportamento inconsciente da dor controlado pelo cerebelo (68). O CPF tem um papel bem estabelecido no controle de atividade mental superior, função executiva, controle emocional e do comportamento (69). Já o cerebelo parece ter um papel integrador na modulação de dor, apesar do mecanismo como isto ocorre permanecer desconhecido (70).

\subsection{Justificativa}

Este estudo propõe avaliar o padrão de perfusão cerebral de pacientes com dor crônica secundária a hérnia discal lombar antes e após o tratamento com gabapentina, utilizando SPECT cerebral. Objetivamos ainda mensurar o FSCr nos portadores de dor crônica, comparando-os com um banco de dados de voluntários saudáveis, e identificar se há diferenças perfusionais 
entre pacientes que melhoram em relação ao grupo que não apresenta melhora clínica com o uso da gabapentina. Também avaliaremos a correlação da dor crônica com aspectos biopsicossociais como ansiedade, depressão, catastrofização e qualidade de vida. A hipótese em teste é que a gabapentina promove alterações no FSCr e que estas podem estar associadas à eficácia da droga em termos de melhora na intensidade da dor. Queremos avaliar também qual o padrão perfusional de áreas cerebrais envolvidas com a nocicepção e com aspectos afetivo-emocionais da dor. Identificar o substrato neurobiológico cerebral associado a dor poderá auxiliar na otimização do tratamento com drogas como a gabapentina, além de ser um novo passo para auxiliar na titulação posológica desta droga com bases na neuroimagem funcional. Considerando o exposto acima, o presente projeto permite abrir uma nova perspectiva na busca pelas correlações entre a resposta clínica à gabapentina e a perfusão cerebral, em pacientes com dor neuropática crônica, como uma medida indireta do efeito do fármaco no SNC. 


\section{OBJETIVOS}

\subsection{Objetivos gerais}

Analisar o padrão de fluxo sanguíneo cerebral regional antes e após o uso da gabapentina de pacientes portadores de dor neuropática crônica secundária à hérnia de disco lombar.

\subsection{Objetivos específicos}

2.2.1. Comparar o padrão de FSCr dos pacientes com dor lombar crônica e controles saudáveis (banco de dados);

2.2.2. Comparar o padrão de FSCr dos pacientes com dor lombar crônica antes e após o uso da gabapentina;

2.2.3. Comparar o padrão do FSCr entre os pacientes respondedores e os não respondedores ao uso da gabapentina, e deles com controles saudáveis;

2.2.4. Avaliar relações entre as áreas de maior ou menor perfusão cerebral que podem estar associadas ao processamento doloroso ou às mudanças nos aspectos afetivo-motivacionais da dor;

2.2.5. Verificar se há correlação entre o efeito terapêutico da gabapentina com as seguintes escalas: Escala Hospitalar de Ansiedade e Depressão, Escala de Pensamentos Catastróficos sobre Dor e Escala de Sonolência de Epworth;

2.2.6. Avaliar se a melhora da dor leva à uma melhor percepção da qualidade de vida através do uso do Instrumento Abreviado de Avaliação da Qualidade de Vida da Organização Mundial de Saúde (WHOQOL-bref). 


\section{CASUÍSTICA E MÉTODOS}

\subsection{Casuística}

Este estudo foi conduzido entre janeiro a dezembro de 2016. Foram recrutados ao todo 16 pacientes portadores de dor neuropática crônica por hérnia de disco lombar, de ambos os sexos, avaliados no Ambulatório de Dor Neuropática (DNPT) do Serviço de Neurologia do Hospital das Clínicas da Faculdade de Medicina de Ribeirão Preto-USP (HCFMRP-USP), e que iriam iniciar tratamento para dor neuropática pela primeira vez com gabapentina. Todos os pacientes avaliados preenchiam os critérios de inclusão e não possuíam critérios de exclusão conforme descritos abaixo.

\subsubsection{Critérios de inclusão}

a) Indivíduos com 18 anos ou mais;

b) Portadores de dor lombar crônica com características neuropáticas;

c) Presença de hérnia discal lombar comprovada por ressonância magnética;

d) Não estar em tratamento com gabapentinoides para a dor;

e) Duração da dor superior à 3 meses; e

f) Intensidade da dor igual ou superior à 4 na EVN.

\subsubsection{Critérios de exclusão}
a) Hipertensão arterial sistêmica descontrolada;
b) Diabetes mellitus;
c) Anemia;
d) Presença de outras doenças neurológicas que cursem com dor neuropática;
e) Alcoolismo crônico;
f) Obesos;
g) Tabagistas; 
h) Alterações de função hepática, cardíaca e renal que pudessem influenciar a farmacocinética da gabapentina; e

i) Evidência ao exame físico de outra causa para a dor referida pelo paciente.

Após o início do estudo, 3 pacientes foram excluídos, sendo um por inviabilidade técnica para a realização da SPECT cerebral (presença de clipe cirúrgico por aneurisma prévio), outro por identificação de lesão expansiva cerebral após a realização da SPECT (que posteriormente foi confirmada como um meningioma por ressonância magnética cerebral) e o terceiro por intolerância aos eventos adversos da gabapentina. Este terceiro paciente excluído teve seus dados utilizados em parte das análises realizadas, para comparação do grupo pré-tratamento com gabapentina com banco de dados de voluntários saudáveis (grupo controle), cujos resultados são objeto de tese de pós-doutorado de colaboradora deste estudo (Prof. Dra. Érika Negrini Lia). Portanto, a avaliação pré-tratamento com gabapentina incluiu a análise de dados de 14 pacientes, e processamento final do estudo após o uso da gabapentina contemplou dados de 13 pacientes.

O estudo foi aprovado pelo comitê de Ética Médica do HCFMRP-USP sob o protocolo 1.190.720 (APÊNDICE A). Todos os pacientes assinaram o termo de consentimento livre e esclarecido (TCLE) antes do início do estudo (APÊNDICE B).

\subsection{Método}

Após anamnese e exame físico, os voluntários que preencheram os critérios de inclusão foram convidados a assinar o TCLE e submetidos à realização de exames bioquímicos (hemograma, creatinina, TGO, gama GT, bilirrubinas e glicemia), bem como à um eletrocardiograma (ECG). Com os resultados em mãos, sem anormalidades, agendamos uma primeira visita para aplicação das seguintes escalas: Escala Visual Numérica (EVN), Douleur Neurophatique en 4 Questions (DN4), Escala Hospitalar de Ansiedade e Depressão (HADS), Escala de Pensamentos Catastróficos em Dor da PRSS (EPCD), Escala de Sonolência de Epworth e Escala de Qualidade de vida da Organização Mundial de Saúde - versão abreviada (WHOQOL-bref). Todos os dados foram anotados em um caderno de registro de dados (CRF) (APÊNDICE C). Após responder a todas as escalas, os voluntários eram encaminhados para a realização da primeira SPECT cerebral, antes do início do uso da gabapentina. 
$\mathrm{Na}$ noite após a realização da primeira SPECT, era iniciado o tratamento com a gabapentina na dose de $600 \mathrm{mg}$ ao dia (300 mg a cada 12 horas, por via oral, uso contínuo). Todos os comprimidos de gabapentina eram fornecidos pelos pesquisadores aos pacientes a fim de uniformizar a amostra. O medicamento foi comprado em lote único de um mesmo laboratório e as cartelas vazias eram devolvidas pelos pacientes semanalmente. Após sete dias do início do medicamento, os pacientes retornavam para avaliação na Unidade de Pesquisa Clínica (UPC), e os considerados responsivos, ou seja, aqueles que apresentavam queda de pelo menos 4 pontos na EVN (em relação à pontuação inicial), eram encaminhados para a finalização da pesquisa.

Caso o paciente fosse considerado não responsivo, ou seja, não houvesse apresentado queda de pelo menos 4 pontos na EVN, a dose de gabapentina era elevada para $900 \mathrm{mg}$ ao dia (300 mg pela manhã e 600 mg à noite), como nova reavaliação agendada em 7 dias. Caso o paciente respondesse após 7 dias, era encaminhado para a finalização da pesquisa. Finalmente, caso o paciente não fosse responsivo à dose de $900 \mathrm{mg}$ ao dia após 7 dias, uma dose de 1.200 mg era prescrita (600 mg a cada 12 horas), e nova reavaliação era reagendada em 7 dias. Todos os voluntários que receberam gabapentina $1.200 \mathrm{mg}$ ao dia por 7 dias finalizaram a pesquisa, realizando a segunda SPECT, sendo responsivos ou não ao tratamento. Essa foi a dose máxima estipulada no protocolo deste estudo.

$\mathrm{Na}$ visita de finalização da pesquisa, após avaliação da EVN, os voluntários eram submetidos novamente à aplicação das seguintes escalas: HADS, EPCD, ESE e WHOQOLbref. A seguir, eram encaminhados para realizar nova SPECT cerebral.

Os pacientes que obtiveram melhora clínica significativa com o uso da gabapentina durante o protocolo de estudo puderam continuar o tratamento em nosso ambulatório de dor neuropática (DNPT) para prosseguir com o uso da medicação. Aqueles que não obtiveram melhora expressiva passavam por reavaliação médica para uma nova proposta terapêutica. 


\subsubsection{SPECT}

Os exames foram realizados na Seção de Medicina Nuclear do HCFMRP-USP. Cada paciente que concluiu o estudo foi submetido a 2 exames, com intervalo mínimo de sete dias entre eles.

O primeiro exame foi realizado em todos os pacientes antes de iniciar o uso da gabapentina, sendo que 15 voluntários participaram dessa fase da pesquisa. Os pacientes foram submetidos ao exame de SPECT cerebral após a injeção intravenosa do radiofármaco 99mTecnécio-dímero de etil cisteinato (99mTc-ECD) com atividade de $1.295 \mathrm{MBq}$ (35 mCi). A injeção ocorreu com o paciente em estado de repouso por 30 minutos, com os olhos abertos, em um ambiente silencioso e com pouca luminosidade, abstendo-se de falar e escutar.

As SPECTs foram adquiridas em uma gama câmera rotativa de dois detectores, híbrida, SPECT/CT, modelo BrightView XCT (Philips Medical Systems Inc., Cleveland, OH, EUA) equipada com um colimador de alta resolução e baixa energia (LEHR), janela de energia de aceitação simétrica de $20 \%$, photopeak centrado em $140 \mathrm{keV}$, usando uma matriz de $128 \mathrm{x}$ 128, fator de zoom de 1,0 e tamanho de pixel $2,13 \mathrm{~mm}$. Os dados foram coletados em modo step-and-shoot em 360 graus, com o total de 128 projeções (64 por cada detector), com um tempo total de aquisição de $30 \mathrm{~min}$ e cerca de 100.000 contagens/projeção/cabeça.

As imagens tomográficas foram processadas na estação de trabalho EBW (Extended Brilliance TM Workspace, Philips Medical Systems Inc., Cleveland, OH, EUA), reconstruídas em cortes transaxiais paralelos à linha orbitomeatal e usando o algoritmo de maximização de subconjuntos ordenados (OSEM) e aplicando um Filtro Butterworth (ordem 2, frequência de corte 0,3$)$. O método de Chang foi aplicado sobre fatias transaxiais para a correção da atenuação dos efeitos de fótons $(\mu=0,12 \mathrm{~cm}-1)$.

O segundo exame, com a mesma atividade de $99 \mathrm{mTc}-\mathrm{ECD}$, era realizado no dia da visita de finalização, 6 horas após a ingestão da dose matinal da gabapentina por via oral. Nesta etapa, apenas 13 pacientes participaram do exame (dois pacientes excluídos durante o estudo, sendo um por descoberta de lesão expansiva cerebral e outro por intolerância aos efeitos colaterais da gabapentina). 
3.2.2. Critérios de retirada do protocolo e plano para eventuais eventos adversos

O protocolo era encerrado quando o paciente atingisse a dose de $1200 \mathrm{mg}$ ao dia de gabapentina por 7 dias, ou antes caso o paciente apresentasse resposta satisfatória com dose menor (600 ou $900 \mathrm{mg}$ ao dia de gabapentina). A resposta era considerada satisfatória quando o paciente apresentava queda de pelo menos 4 pontos na EVN em relação à visita inicial. Houve um caso de efeito adverso relacionado à gabapentina que não foi tolerado pelo participante após quatro dias da sua introdução, tendo sido a droga suspensa e sua participação na pesquisa encerrada. Neste caso, apenas a SPECT inicial foi usada para avaliação de alguns dados.

\subsection{Análise estatística}

Todas as análises foram realizadas através do software SAS 9.2. Para todas as comparações adotou-se um nível de significância de 5\%. Para verificar o efeito de intervenção em relação aos questionários com respostas qualitativas foi proposto o teste de McNemar. Para as comparações dos períodos em relação aos questionários com resposta quantitativa foi proposto o teste de Wilcoxon. Tal teste utiliza a técnica não paramétrica para comparar dois grupos pareados (amostras dependentes). Sendo assim, ela não requer suposições quanto à distribuição dos dados. As comparações envolvendo a melhora clínica e as variáveis qualitativas HADS e EPWORTH foram feitas através do teste qui-quadrado. A comparação dos grupos de melhora, considerando as diferenças entre inicial e final dos questionários quantitativos, foi feita através do teste de Mann-Whitney, técnica não paramétrica que permite a comparação de dois grupos independentes sem que haja suposições quanto à distribuição dos dados.

A análise comparativa das SPECTs cerebrais entre o período basal e o período com presença da gabapentina foi realizada por meio do Software Statistical Parametric Mapping (SPM2; Wellcome Department of Imaging Neuroscience, Institute of Neurology, London, UK) in MATLAB 6.1 (MathWorks, MA). A investigação da SPECT pelo SPM foi feita com quatro desenhos de análise:

a) Diferença entre 2 grupos, antes do uso da gabapentina comparado com banco de dados com controles saudáveis: quatorze pacientes que realizaram a primeira SPECT tiveram 
seus dados analisados e comparados com banco de dados de controles saudáveis. $\mathrm{O}$ resultado foi um único mapa funcional da diferença entre os dois grupos;

b) Diferença individual e entre 2 grupos, antes e depois da gabapentina: Foram comparados dois grupos, sendo o primeiro composto pelos 13 pacientes que finalizaram o estudo, antes do uso da gabapentina, e o segundo grupo composto pelos mesmos pacientes, mas agora após o uso da gabapentina. Foram avaliados dados individuais de cada paciente e também foi gerado um único mapa funcional da diferença entre os dois grupos;

c) Diferença individual e entre 2 grupos, com e sem melhora com a gabapentina, comparados com banco de dados de voluntários saudáveis: Por fim, estes mesmos 13 pacientes foram divididos em 2 grupos, aqueles com boa resposta e os sem resposta ao tratamento com a gabapentina, cujas imagens foram comparadas com banco de dados de voluntários saudáveis. As diferenças perfusionais entre as 2 fases estão exibidas em mapas funcionais que representam o efeito isolado da gabapentina sobre o $\mathrm{FSCr}$;

d) Diferença entre 2 grupos antes e depois do uso da gabapentina, analisados separadamente nos grupos com e sem melhora clínica: as imagens de FSCr foram avaliadas separadamente comparando os voluntários entre si, sendo analisados antes e depois do uso da gabapentina e separando os pacientes que tiveram melhora clínica daqueles que não tiveram.

As coordenadas do pico de cluster foram determinadas usando "Atlas de Talairach Automatizado para Mapeamento Cerebral Funcional" (71). Os resultados foram exibidos nos planos tridimensionais de um modelo padrão de sequência T1 de Ressonância Magnética. 


\section{RESULTADOS}

\subsection{Características demográficas}

O grupo final avaliado foi composto por 13 pacientes, sendo 7 mulheres $(53,8 \%)$ e 6 homens (46,2\%). A idade média do grupo foi de $41 \pm 9,62$ anos (variação de 25 a 62 anos).

Quando questionados quanto ao tempo de doença (há quanto tempo o paciente era portador de ciatalgia), a duração média da dor no momento da inclusão do paciente no estudo era de 4,29 \pm 3,95 anos (variação de 3 meses a 12 anos). A intensidade média da dor avaliada no início do protocolo através da EVN foi de 5,92 $( \pm 1,93)$ pontos em uma escala de 0 a $10 . \mathrm{Na}$ avaliação de triagem para dor neuropática, realizada através da escala DN4, a pontuação média apresentada pelos pacientes foi de 4,54 $\pm 2,63$ pontos. Alguns pacientes incluídos no estudo faziam uso de medicações prévias, e estas não foram suspensas. Os principais dados demográficos dos 13 pacientes que completaram o estudo estão apresentados na Tabela 1.

Em relação à topografia da lesão, em mais de $50 \%$ dos pacientes avaliados o local predominante da hérnia discal lombar foi entre a $4^{\circ}$ e a $5^{\circ}$ vértebras lombares (L4-L5), como vemos no Gráfico 1.

\section{Gráfico 1- Local predominante da hérnia discal lombar}

Topografia da hérnia discal lombar

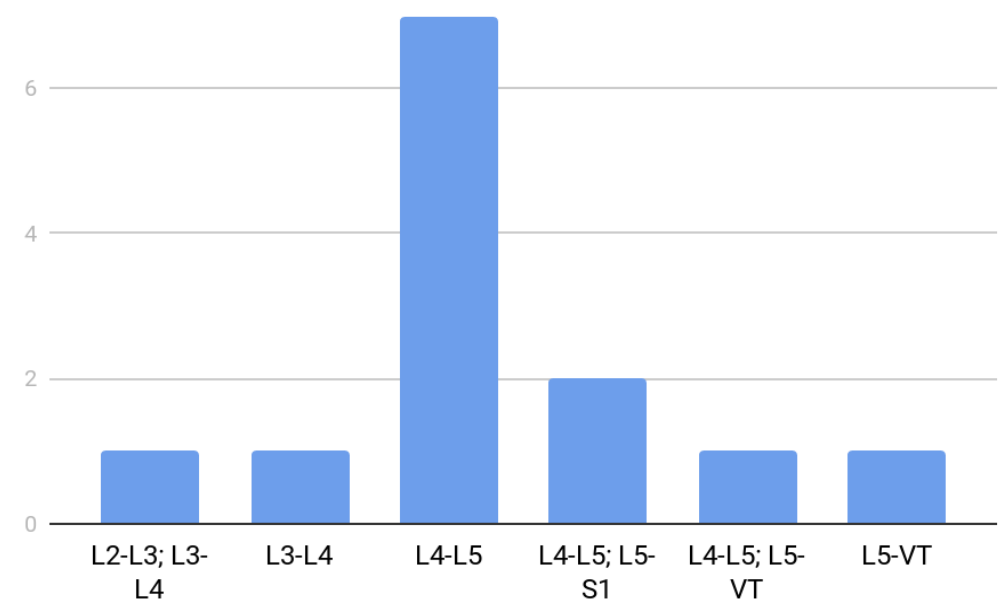


Tabela 1- Características demográficas dos participantes

\begin{tabular}{|c|c|c|c|c|c|}
\hline Paciente & $\begin{array}{l}\text { Idade } \\
\text { (anos) }\end{array}$ & Sexo & $\begin{array}{l}\text { Topografia da } \\
\text { lesão na RM }\end{array}$ & $\begin{array}{l}\text { Tempo de dor } \\
\text { (anos) }\end{array}$ & Medicamentos em uso \\
\hline 1 & 33 & $\mathrm{~F}$ & L4-L5; L5-S1 & 0,25 & - \\
\hline 2 & 37 & $\mathrm{~F}$ & L4-L5 & 12 & - \\
\hline 3 & 38 & $\mathrm{~F}$ & L4-L5 & 1 & $\begin{array}{l}\text { Amitriptilina, Sertralina, } \\
\text { Clonazepam }\end{array}$ \\
\hline 4 & 48 & M & L2-L3; L3-L4 & 6 & - \\
\hline 5 & 48 & $\mathrm{~F}$ & L3-L4 & 3 & Paroxetina, Bupropiona, Clonazepam \\
\hline 6 & 50 & M & L4-L5 & 1,5 & $\begin{array}{l}\text { Dexametasona, } \\
\text { Betametasona dipropionato, } \\
\text { Cetroprofeno, Celecoxibe, } \\
\text { Ciclobenzaprina }\end{array}$ \\
\hline 7 & 62 & M & L4-L5 & 10 & $\begin{array}{l}\text { Citidina, Uridina, } \\
\text { Hidroxocobalamina }\end{array}$ \\
\hline 8 & 41 & $\mathrm{~F}$ & L4-L5; L5-VT & 10 & - \\
\hline 9 & 25 & $\mathrm{~F}$ & L4-L5 & 1 & - \\
\hline 10 & 31 & M & L4-L5; L5-S1 & 3 & Paracetamol \\
\hline 11 & 41 & M & L4-L5 & 4 & Antraquinona, Prednisona, Tiamina \\
\hline 12 & 35 & $\mathrm{~F}$ & L5-VT & 1,6 & - \\
\hline 13 & 44 & M & L4-L5 & 2 & - \\
\hline
\end{tabular}

Abreviações: M, masculino; F, feminino; VT, vértebra de transição; RM, ressonância magnética.

Dentre os efeitos adversos relacionados ao uso da gabapentina relatados pelos voluntários, oito pacientes queixaram-se de tonturas (61,5\%), oito pacientes apresentaram sonolência $(61,5 \%)$ e 3 participantes relataram cefaleia $(23 \%)$, conforme podemos ver no Gráfico 2. 


\section{Gráfico 2 - Eventos adversos relacionados ao uso da gabapentina}

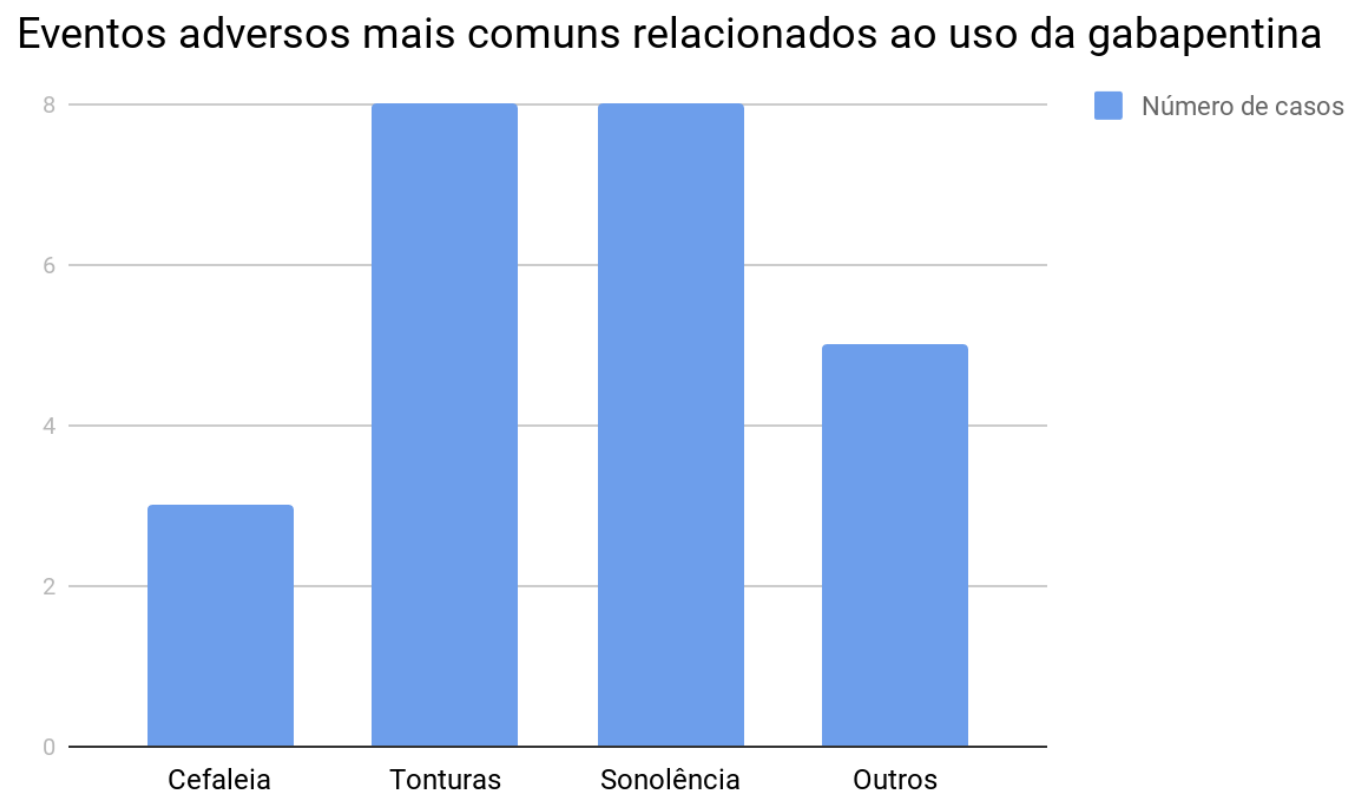

Outros eventos adversos menos frequentes também foram relatados pelos participantes que fizeram uso da gabapentina: hiperfagia e fraqueza foram relatadas por 1 paciente $(7,7 \%)$, epigastralgia foi descrita por 2 participantes $(15,4 \%)$, insônia também foi descrita por 2 voluntários, e bradipsiquismo foi relatado por 1 paciente $(7,7 \%)$.

\subsection{Avaliação da dor}

A melhora clínica dos pacientes que participaram deste estudo com gabapentina foi avaliada através da escala EVN. Comparativamente, analisamos a EVN em todas as visitas, e o paciente era considerado responsivo ao tratamento da dor neuropática caso houvesse uma queda de 4 pontos ou mais em relação à pontuação inicial da EVN, avaliada na primeira visita. Os pacientes que não atingiam essa queda de pelo menos 4 pontos mesmo após chegarem à dose máxima de gabapentina, estipulada em $1.200 \mathrm{mg} /$ dia, eram considerados não responsivos.

Sendo assim, dos 13 pacientes que completaram este estudo, 6 deles (46,2\%) apresentaram melhora clínica com o tratamento proposto com gabapentina, e 7 pacientes $(53,8 \%)$ não apresentaram melhora clínica. 
Dos 6 pacientes que apresentaram melhora clínica, um deles ocorreu com a dose de $600 \mathrm{mg} /$ dia, quatro deles precisaram de dose de $900 \mathrm{mg} /$ dia e um deles chegou à dose máxima de $1.200 \mathrm{mg} /$ dia de gabapentina (Gráfico 3). Os 7 pacientes que não apresentaram melhora clínica chegaram à dose de $1.200 \mathrm{mg} /$ dia de gabapentina.

\section{Gráfico 3 - Melhora clínica de acordo com a dose utilizada de gabapentina}

Dose de gabapentina necessária para melhora clínica

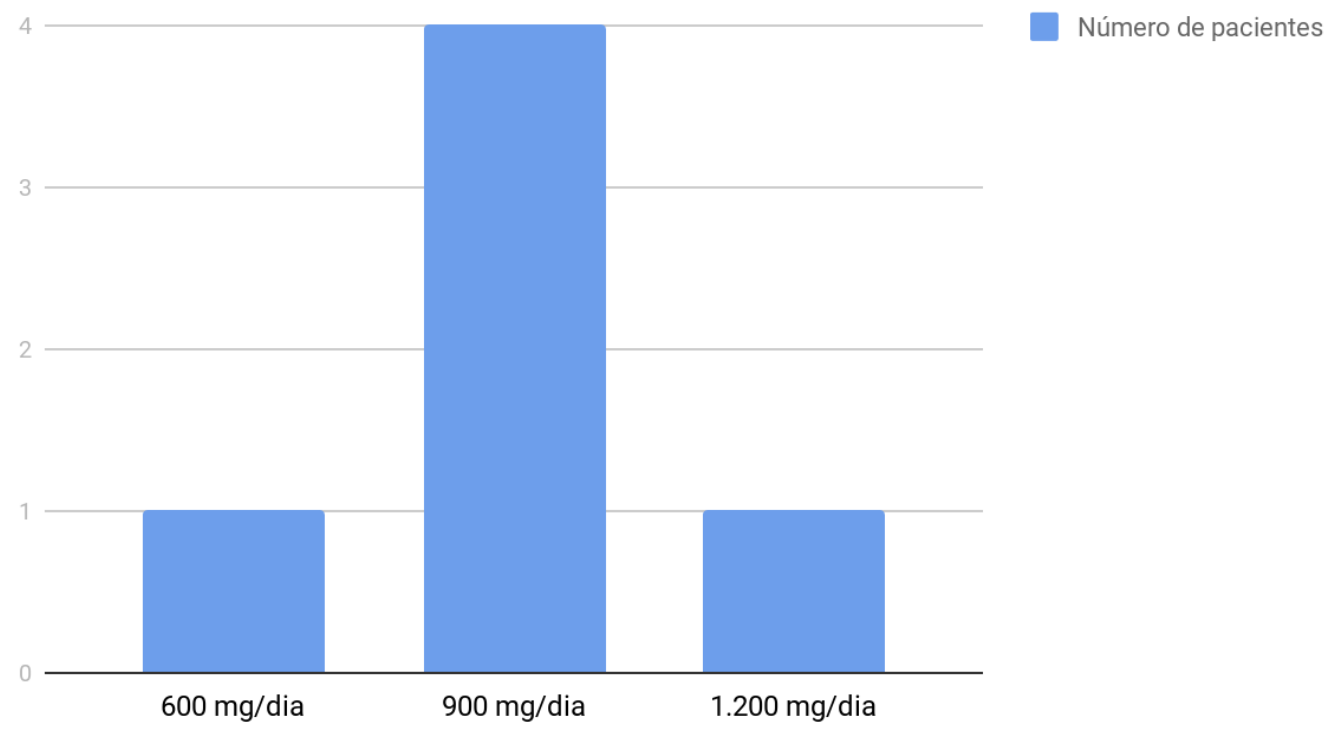

\subsection{Avaliação de depressão e ansiedade}

Em relação à presença ou não de ansiedade dentre os voluntários avaliados, na entrevista inicial do estudo, antes do tratamento com gabapentina, sete participantes $(53,8 \%)$ apresentavam critérios compatíveis com o diagnóstico de ansiedade, de acordo com a ferramenta de screening HADS-A, que considera a presença deste sintoma quando o score é maior ou igual à 9 . Ao final do estudo, destes sete participantes descritos, quatro voluntários $(30,7 \%)$ ainda mantinham pontuação $\geq 9$ nesta escala, caracterizando a presença de ansiedade (Gráfico 4). Entretanto, não houve significância estatística de acordo com o teste de McNemar ( p 0,08) quando comparamos a pontuação da HADS-A entre as avaliações inicial e final do estudo. 
Gráfico 4 - Presença de sintomas de ansiedade de acordo com a escala HADS-A

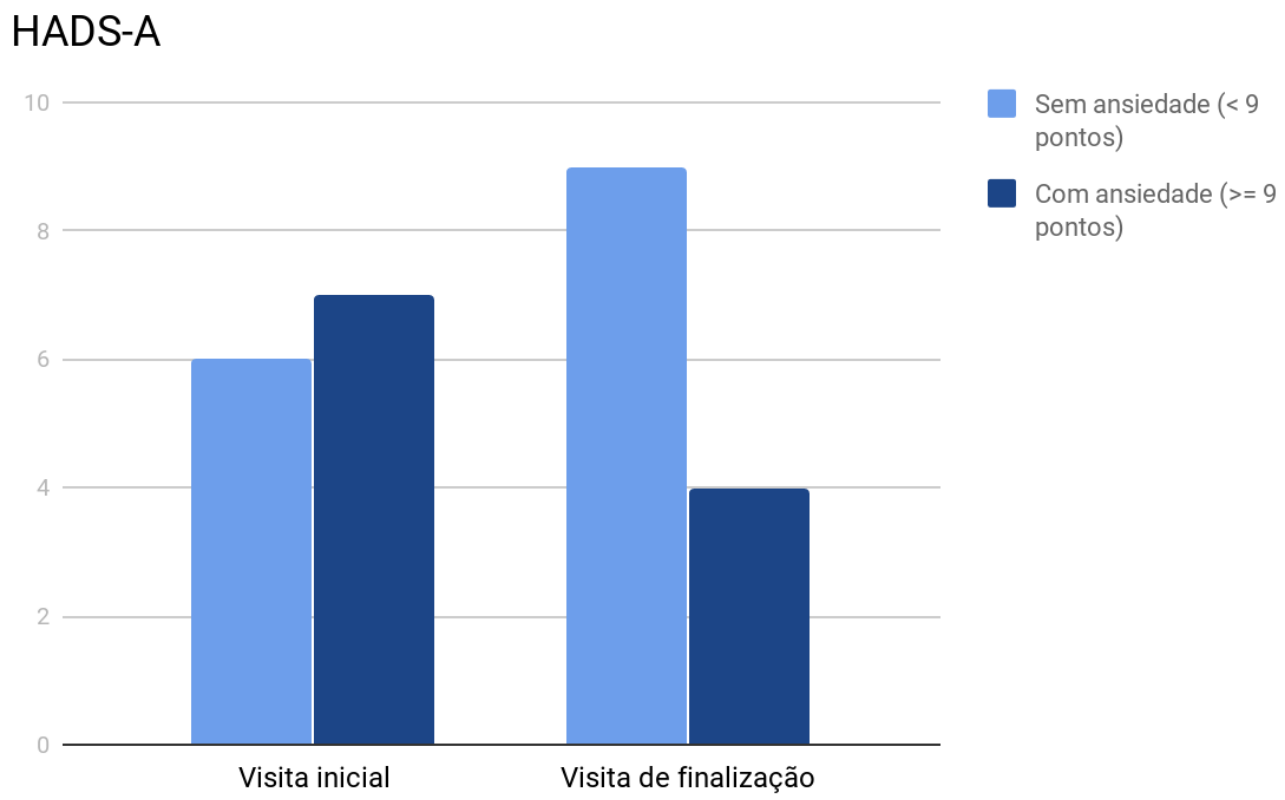

Utilizando a mesma escala, também foi feita a avaliação de sintomas de depressão dentre os voluntários que participaram da pesquisa. De acordo com a escala HADS-D, antes do início do uso da gabapentina, três pacientes preencheram critérios para depressão $(23,08 \%)$, baseados na pontuação $\geq 9$. Ao final da participação no estudo, apenas um deles permaneceu com pontuação $\geq 9$, caracterizando depressão (Gráfico 5). Não houve significância estatística com acordo com o teste de McNemar (p 0,16) quando comparamos a pontuação da HADS-D entre as avaliações inicial e final da pesquisa. 


\section{Gráfico 5 - Presença de sintomas de depressão de acordo com a escala HADS-D}

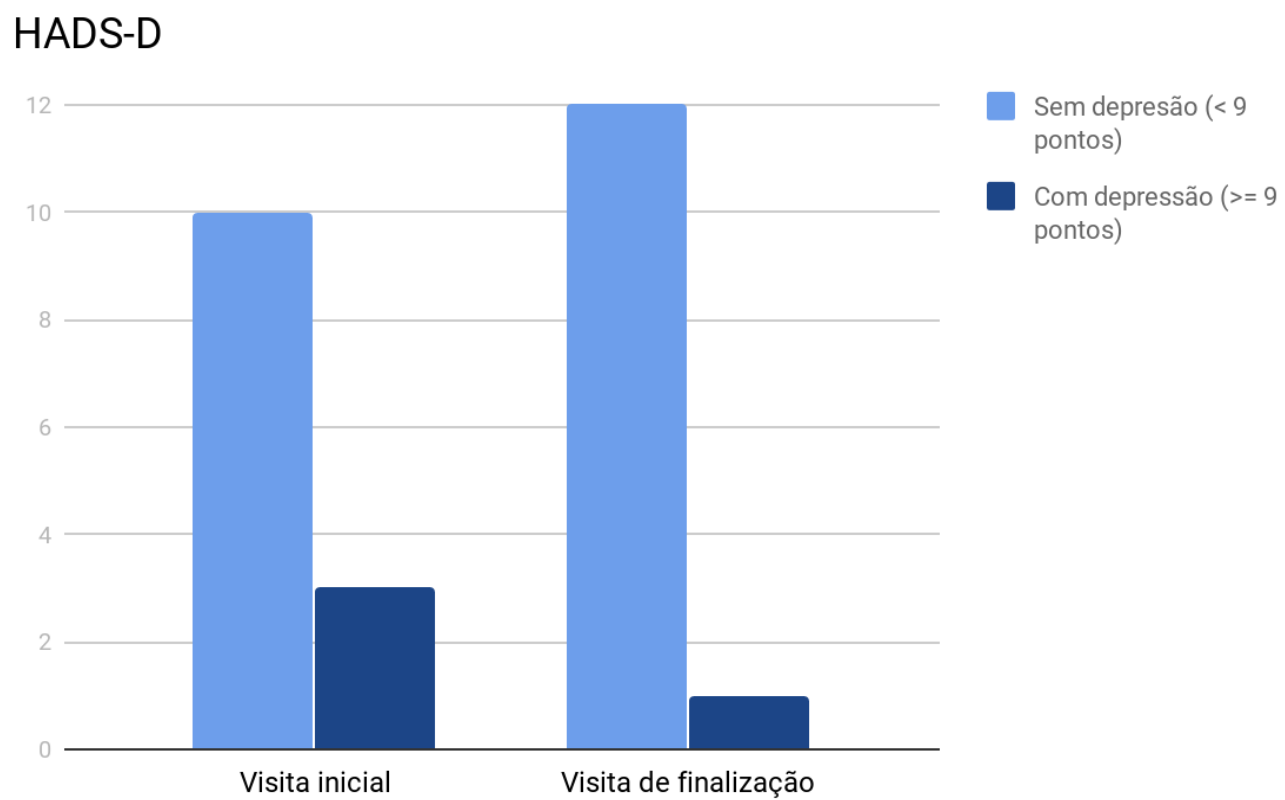

Ao analisarmos separadamente os grupos com e sem melhora clínica após o tratamento com gabapentina, encontramos no grupo com melhora, três pacientes $(50 \%)$ que apresentavam sintomas ansiosos na visita inicial (HADS-A $>=9$ ), e destes dois pacientes $(33,3 \%)$ permaneceram com sintomas ansiosos ao final do tratamento. Para o grupo sem melhora clínica, haviam quatro pacientes $(57,1 \%)$ com sintomas ansiosos na visita inicial, e dois pacientes $(28,5 \%)$ permaneceram com sintomas ansiosos ao final do protocolo de estudo (Gráfico 6). Não houve significância estatística de acordo com o teste exato de Fisher ( $p$ 1,00) quando comparamos a pontuação na HADS-A entre os pacientes que melhoraram e os que não melhoraram clinicamente com o uso da gabapentina.

A mesma análise pode ser feita para os sintomas de depressão pela escala HADS-D. Para o grupo que apresentou melhora clínica com o tratamento, havia um paciente $(16,6 \%)$ ao início do estudo com sintomas de depressão (HADS-D >=9), nenhum deles permaneceu com sintomas depressivos na visita de finalização. Já para o grupo sem melhora clínica, dois pacientes $(28,5 \%)$ apresentavam sintomas depressivos na primeira visita, e um deles $(14,3 \%)$ manteve esse sintoma ao final do tratamento (Gráfico 6). Não houve significância estatística de acordo com o teste exato de Fisher (p 1,00) quando comparamos a pontuação na HADS-D entre os pacientes que melhoraram e os que não melhoraram clinicamente com o uso da gabapentina. 
Gráfico 6 - Comparação entre melhora clínica e sintomas de depressão e ansiedade

\section{Comparação entre melhora clínica e pontuação na escala HADS}

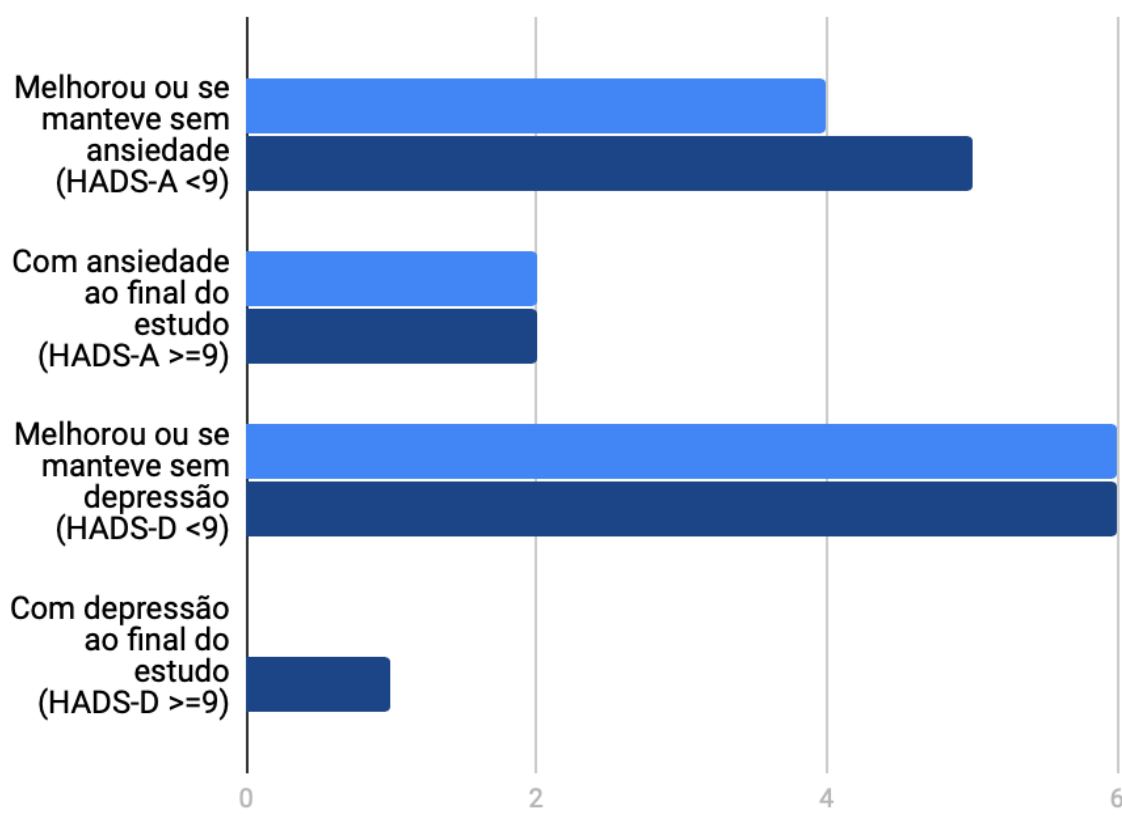

Com melhora clínica

Sem melhora clínica

\subsection{Avaliação de catastrofização}

A avaliação comparativa entre sintomas de catastrofização ao início e ao final da pesquisa foi feita através da aplicação da Escala de Pensamentos Catastróficos em Dor (EPCD) da PRSS. Na primeira visita, os pacientes apresentaram pontuação média de 22,77 pontos $(\underline{+}$ 10,9) com variação de 11 a 45 pontos. Ao final do protocolo, a pontuação média dos pacientes foi de 20,54 pontos $( \pm 12,62)$, variando de 9 a 45 pontos (Gráfico 7). Esta diferença foi estatisticamente significativa de acordo com o teste de Wilcoxon (p 0,04). 


\section{Gráfico 7 - Comparação entre a pontuação da escala EPCD na visita inicial e na visita de finalização}

\section{Escala de Pensamentos Catastróficos em Dor}

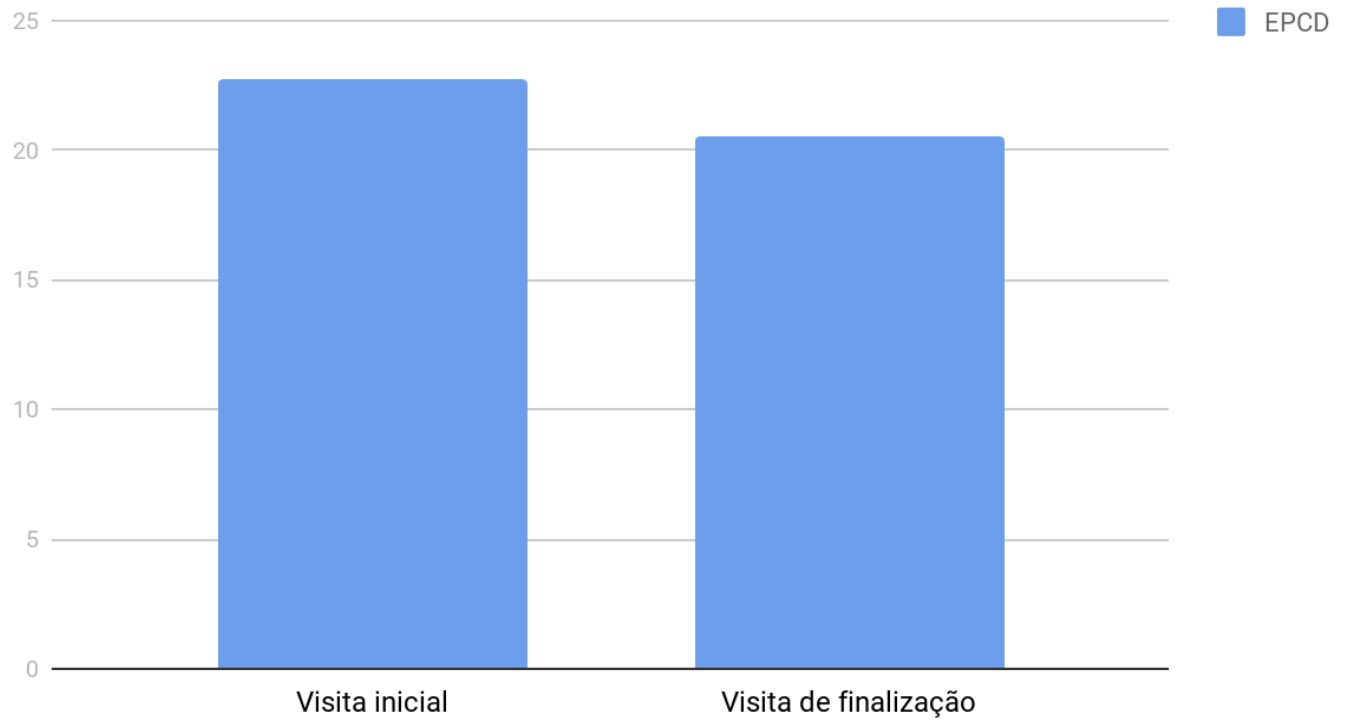

Quando analisamos separadamente a EPCD entre o grupo de pacientes que apresentou melhora clínica com o tratamento com gabapentina e o que não apresentou melhora, vemos que não houve significância estatística (p 0,83 ) em relação aos sintomas de catastrofização, de acordo com o teste de Mann-Whitney.

\subsection{Avaliação da qualidade de vida}

A avaliação da qualidade de vida dos voluntários deste estudo foi feita através do instrumento abreviado da escala de avaliação de qualidade de vida da Organização Mundial de Saúde (WHOQOL-bref). Os quatro domínios que compõem este questionário foram aplicados para cada participante na visita inicial e na visita de finalização do estudo, e seus dados foram comparados conforme o Gráfico 8.

Em relação ao domínio físico desta escala, a média de pontos apresentada na visita inicial foi de 54,67 $( \pm 11,33)$, com variação entre 32,14 a 75 pontos; já na visita de finalização, a média foi $54,67( \pm 10,14)$ pontos e variação de 35,71 a 71,43 pontos. Não houve diferença estatística significativa de acordo com o teste de Wilcoxon $(\mathrm{p} 0,99)$. 
No domínio psicológico da WHOQOL-bref, a pontuação média dos voluntários na visita inicial foi de 61,86 ( $\pm 15,94)$ pontos, com variação de 16,67 a 83,33. Na visita final, os voluntários pontuaram em média 60,26 $( \pm$ 12,57) pontos, variando entre 33,33 a 75. Também não houve diferença estatística significativa pelo teste de Wilcoxon (p 0,39).

Para o domínio social da WHOQOL-bref, os participantes do estudo apresentaram pontuação média de $60,9( \pm 21,62)$ pontos na primeira avaliação, com variação de 0 a 83,33 pontos. Já na visita final, a pontuação média foi $61,54( \pm 15,04)$ pontos, com variação de 33,33 a 83,33, também sem nenhuma significância estatística (p 0,73) de acordo com o teste de Wilcoxon.

Quanto ao domínio ambiental, a pontuação média dos voluntários na primeira visita foi de 59,13 ( \pm 17,61) pontos, variação de 12,5 a 75 . Na visita de finalização, estes mesmos voluntários apresentaram média de 65,63 ( \pm 10,83) pontos, variando entre 53,33 a 87,5 pontos, sem significância estatística (p 0,27$)$ calculada através do teste de Wilcoxon.

\section{Gráfico 8 - Comparação da qualidade de vida medida através do WHOQOL-bref antes e após o tratamento com gabapentina}

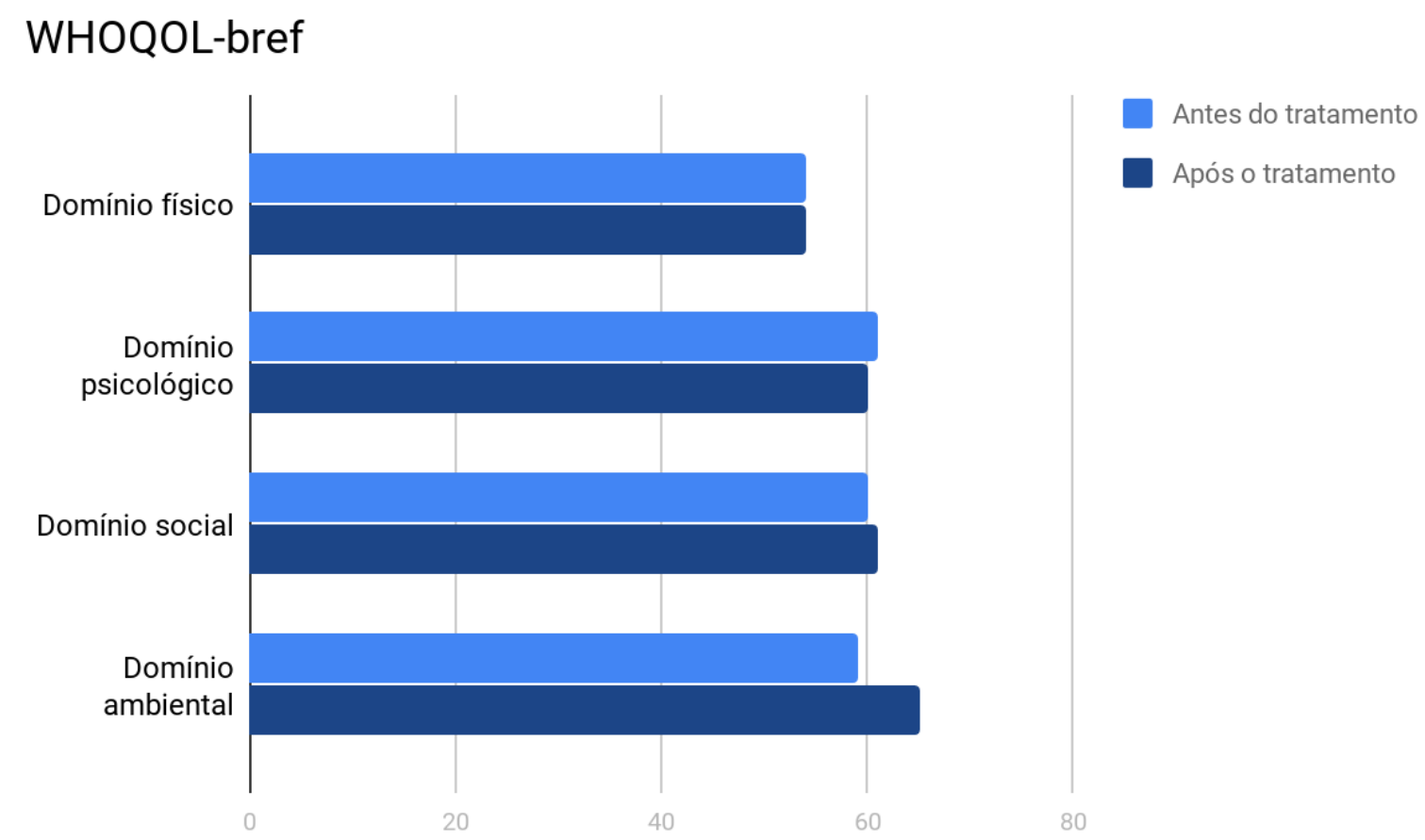


Ao fazer a análise separada por grupos que apresentaram ou não melhora clínica após o tratamento com gabapentina, vemos que também não houve significância estatística para nenhum dos domínios da WHOQOL-bref avaliados pelo teste de Mann-Whitney (físico p 0,78; psicológico p 0,25; social p 0,36; ambiental p 0,53).

\subsection{Avaliação de sonolência}

A presença de sonolência entre os voluntários deste estudo também foi avaliada e comparada entre as visitas inicial e final, visto este ser um efeito colateral comum da gabapentina. Para isso, utilizamos a Escala de Sonolência de Epworth (Gráfico 9).

Ao analisarmos a presença de sonolência entre os voluntários na primeira e na última visita do estudo, encontramos a presença de sonolência diurna excessiva, caracterizada pela pontuação maior ou igual a 11 na Escala de Sonolência de Epworth, em dois pacientes na visita inicial $(15,38 \%)$ e em quatro pacientes na visita final (30,77\%), o que não foi estatisticamente significativo de acordo com o teste de McNemar $(\mathrm{p}=0,41)$. Analisando separadamente os voluntários que apresentaram ou não melhora clínica com a gabapentina, concluímos que também não houve diferença estatisticamente significativa em relação à sonolência de acordo com o teste exato de Fisher (p 0,56).

\section{Gráfico 9 - Presença de sonolência entre os participantes antes e após o tratamento}

\section{Escala de Sonolência de Epworth}

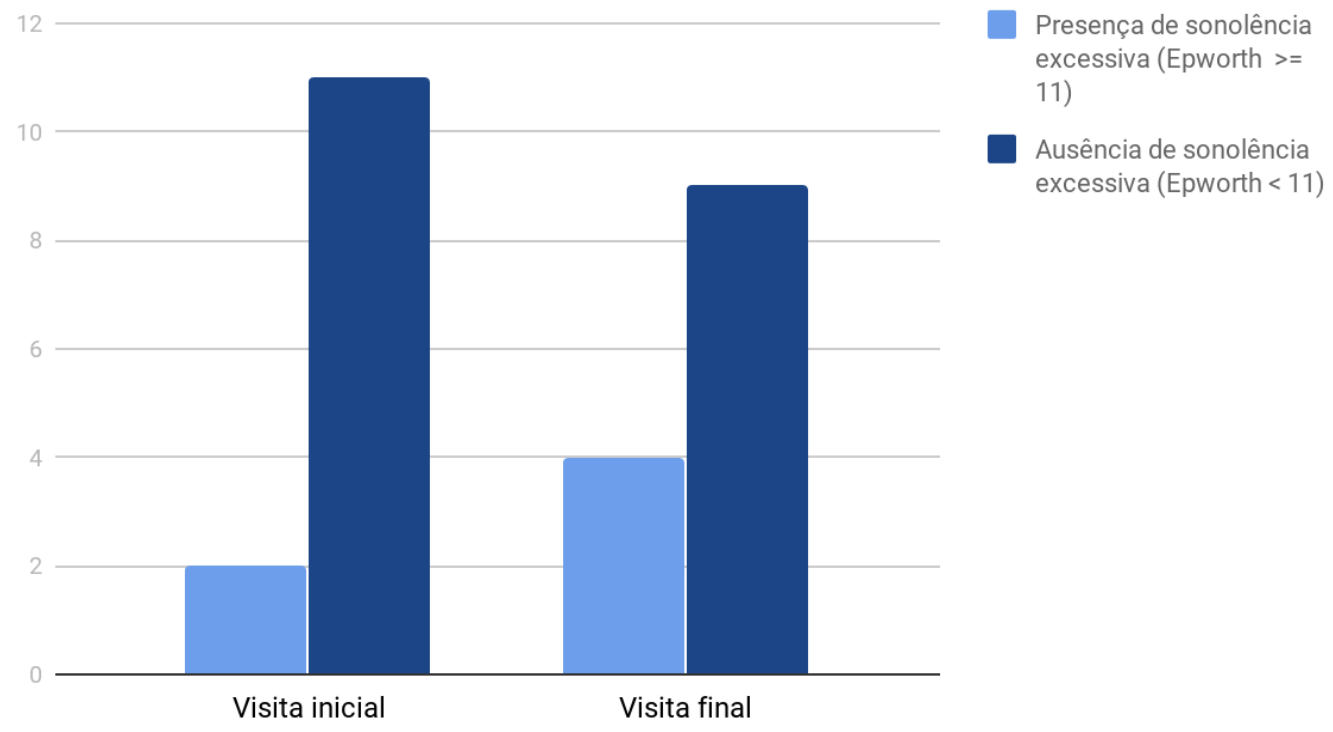




\subsection{Avaliação do fluxo sanguíneo cerebral regional (FSCr)}

4.7.1 Comparação entre grupos. Diferenças no FSCr entre pacientes com dor lombar crônica, antes do uso da gabapentina, versus voluntários saudáveis.

Foram avaliados os 14 pacientes portadores de DLC que realizaram a SPECT inicial do estudo. O resultado foi um único mapa funcional contemplando as principais alterações vistas no FSCr destes pacientes, tanto com hiper quanto com hipoperfusão.

As alterações do FSCr aumentado (hiperperfusão) e diminuído (hipoperfusão) encontradas em pacientes com lombalgia são apresentadas na Tabela 2 e na Figura 3. As alterações mais significativas de aumento do FSCr foram encontradas no hemisfério cerebral direito: lobo occipital direito (giros calcarino, cuneus, giro lingual e occipital médio), cíngulo posterior direito e lobo frontal direito (giros frontais inferior e médio, córtex pré-frontal anterior e córtex pré-frontal dorsolateral). A diminuição do FSCr foi encontrada em um grande agrupamento que incluiu as regiões bilaterais dos lobos parietais e do giro cingulado direito. As coordenadas de Talairach são dadas na Tabela 2.

A figura 3 mostra a sobreposição de clusters na ressonância magnética ponderada em T1 do modelo SPM. Imagens mostram áreas com aumento significativo (A, B, D e E) e diminuição ( $\mathrm{C}$ e F) do FSCr. Os resultados são mostrados em valores de $\mathrm{P}$ menores que 0,05 , corrigidos para comparações múltiplas (FWE, family-wise error rate).

Avaliamos também a relação entre alterações do $\mathrm{FSCr}$ e os resultados da EVN através do coeficiente de correlação de ordem não paramétrica tau de Kendall com intervalo de confiança de 95\%. As imagens podem ser vistas em "a", "b" e "c" na Figura 3 - vide dados numéricos no APÊNDICE D. Em "b", maiores escores de EVN foram inversa e moderadamente correlacionados com a intensidade do aumento do FSCr no cluster B (tau de Kendall = -0,445, $\mathrm{p}=0,033)$. Em "a" e "c" não houve correlação significativa entre as alterações do FSCr e os escores EVN. 
Tabela 2 - Regiões cerebrais com alterações significativas do FSCr nos pacientes com dor lombar crônica antes do uso da gabapentina, em comparação a voluntários saudáveis

\begin{tabular}{lllll}
\hline Regiões cerebrais & $P *$ & Volume do & Coordenadas & Voxel \\
& & cluster $(k)$ & Talairach & máximo \\
& & & $x, y, z$ & $Z$ score \\
\hline
\end{tabular}

\section{Hiperperfusão}

Lobo occipital D (Giros calcarino, cuneus, lingual e occipital médio), Giro do cíngulo posterior D

$0.023 \quad 733 \quad 20,-70,4$

Lobo frontal D (giros frontais inferior e médio).

0.032

660

$36,44,18$

Áreas de Brodmann 10 (CPF anterior) e 46

(CPFDL) D

\section{Hipoperfusão}

Lobos parietais E (Precuneus, lobo paracentral) e D

(Giros pós-central, lobo paracentral).

$$
0.000 \quad 2.774 \quad 0,-52,68
$$

Giro do cíngulo médio D

Áreas de Brodmann 5 e 7

Abreviações: $P *$ valor de significância do cluster; D, direito; E, esquerdo; CPF, córtex pré-frontal; CPFDL, córtex pré-frontal dorsolateral. 
Figura 3 - Alterações do FSCr em pacientes com dor lombar crônica, antes do uso da gabapentina, em relação a voluntários saudáveis

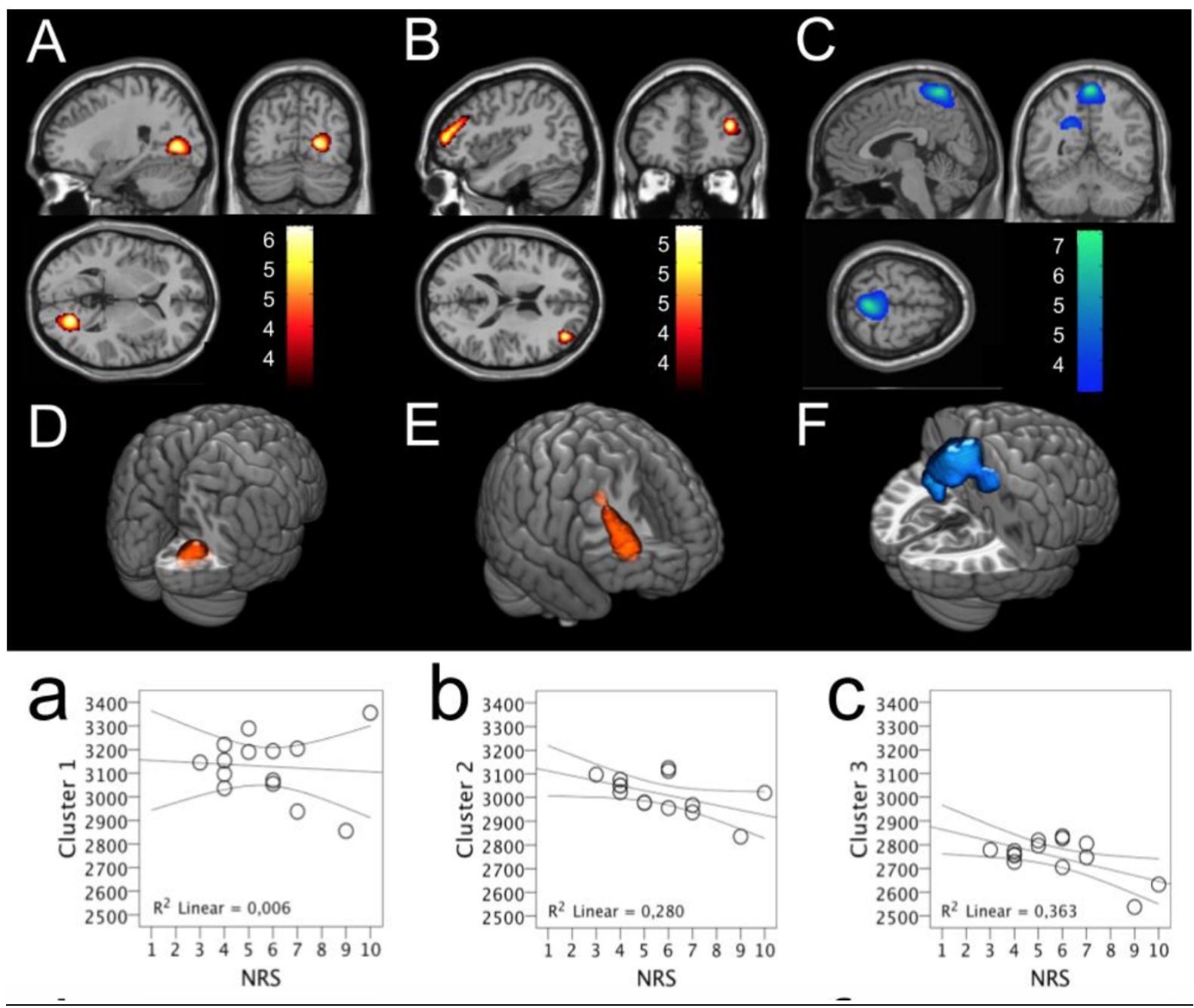

Mapeamento paramétrico estatístico (SPM) mostrando regiões cerebrais com alterações significativas de FSCr em 14 pacientes com DLC. A (vista 3D em D): lóbulo occipital direito e giro posterior do cíngulo direito; B (vista 3D em E): lobo frontal pré-frontal e dorsolateral anterior direitos; C (vista 3D em F): lobo parietal parassagital e póscentral bilaterais e córtex cingulado médio direito. As barras de cores significam Z-scores da intensidade de aumento ou diminuição do FSCr. Em "a", "b" e "c" as linhas curvas mostram o IC 95\% ao redor da linha de regressão. Abreviações: EVN, Escala Visual Numérica (nas figuras a, b e c visto como NRS); IC, intervalo de confiança. 
4.7.2 Comparação individual e entre grupos. Diferenças no FSCr do grupo de 13 pacientes com dor lombar crônica, antes e depois do uso da gabapentina.

Fizemos a comparação entre os 13 pacientes portadores de DLC que finalizaram o estudo, avaliando-os antes e após o uso da gabapentina. Os achados descritos na Tabela 3 referem-se à diferença na quantificação do FSCr entre as fases pré e pós tratamento com gabapentina, avaliada dentro de dois clusters, um de hiper e outro de hipoperfusão.

Tabela 3 - Diferença perfusional individual antes e depois da gabapentina

\begin{tabular}{|c|c|c|c|c|}
\hline Pacientes & $\begin{array}{l}\text { Diferença Pós - Pré } \\
\text { (Cluster } \\
\text { Hiperperfusão) }\end{array}$ & DP Hiper & $\begin{array}{l}\text { Diferença Pós - Pré } \\
\text { (Cluster } \\
\text { Hipoperfusão) }\end{array}$ & DP Hipo \\
\hline 1 & 2.577 & 4.372 & -6.043 & 2.901 \\
\hline 2 & 4.969 & 2.752 & $-0,497$ & 3.565 \\
\hline 3 & 0,336 & 3.339 & -3.134 & 3.856 \\
\hline 4 & 0,873 & 3.009 & -6.155 & 2.607 \\
\hline 5 & 2.696 & 4.965 & -5.199 & 2.117 \\
\hline 6 & 6.501 & 4.157 & -5.723 & 3.131 \\
\hline 7 & 4.245 & 3.384 & -4.104 & 3.221 \\
\hline 8 & 3.797 & 4.524 & -3.829 & 2.975 \\
\hline 9 & 6.924 & 3.077 & -1.288 & 2.046 \\
\hline 10 & 3.386 & 4.102 & -3.586 & 2.342 \\
\hline 11 & 4.032 & 5.121 & -1.068 & 3.348 \\
\hline 12 & 2.941 & 2.917 & -1.070 & 2.042 \\
\hline 13 & 7.088 & 4.284 & -4.316 & 3.212 \\
\hline
\end{tabular}

Abreviações: DP, desvio-padrão. OBS: Os dados numéricos estão apresentados por volume do cluster (k).

Foi gerado um único mapa funcional da diferença entre os dois grupos, vistos na Tabela 4 e na Figura 4.

A Figura 4 mostra a sobreposição de clusters na ressonância magnética ponderada em T1 do modelo SPM. Imagens mostram uma área (cluster) com significativos aumento (A e D) e diminuição (B e E) do FSCr após o uso da gabapentina. O aumento significativo de FSCr foi encontrado no giro do cíngulo anterior (região límbica), como visto nos planos axial, transversal e sagital (em A) e em reconstrução tridimensional (em D). A diminuição do FSCr foi encontrada nas regiões posteriores do mesencéfalo e ponte a direita, envolvendo parcialmente o culmen do 
cerebelo (visão em planos em B, e tridimensional em E). As coordenadas de Talairach são dadas na Tabela 4. Os resultados são mostrados em valores de $\mathrm{P}$ menores que 0,05 , corrigidos para comparações múltiplas (FWE).

Tabela 4 - Comparação do grupo de 13 pacientes com dor lombar crônica, antes e depois do uso da gabapentina - Áreas de hiper e hipoperfusão.

\begin{tabular}{|c|c|c|c|c|}
\hline Regiões cerebrais & $\boldsymbol{P} *$ & $\begin{array}{l}\text { Volume do } \\
\text { cluster }(k)\end{array}$ & $\begin{array}{l}\text { Coordenadas } \\
\text { Talairach } \\
\mathbf{x}, \mathbf{y}, \mathbf{z}\end{array}$ & $\begin{array}{l}\text { Voxel } \\
\text { máximo } \\
Z \text { score }\end{array}$ \\
\hline \multicolumn{5}{|l|}{ Hipoperfusão } \\
\hline Lobo límbico bilateral (cíngulo anterior) & 0,05 & 565 & $4,26,14$ & 4.73 \\
\hline \multicolumn{5}{|l|}{ Hipoperfusão } \\
\hline Tronco cerebral D (mesencéfalo, ponte) & 0,04 & 319 & $2,-30,-20$ & 4.14 \\
\hline Cerebelo anterior D (culmen) & & & & \\
\hline
\end{tabular}


Figura 4 - Alterações do FSCr em 13 pacientes com dor lombar crônica após o uso de gabapentina

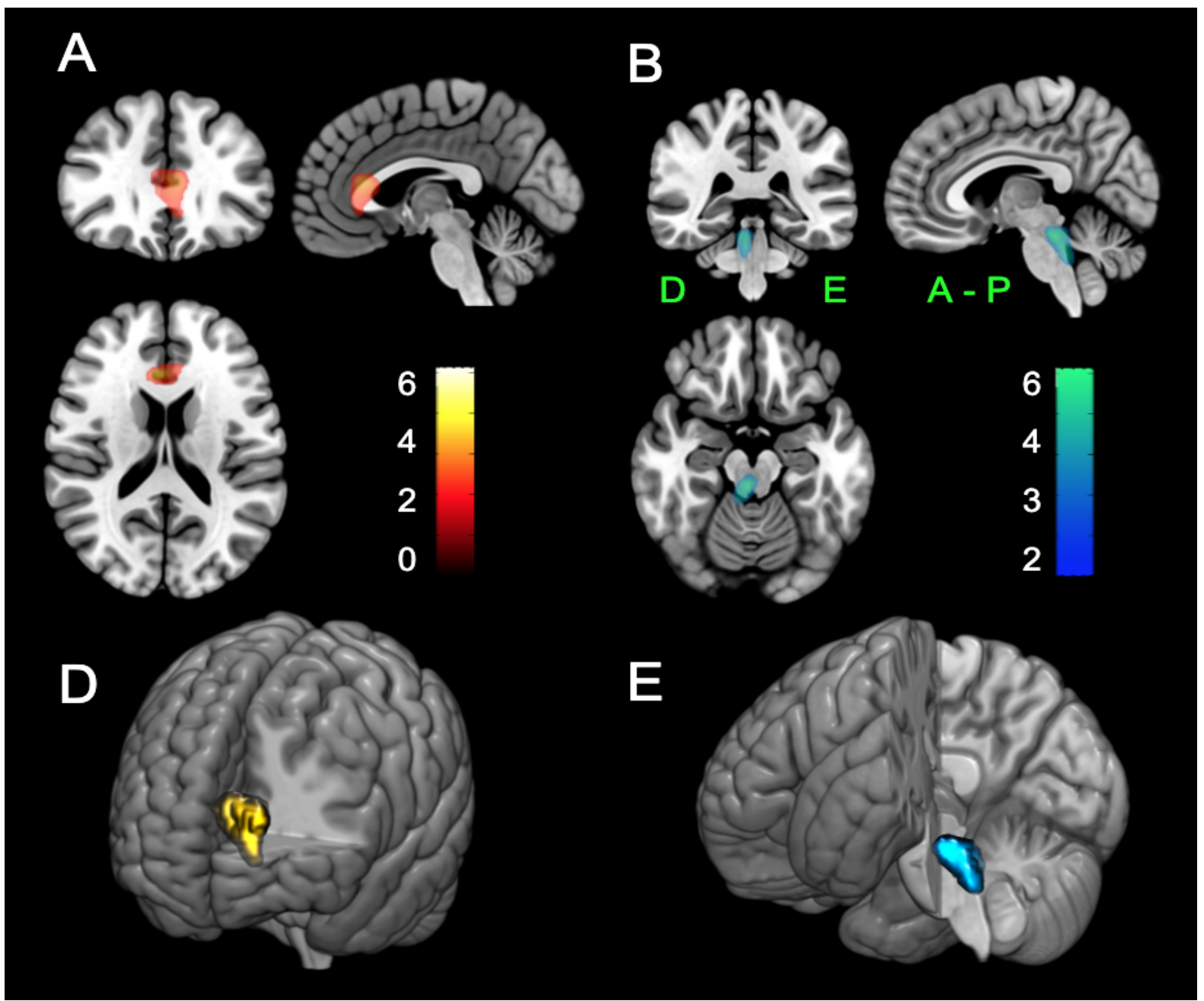

Mapeamento paramétrico estatístico (SPM) mostrando regiões cerebrais com alterações significativas de FSCr em 13 pacientes com DLC, após o uso de gabapentina. A (planos axial, transversal e sagital e reconstrução tridimensional em D): giro do cíngulo anterior (região límbica); B (planos axial, transversal e sagital e reconstrução tridimensional em E): regiões posteriores do mesencéfalo e ponte, envolvendo parcialmente o culmen do cerebelo. As barras de cores significam Z-scores da intensidade de aumento ou diminuição do FSCr. Abreviações: D, direita; E, esquerda; A, anterior; P, posterior. 
4.7.3 Comparação individual e entre grupos. Diferenças do FSCr entre pacientes com melhora $(n=6)$ e sem melhora $(n=7)$ da DLC após o uso da gabapentina, comparativamente aos voluntários saudáveis.

Em outra análise, os 13 pacientes foram avaliados individualmente, sendo separados entre aqueles com boa resposta (6 pacientes) e os sem resposta ao tratamento com gabapentina (7 pacientes), numa tentativa de explorar as características funcionais associadas com a resposta terapêutica da gabapentina. Os resultados individuais se mostraram bastante heterogêneos quando comparados ao banco de dados de voluntários saudáveis, cujos dados são mostrados na Tabela 5 .

Foi feita também a análise entre grupos, dividindo-os entre respondedores à gabapentina e não respondedores. As diferenças perfusionais entre as duas fases estão exibidas em mapas funcionais que representam o efeito isolado da gabapentina sobre o FSCr. Esses dois grupos foram comparados entre si, e também comparados isoladamente com banco de dados de controles saudáveis.

A comparação dos grupos com e sem melhora com a gabapentina entre si não mostrou nenhuma diferença significativa.

Entretanto, a comparação destes grupos com o banco de dados de voluntários saudáveis revelou que o grupo de pacientes que não apresentou melhora com gabapentina apresentava uma redução do FSCr significativa em um cluster que envolve as regiões pré-centrais dos lobos frontais bilateralmente (área motora), e regiões parietais bilateralmente, notadamente nos lóbulos paracentrais, giro pós-central e precuneus, conforme pode ser observado na Tabela 6 e Figura 5.

A Figura 5 mostra a sobreposição de cluster na ressonância magnética ponderada em T1 do modelo SPM. As imagens mostram a área com redução significativa do fluxo sanguíneo cerebral regional (A e B em imagem tridimensional, e C, D e E, em imagens planares transversal, sagital e coronal, respectivamente). Os resultados são mostrados em valores de P menores que 0,05 , corrigidos para comparações múltiplas (FWE). 
Tabela 5 - Análise individual das diferenças no FSCr entre pacientes com e sem melhora com a gabapentina comparativamente aos controles saudáveis - Áreas de hiper e hipoperfusão

\begin{tabular}{|c|c|c|c|c|}
\hline Paciente \# (regiões cerebrais) & $P *$ & $\begin{array}{l}\text { Volume do } \\
\text { cluster }(k)\end{array}$ & $\begin{array}{l}\text { Coordenadas } \\
\text { Talairach } \\
\mathbf{x}, \mathbf{y}, \mathbf{z}\end{array}$ & $\begin{array}{l}\text { Voxel } \\
\text { máximo } \\
Z \text { score }\end{array}$ \\
\hline \multicolumn{5}{|l|}{ Pacientes com melhora com Gabapentina } \\
\hline \multicolumn{5}{|l|}{ Hiperperfusão } \\
\hline \#8 Temporal D, giro médio & 0.04 & 386 & $60,-30,-6$ & 4.38 \\
\hline Frontal E, giros superior, medial e médio & 0.01 & 514 & $-22,48,12$ & 4.26 \\
\hline \#11 Frontal D (giros superior e médio) & 0.05 & 362 & $20,34,34$ & 4.28 \\
\hline $\begin{array}{l}\text { Temporal direito (giro médio), occipital D (giro } \\
\text { médio) }\end{array}$ & 0.05 & 347 & $40,-74,14$ & 4.15 \\
\hline \multicolumn{5}{|l|}{ Hipoperfusão } \\
\hline \#4 Temporal D, giro médio & 0.00 & 640 & $30,-80,-24$ & 4.41 \\
\hline \multicolumn{5}{|l|}{ Pacientes sem melhora com Gabapentina } \\
\hline \multicolumn{5}{|l|}{ Hiperperfusão } \\
\hline $\begin{array}{l}\text { \#5 Occipital D (giros fusiforme e lingual), cerebelo } \\
\text { posterior D (declive) }\end{array}$ & 0.00 & 644 & $10,-68,-16$ & 4.21 \\
\hline \#7 Lobo límbico bilateral (cíngulo anterior) & 0.02 & 464 & $-6,38,14$ & 4.19 \\
\hline $\begin{array}{l}\text { \#13 Lobos bi frontais (giros superior, medial e } \\
\text { médio) e bilímbico (cíngulo anterior) }\end{array}$ & 0.00 & 6435 & $20,34,34$ & 5.31 \\
\hline \multicolumn{5}{|l|}{ Hipoperfusão } \\
\hline \#7 Parietal E (giro pós-central, lóbulo paracentral) & 0.05 & 345 & $-26,40,64$ & 3.55 \\
\hline
\end{tabular}


Tabela 6 - Comparação entre o grupo de pacientes sem melhora clínica com a gabapentina e o banco de dados de voluntários saudáveis - área de hipoperfusão

\begin{tabular}{|c|c|c|c|c|}
\hline Regiões cerebrais & $P *$ & $\begin{array}{l}\text { Volume do } \\
\text { cluster }(k)\end{array}$ & $\begin{array}{l}\text { Coordenadas } \\
\text { Talairach } \\
\mathbf{x}, \mathbf{y}, \mathbf{z}\end{array}$ & $\begin{array}{l}\text { Voxel } \\
\text { máximo } \\
Z \text { score }\end{array}$ \\
\hline Hipoperfusão & & & & \\
\hline $\begin{array}{l}\text { Regiões pré-centrais dos lobos frontais } \\
\text { bilateralmente, e regiões parietais (lóbulos } \\
\text { paracentrais, giro pós-central e precuneus) }\end{array}$ & $<0.01$ & 2.837 & $-8,-30,66$ & 0,0724 \\
\hline
\end{tabular}

Abreviações: * $P$ valor de significância do cluster (FWE) 
Figura 5 - Alterações do FSCr em pacientes sem melhora clínica com gabapentina, em relação aos controles saudáveis

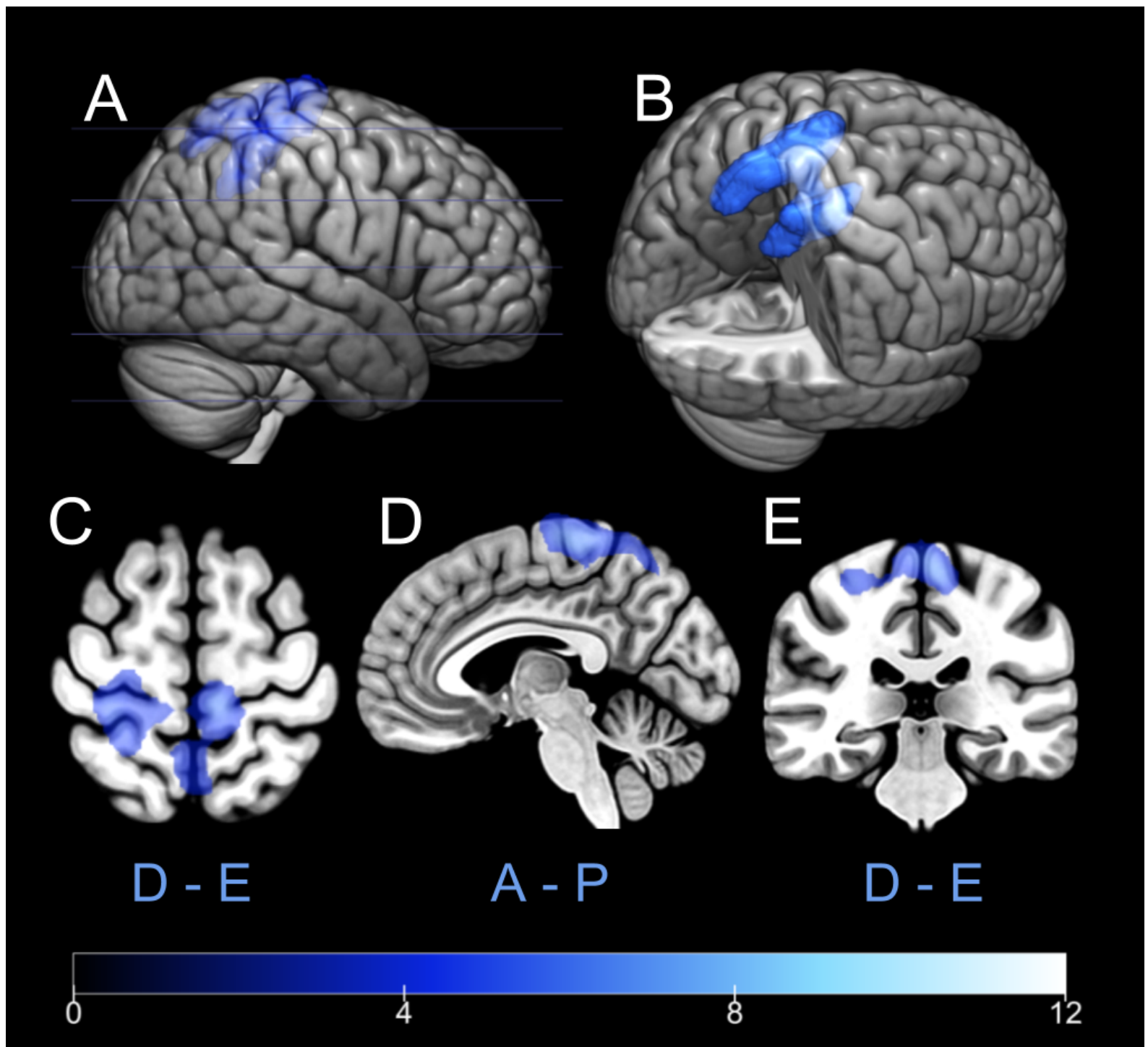

Mapeamento paramétrico estatístico (SPM) mostrando regiões cerebrais com redução significativa de FSCr em grupo de 7 pacientes com DLC sem melhora com a gabapentina. O grupo de 6 pacientes com melhora clínica não exibiu diferença significativa em relação aos voluntários saudáveis e por isto não há imagem para compor esta Figura. A e B em imagem tridimensional, e C, D e E, em imagens planares transversal, sagital e coronal, respectivamente. Os valores na barra de cores representam o $Z$ score. Abreviações: A, anterior; P, posterior; D, direita; E, esquerda. 
4.7.4 Comparação entre grupos. Diferenças do FSCr antes e depois do uso da gabapentina, analisados separadamente nos grupos com e sem melhora clínica.

Analisamos o SPM do grupo de 6 pacientes com melhora clínica antes e depois do uso da gabapentina, procurando pelas áreas cerebrais associadas com o sucesso terapêutico. A mesma análise foi feita no grupo de 7 pacientes que não apresentaram melhora clínica, procurando pelo substrato neurobiológico associado à falha terapêutica.

Conforme pode ser observado na Tabela 7, a análise estatística mostra o aumento do FSCr apenas no grupo que não apresentou melhora clínica com gabapentina. Este grupo apresentou hiperperfusão na região do giro do cíngulo anterior esquerdo (Figura 6).

A Figura 6 mostra a sobreposição de cluster na ressonância magnética ponderada em T1 do modelo SPM. As imagens mostram a área com aumento significativo do FSCr (no sentido horário, imagens em coronal, sagital, tridimensional e transversal). $\mathrm{O}$ aumento do $\mathrm{FSCr}$ foi encontrado em um cluster que envolve principalmente o sistema límbico, notadamente o giro do cíngulo anterior à esquerda. Os resultados são mostrados em valores de $\mathrm{P}$ menores que 0,05 , corrigidos para comparações múltiplas (FWE).

Tabela 7 - Comparação entre grupos. Diferenças do FSCr antes e depois do uso da gabapentina, analisados separadamente nos grupos com e sem melhora clínica.

\begin{tabular}{lcccc}
\hline Áreas de alteração do FSCr (SPECT pós versus pré & $P *$ & Volume do & Coordenadas & Voxel \\
tratamento com gabapentina) & cluster $(k)$ & Talairach & máximo \\
& & $\mathbf{x}, \mathbf{y}, \mathrm{z}$ & $Z$ score \\
\hline
\end{tabular}

Pacientes com melhora com a Gabapentina $(n=6)$

Hiperperfusão

Hipoperfusão

Pacientes sem melhora com a Gabapentina $(n=7)$

Hiperperfusão

Lobo límbico E (cíngulo anterior)

$\begin{array}{llll}0.013 & 260 & -2,26,12 & 3.96\end{array}$

Hipoperfusão

Abreviações: FSCr, Fluxo sanguíneo cerebral regional; P* valor de significância dos clusters; E, esquerdo. 
Figura 6 - Comparação do FSCr pós versus pré tratamento com gabapentina, no grupo de 7 pacientes que não apresentaram melhora clínica

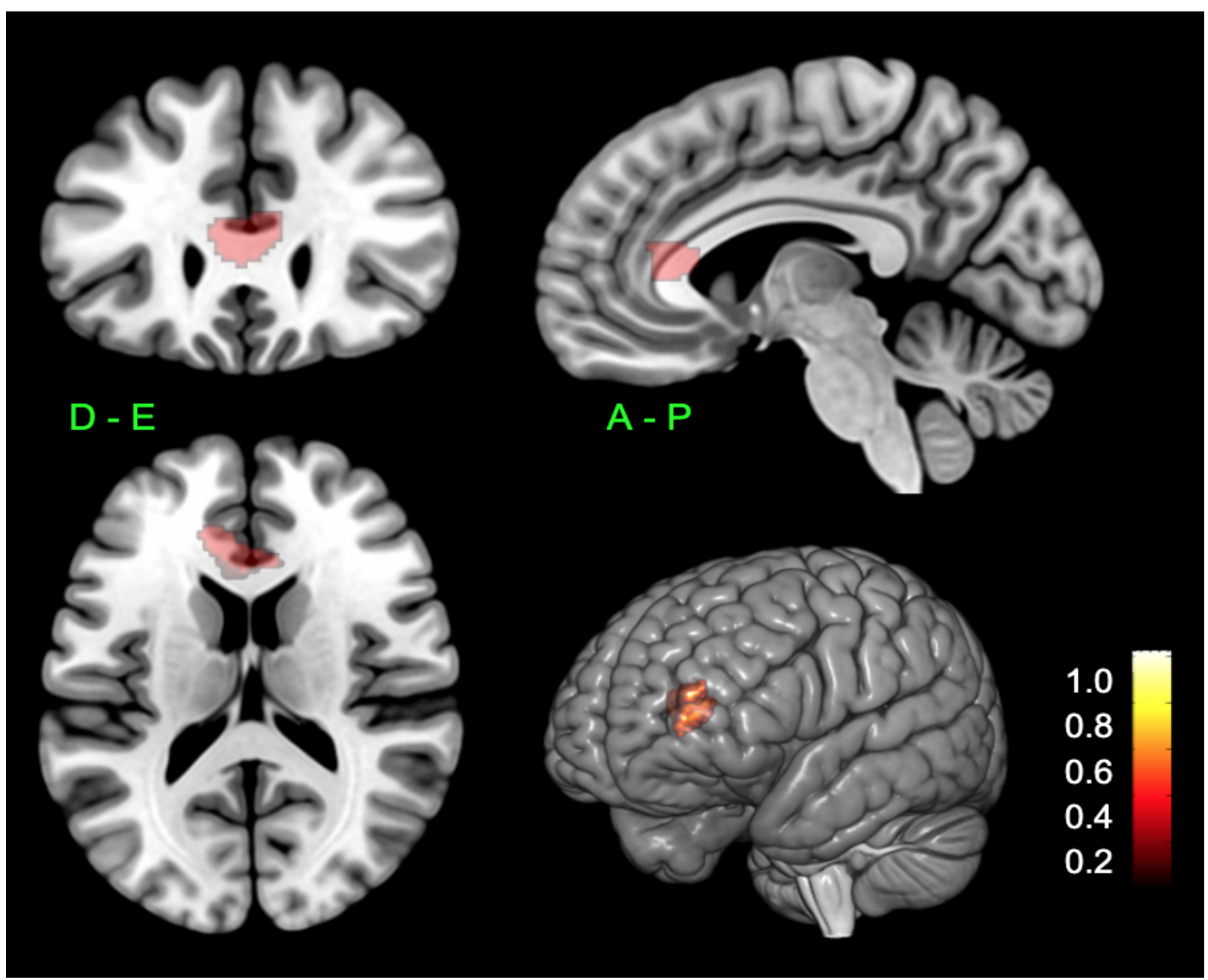

Mapeamento paramétrico estatístico (SPM), comparando-se a SPECT pós versus pré tratamento com gabapentina, no grupo de 7 pacientes que não apresentaram melhora clínica. No sentido horário, imagens em coronal, sagital, tridimensional e transversal. Os valores na barra de cores representam o $Z$ score. Abreviações: A, anterior; P, posterior; D, direita; E, esquerda. 


\section{DISCUSSÃO}

O presente estudo representa uma série de 14 casos de pacientes portadores de dor lombar crônica (DLC), de característica neuropática, secundária à presença de hérnia discal lombar, a qual era comprovada por ressonância magnética (RM). Tais casos foram avaliados através de exame de neuroimagem funcional (SPECT cerebral) a fim de evidenciar quais regiões cerebrais podem estar relacionadas com a dor e se há mudanças no fluxo sanguíneo cerebral regional (FSCr) após o tratamento. A proposta terapêutica escolhida foi a gabapentina, visto ser medicação de primeira linha em diversos guidelines para tratamento de dor neuropática. Objetivamos ainda correlacionar a dor crônica com escalas de depressão, ansiedade, catastrofização, qualidade de vida e sonolência. Apenas 13 pacientes completaram o estudo, entretanto a SPECT inicial do $14^{\circ}$ paciente foi utilizada em um dos braços do estudo para comparação com banco de dados de imagens de controles saudáveis.

Sabemos que a DLC é um problema de saúde pública comum, com alto impacto econômico e social no mundo todo, responsável por grande número de anos vividos com incapacidade $(72,73)$. Seu mecanismo é multifatorial, e estudos não invasivos de neuroimagem estrutural e funcional tem emergido a fim de colaborar com o melhor entendimento das características neurobiológicas associadas à DLC.

A média de idade dos participantes em nosso estudo foi de $41( \pm 9,62)$ anos. Uma revisão sistemática publicada em 2015 mostrava média de idade dos participantes de 46,6 anos (74). Uma prevalência maior de DLC entre adultos na quinta e sexta décadas de vida foi encontrada em um estudo epidemiológico americano envolvendo 5.103 participantes (75). Outros estudos mostram uma maior incidência de dor lombar crônica na terceira década de vida, enquanto a prevalência aumenta até a idade de 65 anos, quando então passa a cair (7678). Um estudo populacional português envolvendo mais de 10 mil voluntários encontrou média de idade aferida em 57,9 $( \pm 17,2)$ anos, e mostrou que a prevalência da DLC aumenta significativamente com a idade; enquanto a faixa etária de 36 a 45 anos apresentou prevalência estimada de DLC em 7,2\%, essa proporção aumentou para $29,7 \%$ no grupo acima de 86 anos (79).

Em relação à intensidade da dor, encontramos em nossa média amostral EVN de 5,92 $( \pm 1,93)$ pontos. O estudo populacional português supracitado encontrou uma intensidade média de $6,0( \pm 2,14)$ pontos na EVN, e os escores reportados pelas mulheres foram ligeiramente superiores aos dos pacientes do sexo masculino $(6,2 \pm 2,53$ das mulheres vs. $5,7 \pm 2,29$ dos 
homens) (79). Nakamura e cols., utilizando o SPECT cerebral para avaliar pacientes com dor lombar aguda e crônica, encontraram uma pontuação EVA média para pacientes com DLC de 6,3, semelhante à nossa série de casos (68). Outro estudo em portadores de dor lombar comparou pacientes com dor crônica e aguda, tanto nociceptiva quanto neuropática; entre pacientes com DLC neuropática, a média de intensidade de dor foi de 7,4 $( \pm 1,9)$ pontos avaliados pela EVA; já os pacientes com DLC de origem nociceptiva apresentaram menor intensidade de dor, com média de 5,1 $( \pm 2,0)$ pontos na EVA. Em geral, os casos crônicos de dor lombar, tanto de origem nociceptiva quanto neuropática, apresentam maior gravidade da dor do que os casos agudos e subagudos (80).

A topografia da lesão mais comum dentre os voluntários do nosso estudo foi L4-L5, correspondendo a quase $80 \%$ dos casos. Estudos que comparavam tratamento cirúrgico versus terapia conservadora encontraram quase $95 \%$ de prevalência das hérnias discais lombares em L4-L5 e L5-S1. Essa região sofre alto impacto por sobrecarga e é um ponto de grande amplitude de movimento da coluna lombar, justificando a maior ocorrência de hérnias discais neste local $(81,82)$.

Associação entre DLC e transtornos de ansiedade e depressão são comuns (83-85). Em nosso estudo, a prevalência de sinais e sintomas de ansiedade dentre os portadores de DLC foi de $53,8 \%$, e de sinais e sintomas de depressão foi de $23,08 \%$. Uma coorte multicêntrica que avaliou 284 pacientes portadores de DLC encontrou prevalência de 72,9\% para ansiedade e $58,1 \%$ para depressão, taxas bem mais altas do que as que encontramos e também que na população em geral (86). Após o tratamento com gabapentina, não encontramos significância estatística quanto à redução dos escores de depressão e ansiedade medidos pela HADS. Isso pode ser explicado pelo número amostral reduzido para essa comparação, pelo tempo limitado de estudo, pela falta de resposta dos pacientes ao tratamento com gabapentina em mais de 50\% da amostra, além do que a mesma não interfere em neurotransmissores relacionados à distúrbios psiquiátricos. Em casos de dor crônica, hipotetiza-se que os pacientes tenham uma percepção distorcida da dor e respostas menos eficazes em seu manejo cognitivo, gerando maior sofrimento mental, e contribuindo para o aumento da incapacidade física e depressão (85). Caracterizar de modo adequado a doença mental presente em cada um dos pacientes portadores de dor crônica permite-nos proporcionar uma adequação do plano terapêutico que efetivamente os auxilie na melhora da qualidade de vida e no alívio do quadro álgico. De acordo com Hung e colaboradores, três possíveis razões podem explicar por qual motivo a depressão está associada com maior incapacidade dentre os portadores de DLC: primeiro, a presença de 
pensamentos negativos e a falta de autoconfiança levam os pacientes a subestimar suas habilidades e funcionalidades do dia-a-dia. Em segundo lugar, sintomas físicos como fadiga e sensação de peso nos membros podem estar presentes na depressão, reduzindo a mobilidade dos pacientes e levando-os a confundir aquilo que pode ser atribuído ao transtorno depressivo ou à dor lombar em si. E por último, a depressão pode levar à presença de outras dores, aumentando o grau de incapacidade destes pacientes (87). Além disso, a presença de ansiedade leva à uma redução no limiar de dor e maior sensibilidade à mesma $(88,89)$.

A relação entre DLC e catastrofização também já foi demonstrada em vários estudos $(32,90)$. Pensamentos catastróficos podem influenciar a habilidade do indivíduo em lidar com a dor, sendo importantes preditores de incapacidade física, estresse, intensidade de dor e resposta inadequada aos tratamentos $(91,92)$. O modelo de medo-evitação propõe que percepção exagerada da dor é consequência de um medo aumentado e que estes pacientes esquivam-se de atividades sociais e físicas (93). Uma nova proposta desse modelo discutida em meados de 2000 sugere que a dor pode levar a um pensamento catastrófico, com o subsequente aumento do medo e do desuso físico, contribuindo para a incapacidade e sofrimento psicológico. Os pacientes identificados como de alta catastrofização têm pior desfecho em comparação com os de baixa catastrofização $(94,95)$. Na escala que utilizamos para avaliar a presença de pensamentos catastróficos em dor entre os portadores de DLC, não há ponto de corte. Sabemos que quanto maior a pontuação, mais expressiva se torna essa relação. Um dado interessante é que houve diferença estatística significativa entre a avaliação inicial e final do nosso estudo. Esse fato pode não pode ser atribuído à melhora da dor, já que entre os grupos com e sem resposta à gabapentina não houve diferença estatística na EPCD. Sabemos que a gabapentina leva alguns dias para iniciar a modulação da dor, e o tempo limitado do estudo interfere diretamente neste dado. Consideramos a possibilidade dessa redução nos escores da EPCD ser ocasionada pelo fato do paciente estar em tratamento, ou seja, a experiência de estar sob de cuidado médico, abertura à uma nova possibilidade terapêutica, especialmente se tratando de pesquisa experimental pode levar estes pacientes à uma sensação de conforto ou esperança em relação à melhora da dor, reduzindo o sentimento negativo relacionado à sua condição dolorosa.

Quanto à qualidade de vida, nosso estudo não mostrou nenhuma diferença significativa entre os escores da WHOQOL-bref antes e após o tratamento. Pacientes com dor neuropática possuem menores níveis de qualidade de vida que a população em geral (96). Uma avaliação da qualidade de vida de portadores de dor lombar crônica neuropática ou nociceptiva utilizando 
o Questionário de Avaliação de Dor Lombar da Associação Ortopédica Japonesa (JOABPEQ) mostrou que os pacientes do grupo com dor neuropática tiveram escores da escala visual analógica (EVA) significativamente mais altos e menores escores no SF-36 (Medical Outcomes Short-Form Health Survey) e no JOABPEQ em comparação com o grupo com dor nociceptiva (80). Recentemente, Wettstein e colaboradores abordam o "paradoxo do bem-estar" (97) dentre idosos portadores de dor lombar crônica que apesar de apresentarem maiores níveis de incapacidade, não necessariamente apresentam piores escores de qualidade de vida. Isso parece ser explicado por melhores estratégias de enfrentamento no grupo da terceira idade, que culturalmente já "espera" ter alguma dor quando se é idoso. Embora a velhice possa ser acompanhada por redução de aptidões cognitivas, físicas, sensoriais e outras, isso nem sempre minimiza o bem-estar deste grupo etário. Assim, esforços devem ser feitos para melhorar a incapacidade que acompanha portadores de dor lombar crônica, já que a idade cronológica em si não implica em pior qualidade de vida obrigatoriamente (98).

Em relação aos resultados de neuroimagem do nosso estudo, a avaliação inicial das SPECTs de 14 pacientes portadores de DLC, quando comparados com indivíduos controles, mostrou aumento de perfusão no córtex pré-frontal dorsolateral (CPFDL) direito, giro do cíngulo posterior direito e lobo occipital direito em comparação ao banco de dados de voluntários saudáveis.

O CPFDL é uma região cerebral grande, heterogênea, que abrange o giro frontal médio e os aspectos laterais do giro frontal superior, e é envolvida com funções executivas como tomada de decisão, inibição, memória de trabalho e raciocínio abstrato, além de planejamento motor e atividade mental complexa (99-101). Essa região do CPFDL encontra-se ativada em diversos estudos de neuroimagem funcional, e parece ser uma estrutura fundamental dentre os circuitos implicados no processamento nociceptivo e modulação da dor (102). A ativação do CPFDL esquerdo em pacientes com DLC não incapacitante foi encontrada em um estudo com Ressonância Magnética funcional (RMf), enquanto do córtex pré-frontal medial foi ativado em pacientes com DLC incapacitante em repouso (103). Li e cols. avaliaram pacientes com DLC utilizando RMf e demonstraram uma alteração da conectividade do default mode network $(\mathrm{DMN})$ em repouso envolvendo o CPFDL, córtex pré-frontal medial, cíngulo anterior e precuneus, o que poderia ser um reflexo do estado de dor constante e também estaria relacionada à modulação do aspecto afetivo-emocional da dor. Essa alteração da conectividade foi revertida após o tratamento com acupuntura e melhora da dor (104). Seminowicz e cols. também encontraram um resultado interessante em relação às alterações estruturais e 
neurofuncionais no CPFDL. Avaliando pacientes portadores de DLC antes e após o tratamento, eles conseguiram demonstrar que estruturalmente o CPFDL esquerdo era mais delgado nos portadores de DLC pré-tratamento, e possuía alterações de ativação durante tarefas cognitivas; após o tratamento essas alterações foram revertidas (105). Estudos anteriores evidenciaram que tanto a região parietal posterior quanto o CPFDL estão envolvidos no aspecto cognitivodiscriminativo da dor (106). De acordo com Seminowicz e Moayedi, o CPFDL pode ser ativado em resposta a estímulos nociceptivos em indivíduos saudáveis ou apresentar uma ativação diferencial entre portadores de dor crônica e controles.

Diversas linhas de pesquisa evidenciam que o CPFDL tem função de supressão e manutenção da inibição da dor, associado ao seu papel nos componentes cognitivos associados à experiência dolorosa $(102,107)$. O controle cognitivo tem grande importância na redução da dor crônica, e envolve outras estruturas além do CPFDL, como córtex pré-frontal ventrolateral, córtex orbitofrontal, ínsula anterior, córtex cingulado anterior e substância cinzenta periaquedutal (108). Consistentemente a estes dados, fizemos uma correlação entre a intensidade do aumento do FSCr e os escores de EVN apresentados por nossos pacientes, e percebemos que maiores escores de EVN foram inversa e moderadamente correlacionados com a intensidade do aumento do FSCr no CPFDL. Isso respalda a ideia de que o CPFDL não está diretamente ligado à percepção dolorosa em si, mas sim aos aspectos cognitivos e afetivos relacionados à percepção dolorosa, podendo modular a intensidade da dor.

$\mathrm{O}$ córtex cingulado posterior $(\mathrm{CCP})$ é uma região tradicionalmente ligada à orientação visuo-espacial, memória episódica, estímulos agradáveis relevantes ao self, depressão maior e ansiedade (109-112). Um estudo que avaliou alterações de ativação cortical durante estímulos mecânicos lombares em portadores de DLC conseguiu demonstrar uma ativação robusta do CCP. Esses pacientes tinham um menor limiar de dor medido pela EVA, e a resposta de ativação exagerada do CCP a um estímulo doloroso pode estar associada a estados patológicos de dor como alodinia (113). Em pacientes com dor neuropática crônica foi encontrado um aumento perfusional no CCP, assim como no córtex cingulado anterior direito, sugerindo uma participação importante dessas regiões no aspecto afetivo-motivacional da dor, bem como uma possível tendência à lateralização para o hemisfério direito dos processos afetivos envolvidos nos casos de dor neuropática crônica (114). Interessante ressaltar que em nossas avaliações também observamos um aumento significativo do FSCr no hemisfério direito nos portadores de DLC, em comparação com o banco de dados de controles saudáveis. As atividades corticais 
geralmente têm distribuição bilateral, mas um padrão assimétrico com predominância no hemisfério cerebral direito já foi demonstrada em outros estudos $(115,116)$.

Junto com a ativação do CCP encontramos também áreas do lobo occipital direito com aumento do FSCr, sendo elas os giros calcarino, cuneus, giro lingual e occipital médio. Não há na literatura muitos estudos que mostram ativação destas áreas em DLC. O giro lingual é citado em pelo menos dois estudos. Yu e cols. demonstraram aumento da conectividade funcional (CF) entre a substância cinzenta periaquedutal (SCP) e o giro lingual em portadores de DLC (117). Um outro estudo realizado por Shimo e cols. avaliou pacientes com DLC em que eram oferecidos estímulos visuais desagradáveis durante a RMf, o que gerava ativação do giro lingual bem como de outras áreas (118). Sabemos que o lobo occipital não é uma região particularmente ligada a matriz da dor, e a carência de resultados semelhantes na literatura deixa dúvidas acerca deste achado. O giro lingual é uma estrutura ligada ao processamento visual, e apesar de nossas SPECTs terem sido feitas em repouso, é possível que algum estímulo visual durante o exame tenha sido responsável pela ativação desta área. É plausível considerar ainda que pode ter ocorrido interpolação dos voxels do CCP com a região occipital, gerando este cluster de ativação.

Ainda dentro da avaliação inicial dos 14 pacientes que iniciaram o protocolo do estudo, encontramos na SPECT hipoperfusão nos lobos parietais esquerdo (precuneus e lobo paracentral) e direito (giro pós central e lobo paracentral) e no giro do cíngulo médio direito. Wasan e cols. avaliaram portadores de DLC em um estado de hipnoanalgesia, e encontraram áreas de desativação através de tomografia por emissão de pósitrons (PET) no córtex somatossensitivo, precuneus e giro posterior do cíngulo, entre outras áreas, assim como em nosso estudo. Essa hipoperfusão poderia refletir um estado de relaxamento do paciente durante a realização da SPECT, visto que o CCP é ativado em estados de emoção negativa. A hipoperfusão do precuneus também parece estar associada ao estado de repouso, visto que as SPECTs foram realizados com o paciente descansado, sem aplicação de nenhum estímulo doloroso ou manobra de ativação de dor (119).

Em um segundo momento, comparamos as SPECTs cerebrais antes e após o uso da gabapentina, e encontramos um aumento da perfusão no lobo límbico bilateralmente, mais especificamente na região do cíngulo anterior. O córtex cingulado anterior (CCA) parece ser a região cortical mais frequentemente associada à experiência de dor, estando envolvido com a reação emocional à dor, e não com a percepção dolorosa em si (120). A porção dorsal do CCA está englobada no córtex pré-frontal (CPF) e tem um papel substancial em funções cognitivas 
relacionadas à dor. A atividade anormal no córtex pré-frontal medial e córtex cingulado anterior já foi encontrada na DLC em estudos anteriores. Pacientes com DLC, em comparação com controles saudáveis, apresentaram ativação do córtex pré-frontal medial e maior conectividade funcional desta região com o núcleo accumbens, relacionada à intensidade da dor experimentada (121). Mais recentemente, utilizando arterial spin labelling (ASL), verificou-se que aumentos dos níveis de DLC foram associados com aumentos no FSCr no CPF medial, bem como em outras áreas relacionadas à matriz da dor (122). O CPF parece exercer controle ativo sobre a percepção da dor, modulando as vias córtico-subcorticais e córtico-corticais (123). Outro estudo que também utilizou ASL demonstrou aumento na conectividade do DMN em repouso com o CPF medial, incluindo o córtex cingulado anterior pré-genual (CCApg), após manobras físicas que exacerbam a dor em pacientes com DLC. O CCApg é uma região envolvida na inibição da dor, devido a suas projeções descendentes à substância cinzenta periaquedutal (124). Também já foi demonstrada maior conectividade funcional entre a substância cinzenta periaquedutal e o CPF ventromedial em pacientes com DLC comparados a controles saudáveis (117). Parece haver evidências de que estados de dor crônica envolvem mais o CPF, enquanto que em indivíduos normais a percepção da dor experimental envolve mais frequentemente S1, S2, tálamo e CCA (108).

Nesta etapa do estudo, em que comparamos o grupo de 13 pacientes antes e após o uso da gabapentina, também encontramos redução do FSCr nas regiões posteriores do mesencéfalo e ponte à direita, correspondente à área da substância cinzenta periaquedutal (SCP), e envolvendo parcialmente o culmen do cerebelo à direita. Outros estudos já demonstraram que a gabapentina reduz o limiar de disparo de neurônios da SCP em ratos $(125,126)$.

A SCP é o centro primário de modulação descendente de dor, através da produção de encefalinas, e possui conexões ascendentes e descendentes com sistemas relacionados ao controle de respostas sensoriais, motoras, autonômicas e límbicas, incluindo CCA, ínsula e amígdala. Ela é ativada durante a apresentação de estímulos nocivos agudos e também em estados de dor crônica como DLC, e exerce um controle dual, inibitório ou excitatório, na modulação dos impulsos nociceptivos $(127,128)$. Diversos neurotransmissores parecem atuar nessa região, como glutamato, GABA, aspartato, acetilcolina, serotonina, noradrenalina, substância P, entre outros $(129,130)$. Um estudo utilizando RMf mostrou que a conectividade funcional da SCP é anormal no estado de repouso em pacientes com DLC (117). A SCP também tem participação fundamental no chamado "sistema emocional motor". Essa rede recebe informações do CPF e CCA e projeta vias ao tronco encefálico, permitindo o controle de 
respostas autonômicas e motoras relacionadas a padrões específicos de comportamento (131). Ela é ainda um componente crítico de uma rede que é ativada em resposta tanto a estressores internos, como dor, ou externos, como um predador. Respostas de enfrentamento distintas são geradas para diferentes estressores. Segundo McNaughton e Corr, estressores evitáveis como dor aguda ou superficial geram uma resposta de enfrentamento ativo, com ativação motora e simpática. Já estressores inevitáveis como a dor crônica ou profunda levam a uma enfrentamento emocional passivo, com inibição simpática e ativação vagal $(132,133)$. Estudos com RMf mostram que a ativação da SCP por estímulos nociceptivos é modulada por atenção, emoção, expectativa de dor e expectativa de analgesia modulada por placebo (134-136). A estimulação da SCP em pacientes com dor intratável através de eletrodos de estimulação cerebral profunda produz alívio da dor associado à liberação de opioides endógenos e bloqueada pelo efeito da naloxona (137). A hipoperfusão que encontramos após o uso da gabapentina mostra que houve uma alteração nos circuitos antinociceptivos a partir do uso da medicação. Considerando que o glutamato é o principal neurotransmissor dos neurônios de projeção e aferentes da SCP, e que neurônios GABAérgicos locais provocam inibição tônica destes neurônios de projeção (138), entendemos que a gabapentina, ao exercer seu mecanismo de ação em que há aumento de GABA e redução de glutamato, influenciou nesta hipoperfusão encontrada nas SPECTs realizadas pós tratamento.

Em relação a hipoperfusão que encontramos no culmen do cerebelo à direita, esta diferiu um pouco de outros estudos. Nakamura e cols. encontraram um aumento do FSCr no lobo posterior do cerebelo bilateralmente entre portadores de DLC (68). Gieseck e cols. evidenciaram maior ativação cerebelar vista em RMf após estímulo pressórico em portadores de DLC. Ele cita que o cerebelo está associado à resposta motora no processamento da dor (139). Já Pijnenburg e cols. avaliaram pacientes com dor lombar não-específica através de RMf no estado de repouso e após a realização de uma tarefa motora (sentar-levantar-sentar), e viram uma menor conectividade funcional tanto no giro pré-central esquerdo quanto nos lóbulos cerebelares esquerdos IV e V, o que foi associado a um maior tempo para a realização da tarefa motora. $\mathrm{O}$ autor associa essa alteração à uma disfunção do controle sensório-motor (140). O cerebelo está associado ao controle da percepção motora, equilíbrio, tônus muscular e integração de movimentos, além de memória procedural de longo prazo. Também tem papel participativo na cognição, fala e emoção, e parece integrar o sistema modulatório de dor (70). Segundo o modelo interno do cerebelo, ele mimetiza o sistema sensório-motor voluntário e determina os comandos motores necessários para realizar tarefas específicas, em vez do 
comando do córtex frontal (141). Nosso estudo demonstrou hipoperfusão em uma pequena região que envolve o culmen cerebelar após o uso da gabapentina, o que poderia refletir uma melhor resposta motora do paciente após o uso da gabapentina, visto que DLC pode causar restrições dos movimentos do paciente. Também não podemos deixar de considerar que pode ter havido interpolação de voxels da SCP com esta pequena região cerebelar.

Posteriormente foi feita a comparação dos SPECTs dos 13 pacientes dividindo-os entre aqueles que apresentaram resposta clínica ao uso da gabapentina e os que não apresentaram melhora, em relação aos voluntários saudáveis. O grupo de pacientes que não apresentou melhora com gabapentina mostrou uma hipoperfusão significativa nas regiões pré-centrais dos lobos frontais bilateralmente, regiões parietais bilateralmente, notadamente nos lóbulos paracentrais, giro pós-central e precuneus. Esse achado é condizente com o padrão de imagem que encontramos em nossa primeira análise, em que vimos que o grupo de 14 pacientes com DLC tinha redução do $\mathrm{FSCr}$ em uma grande região que envolvia regiões bilaterais dos lobos parietais e giro cingulado direito.

O córtex somatossensorial primário ( $\mathrm{S} 1)$ está situado nos lobos parietais, mais especificamente no giro pós-central, e é a região responsável pelo processamento de informações sensório-discriminativas da dor. O S1 é uma das regiões que compõem a matriz da dor, e estudos de neuroimagem prévios mostram que esta região é ativada durante estímulos dolorosos agudos bem como em estados de dor crônica como DLC (122,142,143). A simples expectativa ou antecipação da dor sem um estímulo real físico é suficiente para a ativação da matriz da dor, que é uma rede fluida em que várias projeções interagem entre si, tornando a nocicepção consciente, além da modulação afetivo-motivacional, atencional e reações vegetativas que estão envolvidas na dor (144). Kong e cols. encontraram maior conectividade funcional em regiões bilaterais de S1, M1 e córtex superior frontal esquerdo em pacientes portadores de DLC. Mostraram também aumento da espessura cortical de S1 em portadores de DLC em comparação a controles saudáveis, o que poderia representar o mecanismo de sensibilização central e uma compensação pelo estado constante de dor (145). O precuneus é a porção do lóbulo superior parietal na região medial dos hemisférios cerebrais, correspondente à extensão mesial da área 7 de Brodmann (146). Está envolvido no processamento da memória episódica, orientação visuo-espacial, e aspectos relacionados ao self e autoconsciência. Ele possui conexões córtico-corticais intra-parietais com o CCP e extra-parietais com o CPF, CCA, áreas pré-motora e motora suplementar $(147,148)$. Não há descrição do envolvimento direto do precuneus com estados de dor crônica. 
Estudos prévios já demonstraram que em estados de dor há muitas regiões ativadas e muitas outras desativadas também $(143,149)$. Curiosamente, alguns estudos ressaltam que estados de dor intensa, há mais áreas de desativação do que ativadas $(150,151)$. A redução do FSCr que encontramos envolve algumas estruturas que fazem parte do chamado Default Mode Network, uma rede difusa de estruturas cerebrais que está ativada quando os indivíduos estão em estado de repouso mental, e reduz sua atividade ao nos concentramos para a execução de uma tarefa específica. O DMN abrange o CPF, CCA, precuneus, hipocampo, para-hipocampo e córtex temporal lateral. De acordo com a "hipótese sentinela", esta rede apoiaria o monitoramento amplo do ambiente externo na ausência de estímulos que exijam atenção. Já segundo a "hipótese da mentação interna", o DMN sustentaria uma atividade cognitiva dirigida internamente, amplamente separada do mundo externo, cuja função seria "construir simulações mentais dinâmicas baseadas em experiências pessoais passadas, tais como usadas durante lembrar, pensar no futuro e imaginar perspectivas alternativas e cenários para o presente" $(143,152)$. Nossa hipótese é que essa hipoperfusão envolvendo a as regiões pré-centrais dos lobos frontais bilateralmente, regiões parietais bilateralmente, notadamente nos lóbulos paracentrais, giro pós-central e precuneus seja justificada parcialmente por um estado mal adaptativo do cérebro com dor crônica, que gera um alerta persistente e leva à inativação de estruturas centrais do DMN. Como não há relação direta entre estruturas ativadas e inativadas, é possível que essas alterações de aumento e redução do FSCr sejam subjacentes aos diferentes aspectos da experiência dolorosa (143).

Por fim, analisando separadamente os grupos com e sem melhora clínica antes e após o uso da gabapentina, encontramos, no grupo sem melhora, hiperperfusão no giro do cíngulo anterior à esquerda. Esse aumento da perfusão no cíngulo anterior já havia sido demonstrado na comparação pré e pós uso da gabapentina, sendo então consistente na avaliação isolada do grupo que não teve benefício clínico com o tratamento. Ratificamos assim o fato que portadores de dor crônica tem grande envolvimento de circuitos afetivo-motivacionais relacionados à dor.

O que pudemos perceber é que estudos de neuroimagem envolvendo avaliação da dor neuropática crônica mostram um padrão heterogêneo de ativação cerebral, e isso provavelmente reflete os diversos mecanismos envolvidos na gênese desse quadro (153), bem como as diferenças metodológicas utilizadas. Além disso, a interpretação dos resultados discrepantes deve levar em consideração a história de dor, distribuição anatômica, constituição genética, personalidade, o que pode contribuir para a alteração dos circuitos cerebrais envolvidos na avaliação dos processos de dor crônica (154). Os dados disponíveis atualmente 
e o número ainda limitado de estudos em dor crônica utilizando SPECT cerebral mostram a necessidade de novas pesquisas que possam auxiliar a entender melhor o substrato neurobiológico envolvido nas distintas causas de dor lombar crônica e suas opções terapêuticas.

Existem algumas potenciais limitações em nosso estudo. Em relação ao grupo de voluntários avaliados, havia uma heterogeneidade quanto ao uso de outros medicamentos prévios que poderiam afetar o resultado da SPECT cerebral. Além disso, a duração de nosso estudo foi curta, de no máximo 4 semanas, e sabemos que alguns pacientes exigem um tempo maior de tratamento para perceberam uma alteração significativa da dor com o uso da gabapentina. Ademais, limitamos a dose máxima de gabapentina à $1.200 \mathrm{mg}$ ao dia, todavia diretrizes de dor neuropática preconizam doses de até $3.600 \mathrm{mg}$ ao dia para otimização da dor. Por último, o baixo número de participantes do estudo seria o fator mais impactante, visto que pode comprometer a reprodutibilidade dos resultados clínicos, contudo o número de pacientes de nossa amostra está compatível com os demais estudos para avaliação do FSCr por SPECT. Ressaltamos a importância de novos estudos com SPECT que possam auxiliar a elucidar o substrato neurobiológico associado a dor neuropática crônica.

Finalmente, como pontos fortes, elencamos a homogeneidade da amostra quanto às características clínicas da dor, topografia da lesão e achados de neuroimagem. Não encontramos na literatura nenhum estudo de neuroimagem funcional que avaliasse apenas pacientes com dor lombar crônica de etiologia exclusivamente causada por hérnia discal lombar. A maioria dos estudos disponíveis avaliou pacientes portadores de dor lombar inespecífica ou de etiologia indefinida, tornando nosso estudo pioneiro neste tema. 


\section{CONCLUSÃO}

1. Pacientes com dor lombar crônica, comparados aos voluntários saudáveis, apresentam aumento da perfusão cerebral no lobo frontal direito (córtex pré-frontal anterior e dorsolateral), lobo occipital direito e giro do cíngulo posterior direito, e redução da perfusão cerebral nos lobos parietais bilaterais e cíngulo médio direito;

2. Após o uso da gabapentina, houve aumento de perfusão no lobo límbico bilateral (cíngulo anterior) e redução da perfusão na substância cinzenta periaquedutal em comparação aos voluntários saudáveis;

3. O grupo que não apresentou melhora clínica com a gabapentina mostrou redução do FSCr nas regiões pré-centrais dos lobos frontais bilateralmente e regiões parietais bilateralmente, notadamente nos lóbulos paracentrais, giro pós-central e precuneus, em comparação aos voluntários saudáveis;

4. Na comparação entre grupos com e sem resposta terapêutica, observou-se hiperperfusão no cíngulo anterior esquerdo no grupo de pacientes sem melhora clínica após o uso da gabapentina; e

5. O tratamento desses pacientes com gabapentina não trouxe mudança nos escores de depressão, ansiedade e qualidade de vida; entretanto, houve diferença significativamente estatística nos escores de catastrofização ao final do tratamento. 


\section{REFERÊNCIAS BIBLIOGRÁFICAS}

1. Pain terms: a list with definitions and notes on usage. Recommended by the IASP Subcommittee on Taxonomy. Pain [Internet]. junho de 1979;6(3):249. Disponível em:

https://www.ncbi.nlm.nih.gov/pubmed/460932

2. Bonica JJ. Bonica's Management of Pain [Internet]. Lippincott Williams \& Wilkins; 2001. 2178 p. Disponível em:

https://books.google.com/books/about/Bonica_s_Management_of_Pain.html?hl=\&id=TyNEicOiJ $\mathrm{qQC}$

3. Rosenbaum SH. Book Review The Management of Pain Second edition. Edited by John J. Bonica, with John D. Loeser, C. Richard Chapman, and Wilbert E. Fordyce. 2120 pp. in two volumes, illustrated. Philadelphia, Lea and Febiger, 1990. \$225 [Internet]. Vol. 323, New England Journal of Medicine. 1990. p. 1713-1713. Disponível em: http://dx.doi.org/10.1056/nejm199012133232426

4. Cervero F, Iggo A. The substantia gelatinosa of the spinal cord: a critical review. Brain [Internet]. dezembro de 1980;103(4):717-72. Disponível em:

https://www.ncbi.nlm.nih.gov/pubmed/7437888

5. Bowsher D. Role of the reticular formation in responses to noxious stimulation. Pain [Internet]. dezembro de 1976;2(4):361-78. Disponível em: https://www.ncbi.nlm.nih.gov/pubmed/800640

6. Pimenta CA de M, de Mattos Pimenta CA, Koizumi MS, Teixeira MJ. Dor crônica e depressão: estudo em 92 doentes. Rev Esc Enferm USP [Internet]. 2000;34(1):76-83. Disponível em: http://dx.doi.org/10.1590/s0080-62342000000100010

7. Ignelzi RJ, Atkinson JH. Pain and its modulation. Part 1. Afferent mechanisms. Neurosurgery [Internet]. maio de 1980;6(5):577-83. Disponível em: https://www.ncbi.nlm.nih.gov/pubmed/6158014

8. Loeser JD. Pain and suffering. Clin J Pain [Internet]. junho de 2000;16(2 Suppl):S2-6. Disponível em: https://www.ncbi.nlm.nih.gov/pubmed/10870733

9. Campbell JN. APS 1995 Presidential address [Internet]. Vol. 5, Pain Forum. 1996. p. 85-8. Disponível em: http://dx.doi.org/10.1016/s1082-3174(96)80076-6

10. Katz J, Melzack R. Measurement of pain. Surg Clin North Am [Internet]. abril de 1999;79(2):231-52. Disponível em: https://www.ncbi.nlm.nih.gov/pubmed/10352653

11. Mannion AF, Balagué F, Pellisé F, Cedraschi C. Pain measurement in patients with low back pain. Nat Clin Pract Rheumatol [Internet]. novembro de 2007;3(11):610-8. Disponível em: http://dx.doi.org/10.1038/ncprheum0646

12. Treede R-D, Jensen TS, Campbell JN, Cruccu G, Dostrovsky JO, Griffin JW, et al. Neuropathic pain: redefinition and a grading system for clinical and research purposes. Neurology [Internet]. 29 de abril de 2008;70(18):1630-5. Disponível em: http://dx.doi.org/10.1212/01.wnl.0000282763.29778.59

13. Torrance N, Smith BH, Bennett MI, Lee AJ. The epidemiology of chronic pain of predominantly neuropathic origin. Results from a general population survey. J Pain [Internet]. abril de 2006;7(4):281-9. Disponível em: http://dx.doi.org/10.1016/j.jpain.2005.11.008

14. Magrinelli F, Zanette G, Tamburin S. Neuropathic pain: diagnosis and treatment. Pract Neurol 
[Internet]. outubro de 2013;13(5):292-307. Disponível em: http://dx.doi.org/10.1136/practneurol2013-000536

15. Bouhassira D, Lantéri-Minet M, Attal N, Laurent B, Touboul C. Prevalence of chronic pain with neuropathic characteristics in the general population. Pain [Internet]. junho de 2008;136(3):3807. Disponível em: http://dx.doi.org/10.1016/j.pain.2007.08.013

16. Jensen TS, Finnerup NB. Allodynia and hyperalgesia in neuropathic pain: clinical manifestations and mechanisms. Lancet Neurol [Internet]. setembro de 2014;13(9):924-35. Disponível em: http://dx.doi.org/10.1016/S1474-4422(14)70102-4

17. Colloca L. Sham opioids relieve multidimensional aspects of chronic back pain. Pain [Internet]. outubro de 2017;158(10):1849-50. Disponível em: http://dx.doi.org/10.1097/j.pain.0000000000000996

18. Finnerup NB, Haroutounian S, Kamerman P, Baron R, Bennett DLH, Bouhassira D, et al. Neuropathic pain: an updated grading system for research and clinical practice. Pain [Internet]. agosto de 2016;157(8):1599-606. Disponível em: http://dx.doi.org/10.1097/j.pain.0000000000000492

19. Bouhassira D, Attal N, Alchaar H, Boureau F, Brochet B, Bruxelle J, et al. Comparison of pain syndromes associated with nervous or somatic lesions and development of a new neuropathic pain diagnostic questionnaire (DN4). Pain [Internet]. março de 2005;114(1-2):29-36. Disponível em: http://dx.doi.org/10.1016/j.pain.2004.12.010

20. Santos JG, Brito JO, de Andrade DC, Kaziyama VM, Ferreira KA, Souza I, et al. Translation to Portuguese and validation of the Douleur Neuropathique 4 questionnaire. J Pain [Internet]. maio de 2010;11(5):484-90. Disponível em: http://dx.doi.org/10.1016/j.jpain.2009.09.014

21. Airaksinen O, Brox JI, Cedraschi C, Hildebrandt J, Klaber-Moffett J, Kovacs F, et al. Chapter 4 European guidelines for the management of chronic nonspecific low back pain. Eur Spine $J$ [Internet]. 2006;15(S2):s192-300. Disponível em: http://dx.doi.org/10.1007/s00586-006-1072-1

22. Baron R, Binder A, Attal N, Casale R, Dickenson AH, Treede R-D. Neuropathic low back pain in clinical practice. Eur J Pain [Internet]. julho de 2016;20(6):861-73. Disponível em: http://dx.doi.org/10.1002/ejp.838

23. Hoy D, March L, Brooks P, Blyth F, Woolf A, Bain C, et al. The global burden of low back pain: estimates from the Global Burden of Disease 2010 study. Ann Rheum Dis [Internet]. junho de 2014;73(6):968-74. Disponível em: http://dx.doi.org/10.1136/annrheumdis-2013-204428

24. Freynhagen R, Baron R. The evaluation of neuropathic components in low back pain. Curr Pain Headache Rep [Internet]. junho de 2009;13(3):185-90. Disponível em: https://www.ncbi.nlm.nih.gov/pubmed/19457278

25. Merskey H, Bogduk N. Classification of Chronic Pain: Descriptions of Chronic Pain Syndromes and Definitions of Pain Terms [Internet]. International Assn for the Study of Pain; 1994. 222 p. Disponível em:

https://books.google.com/books/about/Classification_of_Chronic_Pain.html?hl=\&id=GqhqAAA AMAAJ

26. Mixter WJ, Barr JS. Rupture of the Intervertebral Disc with Involvement of the Spinal Canal. J Neurosurg [Internet]. 1964;74-81. Disponível em: http://dx.doi.org/10.3171/jns.1964.21.1.0074

27. Ropper AH, Zafonte RD. Sciatica. N Engl J Med [Internet]. 2015;372(13):1240-8. Disponível em: http://dx.doi.org/10.1056/nejmra1410151 
28. Kreiner DS, Hwang SW, Easa JE, Resnick DK, Baisden JL, Bess S, et al. An evidence-based clinical guideline for the diagnosis and treatment of lumbar disc herniation with radiculopathy. Spine J [Internet]. janeiro de 2014;14(1):180-91. Disponível em: http://dx.doi.org/10.1016/j.spinee.2013.08.003

29. Cohen SP, Argoff CE, Carragee EJ. Management of low back pain. BMJ [Internet]. 22 de dezembro de 2008;337:a2718. Disponível em: http://dx.doi.org/10.1136/bmj.a2718

30. Haanpää M, Attal N, Backonja M, Baron R, Bennett M, Bouhassira D, et al. NeuPSIG guidelines on neuropathic pain assessment. Pain [Internet]. janeiro de 2011;152(1):14-27. Disponível em: http://dx.doi.org/10.1016/j.pain.2010.07.031

31. Storheim K, Zwart J-A. Musculoskeletal disorders and the Global Burden of Disease study. Ann Rheum Dis [Internet]. junho de 2014;73(6):949-50. Disponível em: http://dx.doi.org/10.1136/annrheumdis-2014-205327

32. Moix J, Kovacs FM, Martín A, Plana MN, Royuela A, Spanish Back Pain Research Network. Catastrophizing, state anxiety, anger, and depressive symptoms do not correlate with disability when variations of trait anxiety are taken into account. a study of chronic low back pain patients treated in Spanish pain units [NCT00360802]. Pain Med [Internet]. julho de 2011;12(7):1008-17. Disponível em: http://dx.doi.org/10.1111/j.1526-4637.2011.01155.x

33. Finnerup NB, Attal N, Haroutounian S, McNicol E, Baron R, Dworkin RH, et al. Pharmacotherapy for neuropathic pain in adults: a systematic review and meta-analysis. Lancet Neurol [Internet]. fevereiro de 2015;14(2):162-73. Disponível em: http://dx.doi.org/10.1016/S1474-4422(14)70251-0

34. Fan H, Yu W, Zhang Q, Cao H, Li J, Wang J, et al. Efficacy and safety of gabapentin $1800 \mathrm{mg}$ treatment for post-herpetic neuralgia: a meta-analysis of randomized controlled trials. J Clin Pharm Ther [Internet]. agosto de 2014;39(4):334-42. Disponível em: http://dx.doi.org/10.1111/jcpt.12167

35. Moore RA, Wiffen PJ, Derry S, Toelle T, Rice ASC. Gabapentin for chronic neuropathic pain and fibromyalgia in adults. Cochrane Database Syst Rev [Internet]. 27 de abril de 2014;(4):CD007938. Disponível em: http://dx.doi.org/10.1002/14651858.CD007938.pub3

36. Kukkar A, Bali A, Singh N, Jaggi AS. Implications and mechanism of action of gabapentin in neuropathic pain. Arch Pharm Res [Internet]. março de 2013;36(3):237-51. Disponível em: http://dx.doi.org/10.1007/s12272-013-0057-y

37. Mehta S, McIntyre A, Dijkers M, Loh E, Teasell RW. Gabapentinoids are effective in decreasing neuropathic pain and other secondary outcomes after spinal cord injury: a meta-analysis. Arch Phys Med Rehabil [Internet]. novembro de 2014;95(11):2180-6. Disponível em: http://dx.doi.org/10.1016/j.apmr.2014.06.010

38. Shanthanna H, Gilron I, Rajarathinam M, AlAmri R, Kamath S, Thabane L, et al. Benefits and safety of gabapentinoids in chronic low back pain: A systematic review and meta-analysis of randomized controlled trials. PLoS Med [Internet]. agosto de 2017;14(8):e1002369. Disponível em: http://dx.doi.org/10.1371/journal.pmed.1002369

39. Kasimcan O, Kaptan H. Efficacy of gabapentin for radiculopathy caused by lumbar spinal stenosis and lumbar disk hernia. Neurol Med Chir [Internet]. 2010;50(12):1070-3. Disponível em: https://www.ncbi.nlm.nih.gov/pubmed/21206180

40. Kessler RC, Berglund P, Demler O, Jin R, Koretz D, Merikangas KR, et al. The epidemiology of major depressive disorder: results from the National Comorbidity Survey Replication (NCS-R). 
JAMA [Internet]. 18 de junho de 2003;289(23):3095-105. Disponível em: http://dx.doi.org/10.1001/jama.289.23.3095

41. Shaw WS, Means-Christensen AJ, Slater MA, Webster JS, Patterson TL, Grant I, et al. Psychiatric disorders and risk of transition to chronicity in men with first onset low back pain. Pain Med [Internet]. setembro de 2010;11(9):1391-400. Disponível em: http://dx.doi.org/10.1111/j.1526-4637.2010.00934.x

42. Magni G, Marchetti M, Moreschi C, Merskey H, Luchini SR. Chronic musculoskeletal pain and depressive symptoms in the National Health and Nutrition Examination. I. Epidemiologic followup study. Pain [Internet]. maio de 1993;53(2):163-8. Disponível em: https://www.ncbi.nlm.nih.gov/pubmed/8336986

43. Zigmond AS, Snaith RP. Hospital Anxiety and Depression Scale [Internet]. PsycTESTS Dataset. 1983. Disponível em: http://dx.doi.org/10.1037/t03589-000

44. Castro MMC, Quarantini L, Batista-Neves S, Kraychete DC, Daltro C, Miranda-Scippa Â. Validade da escala hospitalar de ansiedade e depressão em pacientes com dor crônica. Rev Bras Anestesiol [Internet]. 2006;56(5). Disponível em: http://dx.doi.org/10.1590/s003470942006000500005

45. Sullivan MJL, Thorn B, Haythornthwaite JA, Keefe F, Martin M, Bradley LA, et al. Theoretical Perspectives on the Relation Between Catastrophizing and Pain. Clin J Pain [Internet]. 2001;17(1):52-64. Disponível em: http://dx.doi.org/10.1097/00002508-200103000-00008

46. Diller L. Book Reviews: Managing the Chronic Pain Patient--Theory and Practice at the University of Washington. John D. Loeser and Kelly J. Egan. Raven Press, New York, 1989, 253 pp [Internet]. Vol. 3, Neurorehabilitation and Neural Repair. 1989. p. 110-1. Disponível em: http://dx.doi.org/10.1177/136140968900300212

47. Fordyce WE, Mosby C. V. Company. Behavioral methods for chronic pain and illness. Pain [Internet]. 1977;3(3):291-2. Disponível em: http://dx.doi.org/10.1016/0304-3959(77)90029-x

48. Sullivan MJ, Stanish W, Waite H, Sullivan M, Tripp DA. Catastrophizing, pain, and disability in patients with soft-tissue injuries. Pain [Internet]. setembro de 1998;77(3):253-60. Disponível em: https://www.ncbi.nlm.nih.gov/pubmed/9808350

49. Flor H, Behle DJ, Birbaumer N. Pain-Related Self-Statements Scale [Internet]. PsycTESTS Dataset. 1993. Disponível em: http://dx.doi.org/10.1037/t02417-000

50. Sardá Junior J, Junior JS, Nicholas MK, Pereira IA, de Matos Pimenta CA, Asghari A, et al. Validation of the Pain-Related Catastrophizing Thoughts Scale. Acta Fisiátrica [Internet]. 2008;15(1). Disponível em: http://dx.doi.org/10.5935/0104-7795.20080001

51. The WHOQOL Group. The Development of the World Health Organization Quality of Life Assessment Instrument (the WHOQOL). In: Quality of Life Assessment: International Perspectives [Internet]. 1994. p. 41-57. Disponível em: http://dx.doi.org/10.1007/978-3-64279123-9_4

52. Jensen MP, Chodroff MJ, Dworkin RH. The impact of neuropathic pain on health-related quality of life: review and implications. Neurology [Internet]. 10 de abril de 2007;68(15):1178-82. Disponível em: http://dx.doi.org/10.1212/01.wnl.0000259085.61898.9e

53. O'Connor AB. Neuropathic pain: quality-of-life impact, costs and cost effectiveness of therapy. Pharmacoeconomics [Internet]. 2009;27(2):95-112. Disponível em:

http://dx.doi.org/10.2165/00019053-200927020-00002 
54. Development of the World Health Organization WHOQOL-BREF quality of life assessment. The WHOQOL Group. Psychol Med [Internet]. maio de 1998;28(3):551-8. Disponível em: https://www.ncbi.nlm.nih.gov/pubmed/9626712

55. Fleck MP, Louzada S, Xavier M, Chachamovich E, Vieira G, Santos L, et al. [Application of the Portuguese version of the abbreviated instrument of quality life WHOQOL-bref]. Rev Saude Publica [Internet]. abril de 2000;34(2):178-83. Disponível em: https://www.ncbi.nlm.nih.gov/pubmed/10881154

56. Call-Schmidt TA, Richardson SJ. Prevalence of sleep disturbance and its relationship to pain in adults with chronic pain. Pain Manag Nurs [Internet]. 2003;4(3):124-33. Disponível em: http://dx.doi.org/10.1016/s1524-9042(02)54212-0

57. Kundermann B, Krieg J-C, Schreiber W, Lautenbacher S. The effect of sleep deprivation on pain. Pain Res Manag [Internet]. Primavera de 2004;9(1):25-32. Disponível em: https://www.ncbi.nlm.nih.gov/pubmed/15007400

58. Sezgin M, Hasanefendioğlu EZ, Sungur MA, Incel NA, Çimen ÖB, Kanık A, et al. Sleep quality in patients with chronic low back pain: a cross-sectional study assesing its relations with pain, functional status and quality of life. J Back Musculoskelet Rehabil [Internet]. 2015;28(3):433-41. Disponível em: http://dx.doi.org/10.3233/BMR-140537

59. Pilowsky I, Crettenden I, Townley M. Sleep disturbance in pain clinic patients. Pain [Internet]. setembro de 1985;23(1):27-33. Disponível em: https://www.ncbi.nlm.nih.gov/pubmed/4058926

60. Atkinson JH, Ancoli-Israel S, Slater MA, Garfin SR, Gillin C. Subjective Sleep Disturbance in Chronic Back Pain. Clin J Pain [Internet]. 1988;4(4):225-32. Disponível em: http://dx.doi.org/10.1097/00002508-198812000-00007

61. Rabini A, Aprile I, Padua L, Piazzini DB, Maggi L, Ferrara PE, et al. Assessment and correlation between clinical patterns, disability and health-related quality of life in patients with low back pain. Eura Medicophys [Internet]. março de 2007;43(1):49-54. Disponível em: https://www.ncbi.nlm.nih.gov/pubmed/17021588

62. Ancoli-Israel S. The impact and prevalence of chronic insomnia and other sleep disturbances associated with chronic illness. Am J Manag Care [Internet]. maio de 2006;12(8 Suppl):S221-9. Disponível em: https://www.ncbi.nlm.nih.gov/pubmed/16686592

63. Marty M, Rozenberg S, Duplan B, Thomas P, Duquesnoy B, Allaert F, et al. Quality of sleep in patients with chronic low back pain: a case-control study. Eur Spine J [Internet]. junho de 2008;17(6):839-44. Disponível em: http://dx.doi.org/10.1007/s00586-008-0660-7

64. Johns MW. Daytime sleepiness, snoring, and obstructive sleep apnea. The Epworth Sleepiness Scale. Chest [Internet]. janeiro de 1993;103(1):30-6. Disponível em: https://www.ncbi.nlm.nih.gov/pubmed/8417909

65. Davis KD, Moayedi M. Central Mechanisms of Pain Revealed Through Functional and Structural MRI [Internet]. Vol. 8, Journal of Neuroimmune Pharmacology. 2013. p. 518-34. Disponível em: http://dx.doi.org/10.1007/s11481-012-9386-8

66. Joo EY, Hong SB, Tae WS, Han SJ, Seo DW, Lee K-H, et al. Effect of lamotrigine on cerebral blood flow in patients with idiopathic generalised epilepsy. Eur J Nucl Med Mol Imaging [Internet]. junho de 2006;33(6):724-9. Disponível em: http://dx.doi.org/10.1007/s00259-005$0029-7$

67. Crippa JA de S, Zuardi AW, Garrido GEJ, Wichert-Ana L, Guarnieri R, Ferrari L, et al. Effects 
of cannabidiol (CBD) on regional cerebral blood flow. Neuropsychopharmacology [Internet]. fevereiro de 2004;29(2):417-26. Disponível em: http://dx.doi.org/10.1038/sj.npp.1300340

68. Nakamura Y, Nojiri K, Yoshihara H, Takahata T, Honda-Takahashi K, Kubo S, et al. Significant differences of brain blood flow in patients with chronic low back pain and acute low back pain detected by brain SPECT. J Orthop Sci [Internet]. maio de 2014;19(3):384-9. Disponível em: http://dx.doi.org/10.1007/s00776-014-0534-2

69. Shansky RM, Lipps J. Stress-induced cognitive dysfunction: hormone-neurotransmitter interactions in the prefrontal cortex. Front Hum Neurosci [Internet]. 5 de abril de 2013;7:123. Disponível em: http://dx.doi.org/10.3389/fnhum.2013.00123

70. Moulton EA, Schmahmann JD, Becerra L, Borsook D. The cerebellum and pain: passive integrator or active participator? Brain Res Rev [Internet]. 5 de outubro de 2010;65(1):14-27. Disponível em: http://dx.doi.org/10.1016/j.brainresrev.2010.05.005

71. Lancaster JL, Woldorff MG, Parsons LM, Liotti M, Freitas CS, Rainey L, et al. Automated Talairach atlas labels for functional brain mapping. Hum Brain Mapp [Internet]. julho de 2000;10(3):120-31. Disponível em: https://www.ncbi.nlm.nih.gov/pubmed/10912591

72. Murray CJL, Atkinson C, Bhalla K, Birbeck G, Burstein R, Chou D, et al. The state of US health, 1990-2010: burden of diseases, injuries, and risk factors. JAMA [Internet]. 14 de agosto de 2013;310(6):591-608. Disponível em: http://dx.doi.org/10.1001/jama.2013.13805

73. Manchikanti L, Singh V, Datta S, Cohen SP, Hirsch JA, American Society of Interventional Pain Physicians. Comprehensive review of epidemiology, scope, and impact of spinal pain. Pain Physician [Internet]. julho de 2009;12(4):E35-70. Disponível em: https://www.ncbi.nlm.nih.gov/pubmed/19668291

74. Kregel J, Meeus M, Malfliet A, Dolphens M, Danneels L, Nijs J, et al. Structural and functional brain abnormalities in chronic low back pain: A systematic review. Semin Arthritis Rheum [Internet]. outubro de 2015;45(2):229-37. Disponível em: http://dx.doi.org/10.1016/j.semarthrit.2015.05.002

75. Shmagel A, Foley R, Ibrahim H. Epidemiology of Chronic Low Back Pain in US Adults: Data From the 2009-2010 National Health and Nutrition Examination Survey. Arthritis Care Res [Internet]. novembro de 2016;68(11):1688-94. Disponível em: http://dx.doi.org/10.1002/acr.22890

76. Hoy D, Brooks P, Blyth F, Buchbinder R. The Epidemiology of low back pain [Internet]. Vol. 24, Best Practice \& Research Clinical Rheumatology. 2010. p. 769-81. Disponível em: http://dx.doi.org/10.1016/j.berh.2010.10.002

77. Waxman R, Tennant A, Helliwell P. A Prospective Follow-Up Study of Low Back Pain in the Community [Internet]. Vol. 25, Spine. 2000. p. 2085-90. Disponível em: http://dx.doi.org/10.1097/00007632-200008150-00013

78. Loney PL, Stratford PW. The prevalence of low back pain in adults: a methodological review of the literature. Phys Ther [Internet]. abril de 1999;79(4):384-96. Disponível em: https://www.ncbi.nlm.nih.gov/pubmed/10201544

79. Gouveia N, Rodrigues A, Eusébio M, Ramiro S, Machado P, Canhão H, et al. Prevalence and social burden of active chronic low back pain in the adult Portuguese population: results from a national survey. Rheumatol Int [Internet]. fevereiro de 2016;36(2):183-97. Disponível em: http://dx.doi.org/10.1007/s00296-015-3398-7 
80. Hiyama A, Katoh H, Sakai D, Tanaka M, Sato M, Watanabe M. Clinical impact of JOABPEQ mental health scores in patients with low back pain: Analysis using the neuropathic pain screening tool painDETECT. J Orthop Sci [Internet]. 2017;22(6):1009-14. Disponível em: http://dx.doi.org/10.1016/j.jos.2017.06.009

81. Peul WC, van Houwelingen HC, van den Hout WB, Brand R, Eekhof JAH, Tans JTJ, et al. Surgery versus Prolonged Conservative Treatment for Sciatica [Internet]. Vol. 356, New England Journal of Medicine. 2007. p. 2245-56. Disponível em: http://dx.doi.org/10.1056/nejmoa064039

82. Weinstein JN, Tosteson TD, Lurie JD, Tosteson ANA, Hanscom B, Skinner JS, et al. Surgical vs Nonoperative Treatment for Lumbar Disk Herniation [Internet]. Vol. 296, JAMA. 2006. p. 2441. Disponível em: http://dx.doi.org/10.1001/jama.296.20.2441

83. Lerman SF, Rudich Z, Brill S, Shalev H, Shahar G. Longitudinal Associations Between Depression, Anxiety, Pain, and Pain-Related Disability in Chronic Pain Patients [Internet]. Vol. 77, Psychosomatic Medicine. 2015. p. 333-41. Disponível em: http://dx.doi.org/10.1097/psy.0000000000000158

84. Rayner L, Hotopf M, Petkova H, Matcham F, Simpson A, McCracken LM. Depression in patients with chronic pain attending a specialised pain treatment centre: prevalence and impact on health care costs. Pain [Internet]. julho de 2016;157(7):1472-9. Disponível em: http://dx.doi.org/10.1097/j.pain.0000000000000542

85. Bair MJ, Robinson RL, Katon W, Kroenke K. Depression and pain comorbidity: a literature review. Arch Intern Med [Internet]. 10 de novembro de 2003;163(20):2433-45. Disponível em: http://dx.doi.org/10.1001/archinte.163.20.2433

86. Oliveira DS, Vélia Ferreira Mendonça L, Sofia Monteiro Sampaio R, Manuel Pereira Dias de Castro-Lopes J, Ribeiro de Azevedo LF. The Impact of Anxiety and Depression on the Outcomes of Chronic Low Back Pain Multidisciplinary Pain Management-A Multicenter Prospective Cohort Study in Pain Clinics with One-Year Follow-up. Pain Med [Internet]. 11 de julho de 2018; Disponível em: http://dx.doi.org/10.1093/pm/pny128

87. Hung C-I, Liu C-Y, Fu T-S. Depression: An important factor associated with disability among patients with chronic low back pain. Int J Psychiatry Med [Internet]. 30 de abril de 2015;49(3):187-98. Disponível em: http://dx.doi.org/10.1177/0091217415573937

88. Sternbach RA. PSYCHOLOGICAL DIMENSIONS AND PERCEPTUAL ANALYSES, INCLUDING PATHOLOGIES OF PAIN [Internet]. Feeling and Hurting. 1978. p. 231-61. Disponível em: http://dx.doi.org/10.1016/b978-0-12-161922-0.50014-7

89. Bouckoms AJ, Litman RE, Baer L. Denial in the Depressive and Pain-Prone Disorders of Chronic Pain [Internet]. Vol. 1, The Clinical Journal of Pain. 1985. p. 165-70. Disponível em: http://dx.doi.org/10.1097/00002508-198501030-00007

90. Marshall PWM, Schabrun S, Knox MF. Physical activity and the mediating effect of fear, depression, anxiety, and catastrophizing on pain related disability in people with chronic low back pain. PLoS One [Internet]. 7 de julho de 2017;12(7):e0180788. Disponível em: http://dx.doi.org/10.1371/journal.pone.0180788

91. Swinkels-Meewisse IEJ, Roelofs J, Oostendorp RAB, Verbeek ALM, Vlaeyen JWS. Acute low back pain: pain-related fear and pain catastrophizing influence physical performance and perceived disability [Internet]. Vol. 120, Pain. 2006. p. 36-43. Disponível em: http://dx.doi.org/10.1016/j.pain.2005.10.005

92. Crombez G, Vlaeyen JWS, Peter H T, Lysens R. Pain-related fear is more disabling than pain 
itself: evidence on the role of pain-related fear in chronic back pain disability [Internet]. Vol. 80, Pain. 1999. p. 329-39. Disponível em: http://dx.doi.org/10.1016/s0304-3959(98)00229-2

93. Lethem J, Slade PD, Troup JD, Bentley G. Outline of a Fear-Avoidance Model of exaggerated pain perception--I. Behav Res Ther [Internet]. 1983;21(4):401-8. Disponível em: https://www.ncbi.nlm.nih.gov/pubmed/6626110

94. Gay CW, Horn ME, Bishop MD, Robinson ME, Bialosky JE. Investigating dynamic pain sensitivity in the context of the fear-avoidance model. Eur J Pain [Internet]. janeiro de 2015;19(1):48-58. Disponível em: http://dx.doi.org/10.1002/ejp.519

95. Wertli MM, Eugster R, Held U, Steurer J, Kofmehl R, Weiser S. Catastrophizing-a prognostic factor for outcome in patients with low back pain: a systematic review. Spine J [Internet]. $1^{\circ}$ de novembro de 2014;14(11):2639-57. Disponível em: http://dx.doi.org/10.1016/j.spinee.2014.03.003

96. Deshpande MA, Holden RR, Gilron I. The Impact of Therapy on Quality of Life and Mood in Neuropathic Pain: What Is the Effect of Pain Reduction? [Internet]. Vol. 102, Anesthesia \& Analgesia. 2006. p. 1473-9. Disponível em: http://dx.doi.org/10.1213/01.ane.0000204295.90178.77

97. Kunzmann U, Little TD, Smith J. Is age-related stability of subjective well-being a paradox? Cross-sectional and longitudinal evidence from the Berlin Aging Study. Psychol Aging [Internet]. setembro de 2000;15(3):511-26. Disponível em: https://www.ncbi.nlm.nih.gov/pubmed/11014714

98. Wettstein M, Eich W, Bieber C, Tesarz J. Profiles of Subjective Well-being in Patients with Chronic Back Pain: Contrasting Subjective and Objective Correlates. Pain Med [Internet]. 28 de setembro de 2018; Disponível em: http://dx.doi.org/10.1093/pm/pny162

99. Kaplan JT, Gimbel SI, Harris S. Neural correlates of maintaining one's political beliefs in the face of counterevidence [Internet]. Vol. 6, Scientific Reports. 2016. Disponível em: http://dx.doi.org/10.1038/srep39589

100. Stein S. The Human Frontal Lobes: Functions and Disorders, edited by Bruce L. Miller and Jeffrey L. Cummings. New York: Guilford Press, 1998, 616 pp. \$75 [Internet]. Vol. 15, Archives of Clinical Neuropsychology. 2000. p. 455-6. Disponível em: http://dx.doi.org/10.1016/s08876177(99)00027-x

101. Goldman-Rakic PS. Architecture of the Prefrontal Cortex and the Central Executive. Ann NY Acad Sci [Internet]. dezembro de 1995;769(1 Structure and):71-84. Disponível em: http://doi.wiley.com/10.1111/j.1749-6632.1995.tb38132.x

102. Seminowicz DA, Moayedi M. The Dorsolateral Prefrontal Cortex in Acute and Chronic Pain [Internet]. Vol. 18, The Journal of Pain. 2017. p. 1027-35. Disponível em: http://dx.doi.org/10.1016/j.jpain.2017.03.008

103. Buckalew N, Haut MW, Aizenstein H, Morrow L, Perera S, Kuwabara H, et al. Differences in Brain Structure and Function in Older Adults with Self-Reported Disabling and Nondisabling Chronic Low Back Pain [Internet]. Vol. 11, Pain Medicine. 2010. p. 1183-97. Disponível em: http://dx.doi.org/10.1111/j.1526-4637.2010.00899.x

104. Li J, Zhang J-H, Yi T, Tang W-J, Wang S-W, Dong J-C. Acupuncture treatment of chronic low back pain reverses an abnormal brain default mode network in correlation with clinical pain relief. Acupunct Med [Internet]. abril de 2014;32(2):102-8. Disponível em: http://dx.doi.org/10.1136/acupmed-2013-010423 
105. Seminowicz DA, Wideman TH, Naso L, Hatami-Khoroushahi Z, Fallatah S, Ware MA, et al. Effective treatment of chronic low back pain in humans reverses abnormal brain anatomy and function. J Neurosci [Internet]. 18 de maio de 2011;31(20):7540-50. Disponível em: http://dx.doi.org/10.1523/JNEUROSCI.5280-10.2011

106. Mertens P, Nuti C, Sindou M, Guenot M, Peyron R, Garcia-Larrea L, et al. Precentral cortex stimulation for the treatment of central neuropathic pain: results of a prospective study in a 20patient series. Stereotact Funct Neurosurg [Internet]. 1999;73(1-4):122-5. Disponível em: http://dx.doi.org/10.1159/000029769

107. Raij TT, Numminen J, Närvänen S, Hiltunen J, Hari R. Strength of prefrontal activation predicts intensity of suggestion-induced pain. Hum Brain Mapp [Internet]. setembro de 2009;30(9):2890-7. Disponível em: http://dx.doi.org/10.1002/hbm.20716

108. Apkarian AV, Bushnell MC, Treede R-D, Zubieta J-K. Human brain mechanisms of pain perception and regulation in health and disease. Eur J Pain [Internet]. agosto de 2005;9(4):46384. Disponível em: http://dx.doi.org/10.1016/j.ejpain.2004.11.001

109. Vogt BA, Derbyshire S, Jones AKP. Pain Processing in Four Regions of Human Cingulate Cortex Localized with Co-registered PET and MR Imaging [Internet]. Vol. 8, European Journal of Neuroscience. 1996. p. 1461-73. Disponível em: http://dx.doi.org/10.1111/j.14609568.1996.tb01608.x

110. Maddock RJ. The retrosplenial cortex and emotion: new insights from functional neuroimaging of the human brain [Internet]. Vol. 22, Trends in Neurosciences. 1999. p. 310-6. Disponível em: http://dx.doi.org/10.1016/s0166-2236(98)01374-5

111. Ho AP. Brain Glucose Metabolism During Non—Rapid Eye Movement Sleep in Major Depression [Internet]. Vol. 53, Archives of General Psychiatry. 1996. p. 645. Disponível em: http://dx.doi.org/10.1001/archpsyc.1996.01830070095014

112. Reiman EM, Armstrong SM, Matt KS, Mattox JH. The application of positron emission tomography to the study of the normal menstrual cycle [Internet]. Vol. 11, Human Reproduction. 1996. p. 2799-805. Disponível em: http://dx.doi.org/10.1093/oxfordjournals.humrep.a019214

113. Kobayashi Y, Kurata J, Sekiguchi M, Kokubun M, Akaishizawa T, Chiba Y, et al. Augmented cerebral activation by lumbar mechanical stimulus in chronic low back pain patients: an FMRI study. Spine [Internet]. 15 de outubro de 2009;34(22):2431-6. Disponível em: http://dx.doi.org/10.1097/BRS.0b013e3181b1fb76

114. Hsieh J-C, Belfrage M, Stone-Elander S, Hansson P, Ingvar M. Central representation of chronic ongoing neuropathic pain studied by positron emission tomography [Internet]. Vol. 63, Pain. 1995. p. 225-36. Disponível em: http://dx.doi.org/10.1016/0304-3959(95)00048-w

115. Hari R, Portin K, Kettenmann B, Jousmäki V, Kobal G. Right-hemisphere preponderance of responses to painful CO2 stimulation of the human nasal mucosa [Internet]. Vol. 72, Pain. 1997. p. 145-51. Disponível em: http://dx.doi.org/10.1016/s0304-3959(97)00023-7

116. Derbyshire SWG, Jones AKP, Collins M, Feinmann C, Harris M. Cerebral responses to pain in patients suffering acute post-dental extraction pain measured by positron emission tomography (PET) [Internet]. Vol. 3, European Journal of Pain. 1999. p. 103-13. Disponível em: http://dx.doi.org/10.1053/eujp.1998.0102

117. Yu R, Gollub RL, Spaeth R, Napadow V, Wasan A, Kong J. Disrupted functional connectivity of the periaqueductal gray in chronic low back pain. Neuroimage Clin [Internet]. 23 de agosto de 2014;6:100-8. Disponível em: http://dx.doi.org/10.1016/j.nicl.2014.08.019 
118. Shimo K, Ueno T, Younger J, Nishihara M, Inoue S, Ikemoto T, et al. Visualization of painful experiences believed to trigger the activation of affective and emotional brain regions in subjects with low back pain. PLoS One [Internet]. 2 de novembro de 2011;6(11):e26681. Disponível em: http://dx.doi.org/10.1371/journal.pone.0026681

119. Nusbaum F, Redouté J, Le Bars D, Volckmann P, Simon F, Hannoun S, et al. Chronic lowback pain modulation is enhanced by hypnotic analgesic suggestion by recruiting an emotional network: a PET imaging study. Int J Clin Exp Hypn [Internet]. janeiro de 2011;59(1):27-44. Disponível em: http://dx.doi.org/10.1080/00207144.2011.522874

120. Price DD. Psychological and Neural Mechanisms of the Affective Dimension of Pain. Science [Internet]. 9 de junho de 2000;288(5472):1769-72. Disponível em: http://www.sciencemag.org/cgi/doi/10.1126/science.288.5472.1769

121. Baliki MN, Geha PY, Fields HL, Apkarian AV. Predicting value of pain and analgesia: nucleus accumbens response to noxious stimuli changes in the presence of chronic pain. Neuron [Internet]. 15 de abril de 2010;66(1):149-60. Disponível em: http://dx.doi.org/10.1016/j.neuron.2010.03.002

122. Wasan AD, Loggia ML, Chen LQ, Napadow V, Kong J, Gollub RL. Neural correlates of chronic low back pain measured by arterial spin labeling. Anesthesiology [Internet]. agosto de 2011;115(2):364-74. Disponível em: http://dx.doi.org/10.1097/ALN.0b013e318220e880

123. Lorenz J, Minoshima S, Casey KL. Keeping pain out of mind: the role of the dorsolateral prefrontal cortex in pain modulation [Internet]. Vol. 126, Brain. 2003. p. 1079-91. Disponível em: http://dx.doi.org/10.1093/brain/awg102

124. Loggia ML, Kim J, Gollub RL, Vangel MG, Kirsch I, Kong J, et al. Default mode network connectivity encodes clinical pain: an arterial spin labeling study. Pain [Internet]. janeiro de 2013;154(1):24-33. Disponível em: http://dx.doi.org/10.1016/j.pain.2012.07.029

125. Samineni VK, Premkumar LS, Faingold CL. Neuropathic pain-induced enhancement of spontaneous and pain-evoked neuronal activity in the periaqueductal gray that is attenuated by gabapentin. Pain [Internet]. julho de 2017;158(7):1241-53. Disponível em: http://dx.doi.org/10.1097/j.pain.0000000000000905

126. Morgado C, Terra PP, Tavares I. Neuronal hyperactivity at the spinal cord and periaqueductal grey during painful diabetic neuropathy: effects of gabapentin. Eur J Pain [Internet]. agosto de 2010;14(7):693-9. Disponível em: http://dx.doi.org/10.1016/j.ejpain.2009.11.011

127. Eippert F, Bingel U, Schoell ED, Yacubian J, Klinger R, Lorenz J, et al. Activation of the Opioidergic Descending Pain Control System Underlies Placebo Analgesia [Internet]. Vol. 63, Neuron. 2009. p. 533-43. Disponível em: http://dx.doi.org/10.1016/j.neuron.2009.07.014

128. Kong J, Tu P-C, Zyloney C, Su T-P. Intrinsic functional connectivity of the periaqueductal gray, a resting fMRI study [Internet]. Vol. 211, Behavioural Brain Research. 2010. p. 215-9. Disponível em: http://dx.doi.org/10.1016/j.bbr.2010.03.042

129. Beitz AJ. Relationship of glutamate and aspartate to the periaqueductal gray-raphe magnus projection: analysis using immunocytochemistry and microdialysis. J Histochem Cytochem [Internet]. dezembro de 1990;38(12):1755-65. Disponível em: http://dx.doi.org/10.1177/38.12.1701457

130. Lovick TA. Interactions Between Descending Pathways from the Dorsal and Ventrolateral Periaqueductal Gray Matter in the Rat [Internet]. The Midbrain Periaqueductal Gray Matter. 1991. p. 101-20. Disponível em: http://dx.doi.org/10.1007/978-1-4615-3302-3_7 
131. Holstege G, Bandler R, Saper CB. Chapter 1 The emotional motor system [Internet]. Progress in Brain Research. 1996. p. 3-6. Disponível em: http://dx.doi.org/10.1016/s0079-6123(08)618555

132. Benarroch EE. Periaqueductal gray: an interface for behavioral control. Neurology [Internet]. 17 de janeiro de 2012;78(3):210-7. Disponível em: http://dx.doi.org/10.1212/WNL.0b013e31823fcdee

133. McNaughton N, Corr PJ. A two-dimensional neuropsychology of defense: fear/anxiety and defensive distance [Internet]. Vol. 28, Neuroscience \& Biobehavioral Reviews. 2004. p. 285 305. Disponível em: http://dx.doi.org/10.1016/j.neubiorev.2004.03.005

134. Tracey I, Ploghaus A, Gati JS, Clare S, Smith S, Menon RS, et al. Imaging attentional modulation of pain in the periaqueductal gray in humans. J Neurosci [Internet]. $1^{\circ}$ de abril de 2002;22(7):2748-52. Disponível em: http://dx.doi.org/20026238

135. Valet M. Distraction modulates connectivity of the cingulo-frontal cortex and the midbrain during pain?an fMRI analysis [Internet]. Vol. 109, Pain. 2004. p. 399-408. Disponível em: http://dx.doi.org/10.1016/s0304-3959(04)00095-8

136. Villemure C, Bushnell MC. Mood influences supraspinal pain processing separately from attention. J Neurosci [Internet]. 21 de janeiro de 2009;29(3):705-15. Disponível em: http://dx.doi.org/10.1523/JNEUROSCI.3822-08.2009

137. Hosobuchi Y, Adams JE, Linchitz R. PAIN RELIEF BY ELECTRICAL STIMULATION OF THE CENTRAL GRAY MATTER IN HUMANS AND ITS REVERSAL BY NALOXONE [Internet]. Vol. 22, Survey of Anesthesiology. 1978. p. 252???253. Disponível em: http://dx.doi.org/10.1097/00132586-197806000-00029

138. Behbehani MM. Functional characteristics of the midbrain periaqueductal gray. Prog Neurobiol [Internet]. agosto de 1995;46(6):575-605. Disponível em: https://www.ncbi.nlm.nih.gov/pubmed/8545545

139. Giesecke T, Gracely RH, Grant MAB, Nachemson A, Petzke F, Williams DA, et al. Evidence of augmented central pain processing in idiopathic chronic low back pain. Arthritis Rheum [Internet]. fevereiro de 2004;50(2):613-23. Disponível em: http://dx.doi.org/10.1002/art.20063

140. Pijnenburg M, Brumagne S, Caeyenberghs K, Janssens L, Goossens N, Marinazzo D, et al. Resting-State Functional Connectivity of the Sensorimotor Network in Individuals with Nonspecific Low Back Pain and the Association with the Sit-to-Stand-to-Sit Task. Brain Connect [Internet]. junho de 2015;5(5):303-11. Disponível em: http://dx.doi.org/10.1089/brain.2014.0309

141. Kawato M, Wolpert D. Internal Models for Motor Control [Internet]. Novartis Foundation Symposia. 2007. p. 291-307. Disponível em: http://dx.doi.org/10.1002/9780470515563.ch16

142. Bushnell MC, Duncan GH, Hofbauer RK, Ha B, Chen J-. I, Carrier B. Pain perception: Is there a role for primary somatosensory cortex? [Internet]. Vol. 96, Proceedings of the National Academy of Sciences. 1999. p. 7705-9. Disponível em: http://dx.doi.org/10.1073/pnas.96.14.7705

143. Kong J, Loggia ML, Zyloney C, Tu P, Laviolette P, Gollub RL. Exploring the brain in pain: activations, deactivations and their relation. Pain [Internet]. fevereiro de 2010;148(2):257-67. Disponível em: http://dx.doi.org/10.1016/j.pain.2009.11.008

144. Garcia-Larrea L, Peyron R. Pain matrices and neuropathic pain matrices: a review. Pain [Internet]. dezembro de 2013;154 Suppl 1:S29-43. Disponível em: 
http://dx.doi.org/10.1016/j.pain.2013.09.001

145. Kong J, Spaeth RB, Wey H-Y, Cheetham A, Cook AH, Jensen K, et al. S1 is associated with chronic low back pain: a functional and structural MRI study. Mol Pain [Internet]. 21 de agosto de 2013;9:43. Disponível em: http://dx.doi.org/10.1186/1744-8069-9-43

146. Cavanna AE, Trimble MR. The precuneus: a review of its functional anatomy and behavioural correlates. Brain [Internet]. março de 2006;129(Pt 3):564-83. Disponível em: http://dx.doi.org/10.1093/brain/aw1004

147. Petrides M, Pandya DN. Projections to the frontal cortex from the posterior parietal region in the rhesus monkey. J Comp Neurol [Internet]. $1^{\circ}$ de setembro de 1984;228(1):105-16. Disponível em: http://dx.doi.org/10.1002/cne.902280110

148. Goldman-Rakic PS. Topography of cognition: parallel distributed networks in primate association cortex. Annu Rev Neurosci [Internet]. 1988;11:137-56. Disponível em: http://dx.doi.org/10.1146/annurev.ne.11.030188.001033

149. Iannetti GD, Zambreanu L, Wise RG, Buchanan TJ, Huggins JP, Smart TS, et al. Pharmacological modulation of pain-related brain activity during normal and central sensitization states in humans. Proc Natl Acad Sci U S A [Internet]. 13 de dezembro de 2005;102(50):18195200. Disponível em: http://dx.doi.org/10.1073/pnas.0506624102

150. Coghill RC, Sang CN, Maisog JM, Iadarola MJ. Pain Intensity Processing Within the Human Brain: A Bilateral, Distributed Mechanism [Internet]. Vol. 82, Journal of Neurophysiology. 1999. p. 1934-43. Disponível em: http://dx.doi.org/10.1152/jn.1999.82.4.1934

151. Porro CA, Cettolo V, Francescato MP, Baraldi P. Temporal and intensity coding of pain in human cortex. J Neurophysiol [Internet]. dezembro de 1998;80(6):3312-20. Disponível em: http://dx.doi.org/10.1152/jn.1998.80.6.3312

152. Buckner RL, Andrews-Hanna JR, Schacter DL. The Brain's Default Network [Internet]. Vol. 1124, Annals of the New York Academy of Sciences. 2008. p. 1-38. Disponível em: http://dx.doi.org/10.1196/annals.1440.011

153. Moisset X, Bouhassira D. Brain imaging of neuropathic pain. Neuroimage [Internet]. 10 de abril de 2007;37 Suppl 1:S80-8. Disponível em: http://dx.doi.org/10.1016/j.neuroimage.2007.03.054

154. Kupers R, Kehlet H. Brain imaging of clinical pain states: a critical review and strategies for future studies. Lancet Neurol [Internet]. dezembro de 2006;5(12):1033-44. Disponível em: http://dx.doi.org/10.1016/S1474-4422(06)70624-X 
APÊNDICE A - Aprovação do CEP

\section{HOSPITAL DAS CLÍNICAS DA
FACULDADE DE MEDICINA DE
RIBEIRÃO PRETO DA USP -}

\section{PARECER CONSUBSTANCIADO DO CEP}

\section{DADOS DO PROJETO DE PESQUISA}

Título da Pesquisa: Avaliação clínica e por neuroimagem funcional da eficácia do uso da gabapentina na dor crônica neuropática

Pesquisador: Erica Negrini Lia

Área Temática:

Versão: 2

CAAE: 43541015.7 .0000 .5440

Instituição Proponente: Hospital das Clínicas da Faculdade de Medicina de Ribeirão Preto da USP -

Patrocinador Principal: Financiamento Próprio

\section{DADOS DO PARECER}

Número do Parecer: 1.190 .720

\section{Apresentação do Projeto:}

Trata-se de projeto de pesquisa, nível pós-doutorado, a ser desenvolvido pela Prof ${ }^{\mathrm{a}}$. Dr ${ }^{\mathrm{a}}$. Erica Negrini Lia, tendo como supervisor de pós-doutorado Prof. Dr. Lauro Wichert-Ana, da Seção de Medicina Nuclear Centro de Ciências das Imagens e Física Médica e Departamento de Clínica Médica - Faculdade de Medicina de Ribeirão Preto - USP. Participam como colaboradores da pesquisa: Profa. Dra. Gabriela Rocha Lauretti, Prof.Dr Eduardo Barbosa Coelho, Profa Dra Vera Lucia Lanchote.

\section{Objetivo da Pesquisa:}

Objetivos gerais: Avaliar clinicamente os pacientes portadores de dor crônica em uso de gabapentina e correlacionar a resposta analgésica ao padrão de neuroimagem funcional e a disposição cinética do medicamento.

Objetivos específicos: - Avaliar os pacientes portadores de dor neuropática no Ambulatório de Dor do Hospital das Clínicas da FMRP-USP por meio de aplicação da escala visual numérica (EVN); - Correlacionar os resultados da Escala Visual Numérica (EVN) com a escala REPOS validada para a língua portuguesa; Realizar a modelagem PK/PD com os dados de farmacodinâmica obtidos pela aplicação das escalas EVN ou REPOS e com os dados de disposição cinética da gabapentina em diferentes doses;

- Avaliar as alterações do padrão de perfusão cerebral induzidas pela gabapentina com a resposta clínica obtida pela avaliação com uso de escala EVN ou REPOS; - Realizar a modelagem PK/PD com os dados

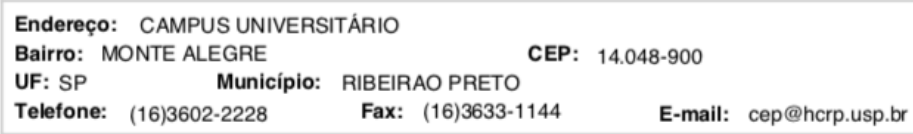




\begin{tabular}{|c|c|c|}
\hline HOSPITAL DAS CLÍNICAS DA \\
FACULDADE DE MEDICINA DE Plotoforma \\
RIBEIRÃO PRETO DA USP -
\end{tabular}

Continuação do Parecer: 1.190.720

farmacodinâmicos obtidos pelo SPECT e comparar o

resultado com a modelagem realizada com os dados oriundos da aplicação das escalas.

- Significado de PK/PD - (farmacocinética /farmacodinâmica).

Avaliação dos Riscos e Benefícios:

Riscos: Efeitos adversos do uso da gabapentina, como sonolência e vertigem, manutenção do estado doloroso por falha do protocolo medicamentoso proposto, efeitos associados ao uso do radio fármaco 99 mTc-ECD (em menos de 1\% dos pacientes pode ocorrer vertigem, ansiedade, agitação).

Benefícios: Além do possível controle medicamentoso da dor neuropática, os dados obtidos permitirão avaliar a utilidade do SPECT ou monitoramento terapêutico na predição da eficácia da gabapentina para o tratamento da dor neuropática em idosos.

Comentários e Considerações sobre a Pesquisa:

A dor neuropática é comum entre idosos e é uma das maiores causas de perda funcional e de dependência, impactando sobre a qualidade de vida. Como tratamento da dor neuropática, a gabapentina tem emergido em função do seu perfil de segurança, o

que a torna uma alternativa possível a idosos. Para a mensuração da dor e do efeito analgésico, escalas podem ser utilizadas, como a escala visual numérica (EVN) e em idosos, a Escala Rotterdam de Observação de Dor em Idosos(REPOS), ainda não validada para a língua portuguesa. Entretanto, os mecanismos de ação da gabapentina e sua atuação nas diferentes áreas do sistema nervoso central propostos são baseados em sua maioria, em estudos experimentais em animais. Mais recentemente, estudos de neuroimagem funcional como a tomografia por emissão de fóton único (SPECT- Single-photon emission computed tomography) têm sido empregados para compreender o mecanismo de ação e o local de atuação de medicamentos que agem no sistema nervoso central.

Conhecer a dor ou sofrimento do paciente e a identificação do substrato neurobiológico cerebral associado à sensibilidade à dor, poderá auxiliar na otimização do tratamento com drogas analgésicas, como a gabapentina além de auxiliar na titulação posológica desta droga em bases clínicas, de farmacocinética e farmacodinâmica. Diante do exposto, o objetivo deste estudo é avaliar clinicamente pacientes idosos portadores de dor crônica orofacial em uso de gabapentina e correlacionar a resposta analgésica ao padrão de neuroimagem funcional e a disposição cinética do medicamento.

Metodologia: Critério de inclusão: idosos (idade igual ou superior a 60 anos) com dor neuropática, não obesos, não tabagistas, com funções hepática, renal e cardiaca dentro dos limites de normalidade. Critério de exclusão: portadores de Diabetes Melittus, doenças neurológicas neuropáticas, alcoolismo crônico, ou qualquer história de doenças relacionadas a dor neuropática prévia. Obesos, tabagistas e casos de

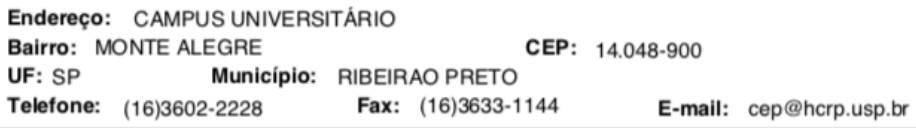




\begin{tabular}{|c|c|}
\hline USP-RIBEIR & $\begin{array}{l}\text { HOSPITAL DAS CLÍNICAS DA } \\
\text { FACULDADE DE MEDICINA DE } \\
\text { RIBEIRÃO PRETO DA USP - }\end{array}$ \\
\hline
\end{tabular}

Continuação do Parecer: 1.190.720

alteração de função hepática, cardiaca e renal. Casuística: Serão avaliados ao total 28 pacientes portadores de dor neuropática, em seguimento no Ambulatório de Dor do Hospital das Clínicas da Faculdade de Medicina de Ribeirão Preto-USP, que não responderam ao tratamento farmacológico padrão adotado no referido serviço (antidepressivo associado ou não a carbamazepina (ou oxcarbazepina); ou oxcarbazepina ou carbamazepina, caso não tenha sido usada em associação com antidepressivo.

Protocolo de estudo: Os voluntários que preencherem os critérios de inclusão e após coleta do TCLE, inicialmente realizarão exames bioquímicos (Creatinina, TGO, gama GT e glicemia). Os voluntários terão os seus dados anotados em uma ficha de pesquisa clínica e serão avaliados por meio da aplicação das escalas de dor EVN e REPOS. Em seguida serão submetidos à uma Tomografia por emissão de fóton único (Single-photon emission computed tomography) SPECT cerebral, conforme detalhes abaixo. Na noite após o SPECT-CT, será iniciada gabapentina na dose de $300 \mathrm{mg}$ por via oral. Após sete dias do início do medicamento, os pacientes retornarão para avaliação no Ambulatório de Dor do HCFMRP-USP e os considerados responsivos, ou seja, aqueles que apresentarem escore menor que 4 na EVN, serão convidados a comparecer em jejum de 12horas na Unidade de Pesquisa Clínica do HCFMRP-USP onde realizarão a coleta de sangue seriada para estudo farmacocinético e repetirão o SPECT cerebral. Caso o paciente seja considerado não responsivo, a dose de gabapentinaserá elevada para $600 \mathrm{mg}$. Caso o paciente responda em 7 dias, ele será submetido a coleta cinética e SPECT de forma semelhante a descrita para a dose de $300 \mathrm{mg}$. Finalmente, caso o paciente não responda à dose de $600 \mathrm{mg}$ em 7 dias, uma dose de 1200 mg será prescrita. Todos os voluntários que receberão (responsivos ou não) 1200 mg serão convidados para o protocolo de estudo farmacocinético e para a realização do SPECT em vigência da gabapentina, conforme descrito acima. Desta forma, planeja-se incluir 7 voluntários por grupo (300mg, $600 \mathrm{mg}, 1200 \mathrm{mg}$ responsivos e $1200 \mathrm{mg}$ não responsivos), totalizando 28 pacientes. TOMOGRAFIA POR EMISSÃO DE FÓTON ÚNICO - SPECT cerebral (Single-photon emission computed tomography) Os exames serão realizados no Setor de Medicina Nuclear do HCFMRP-USP. Cada paciente será submetido a 2 exames, com intervalo mínimo de sete dias entre eles. No primeiro exame, antes de se iniciar a gabapentina, os voluntários receberão por via endovenosa o radiofármaco $99 \mathrm{mTC}-\mathrm{ECD}$ na dose de $20 \mathrm{mCi}$ de atividade radioativa preconizada internacionalmente (Juni et al., 2009) e serão submetidos ao SPECT basal de controle. O segundo exame, com a mesma dose de radiofármaco, será realizado durante a internação na UPC do HCFMRP-USP que será realizada para o estudo farmacocinético da gabapentina, 6 horas após a ingestão do medicamento por via oral. Os SPECTs cerebrais serão realizados através da injeção endovenosa do radiofármaco de perfusão cerebral, 99mTcECD. Os sujeitos da pesquisa serão colocados em repouso, confortavelmente, em silêncio, com olhos abertos e em ambiente de baixa iluminação. Os SPECTs serão adquiridos em gama-câmara SOPHA (modelo Vision DST, SMV América, Twinsburg, Ohio), com duplo detector, equipada com colimador de baixa

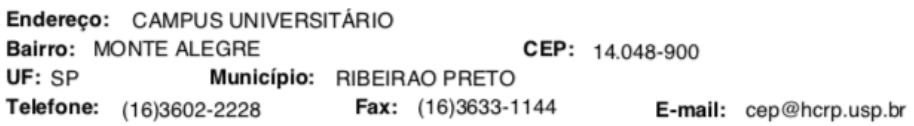




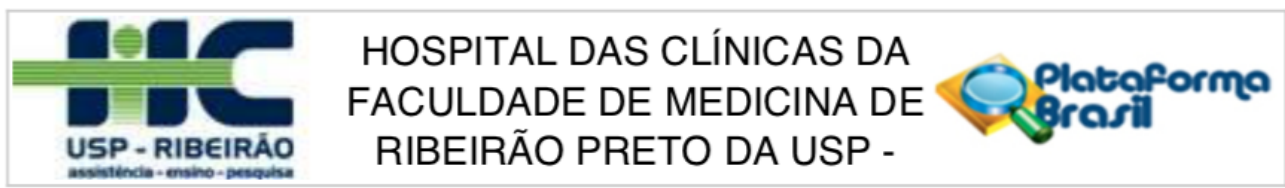

Continuação do Parecer: 1.190.720

energia e alta resolução (LEHR), fotopico para 99mTc-ECD centrado em $140 \mathrm{keV}$ e janela de aceitação de $20 \%$, 32projeções em $180^{\circ}$ por cada detector e magnificação (zoom) de 2 vezes. As imagens serão adquiridas em matriz $128 \times 128$, tempo de aquisição de 30 minutos e aproximadamente 100.000 contagens por projeção. As

imagens serão processadas através de filtro Butterworth (ordem $=9$, frequência de corte $=0.14$ ciclos $/ \mathrm{mm}$ ) e reconstruídas em seções transversais paralelas ao plano orbito-meatal e, adicionalmente, reconstruídas paralelamente ao eixo longo dos lobos temporais. A correção de atenuação será realizada considerando-se o pixel de $1,7 \mathrm{~mm}$, e utilizando o método Chang de $1^{\text {a }}$. ordem (coeficiente $=0.12 \mathrm{~cm}-1$ ) (WICHERT-ANA et al., 2001; WICHERT-ANA et al., 2008a; WICHERT-ANA et al., 2008b). DISPOSIÇÃO CINÉTICA DA GABAPENTINA As amostras seriadas de sangue serão coletadas na UPC-HCFMRP-USP após a administração de gabapentina (300,600 ou 1200mg) por via oral com $200 \mathrm{~mL}$ de água. As amostras seriadas de sangue $(5 \mathrm{~mL})$ serão coletadas via cateter intravenoso em seringas heparinizadas (Liquemine ${ }^{\circledR}$ $5000 U$ I, Roche) nos tempos zero; 0,$25 ; 0,5 ; 0,451 ; 1,5 ; 2 ; 2,5 ; 3 ; 3,5 ; 4 ; 5 ; 6 ; 8 ; 10$ e 12 h após a administração do fármaco. Os

plasmas para análise cromatográfica serão obtidos por centrifugação (1800g × $20 \mathrm{~min}$ ) das amostras de sangue. As amostras de plasma serão armazenadas a $-70^{\circ} \mathrm{C}$ até o momento da análise. $\mathrm{O}$ método para a análise da gabapentina será desenvolvido e validado no laboratório da Profa. Dra. Vera Lucia Lanchote (FCFRP-USP), utilizando LC/MS/MS.

\section{Considerações sobre os Termos de apresentação obrigatória:}

As pendências foram atendidas.

\section{Recomendações:}

Conclusões ou Pendências e Lista de Inadequações:

Diante do exposto e à luz da Resolução CNS 466/2012, o projeto de pesquisa versão 2 de 10/07/2015, assim como o Termo de Consentimento Livre e Esclarecido versão 2 de 10/07/2015, podem ser enquadrados na categoria APROVADO.

\section{Considerações Finais a critério do CEP:}

Projeto Aprovado: Tendo em vista a legislação vigente, devem ser encaminhados ao CEP, relatórios parciais anuais referentes ao andamento da pesquisa e relatório final ao término do trabalho. Qualquer modificação do projeto original deve ser apresentada a este CEP em nova versão, de forma objetiva e com justificativas, para nova apreciação.

Endereço: CAMPUS UNIVERSITÁRIO

Bairro: MONTE ALEGRE

CEP: $14.048-900$

UF: SP Município: RIBEIRAO PRETO

Telefone: (16)3602-2228 Fax: (16)3633-1144 E-mail: cep@hcrp.usp.br 
HOSPITAL DAS CLÍNICAS DA

FACULDADE DE MEDICINA DE RIBEIRÃO PRETO DA USP -

Continuação do Parecer: 1.190.720

Este parecer foi elaborado baseado nos documentos abaixo relacionados:

\begin{tabular}{|c|c|c|c|c|}
\hline Tipo Documento & Arquivo & Postagem & Autor & Situação \\
\hline Outros & $\begin{array}{l}\text { Orc } \_ \text {amento detalhado posdoc erica } \\
\text { (2).docx }\end{array}$ & $\begin{array}{c}23 / 02 / 2015 \\
12: 39: 26 \\
\end{array}$ & & Aceito \\
\hline $\begin{array}{l}\text { Informações Básicas } \\
\text { do Projeto }\end{array}$ & $\begin{array}{l}\text { PB_INFORMAÇÕES_BÁSICAS_DO_P } \\
\text { ROJETO 458638.pdf }\end{array}$ & $\begin{array}{c}10 / 03 / 2015 \\
09: 12: 43 \\
\end{array}$ & & Aceito \\
\hline \begin{tabular}{|l|l} 
Outros & \\
\end{tabular} & Carta de Acordo - 13.07.2015 Erica.pdf & $\begin{array}{c}17 / 07 / 2015 \\
09: 25: 06 \\
\end{array}$ & & Aceito \\
\hline Outros & Formulário SAME.pdf & $\begin{array}{c}17 / 07 / 2015 \\
09: 25: 27 \\
\end{array}$ & & Aceito \\
\hline Folha de Rosto & Folha de Rosto_Erica.jpg & $\begin{array}{c}16 / 03 / 2015 \\
15: 19: 24 \\
\end{array}$ & & Aceito \\
\hline $\begin{array}{l}\text { Informações Básicas } \\
\text { do Projeto }\end{array}$ & $\begin{array}{l}\text { PB_INFORMAÇÕES_BÁSICAS_DO_P } \\
\text { ROJETO 458638.pdf }\end{array}$ & $\begin{array}{c}16 / 03 / 2015 \\
15: 21: 03 \\
\end{array}$ & & Aceito \\
\hline $\begin{array}{l}\text { Informações Básicas } \\
\text { do Projeto }\end{array}$ & $\begin{array}{l}\text { PB_INFORMAÇÕES_BÁSICAS_DO_P } \\
\text { ROJETO 458638.pdf }\end{array}$ & $\begin{array}{c}23 / 03 / 2015 \\
09: 26: 40 \\
\end{array}$ & & Aceito \\
\hline \begin{tabular}{|l|l} 
Outros & \\
\end{tabular} & Declarac ¿a¿o Po¿s-Doc.pdf & $\begin{array}{c}27 / 03 / 2015 \\
08: 41: 09 \\
\end{array}$ & & Aceito \\
\hline $\begin{array}{l}\text { Informações Básicas } \\
\text { do Projeto }\end{array}$ & $\begin{array}{l}\text { PB_INFORMAÇÕES_BÁSICAS_DO_P } \\
\text { ROJETO 458638.pdf }\end{array}$ & $\begin{array}{c}17 / 07 / 2015 \\
09: 28: 00 \\
\end{array}$ & & Aceito \\
\hline $\begin{array}{l}\text { Informações Básicas } \\
\text { do Projeto }\end{array}$ & $\begin{array}{l}\text { PB_INFORMAÇÕES_BÁSICAS_DO_P } \\
\text { ROJETO 458638.pdf }\end{array}$ & $\begin{array}{c}21 / 07 / 2015 \\
10: 38: 25 \\
\end{array}$ & & Aceito \\
\hline $\begin{array}{l}\text { Informações Básicas } \\
\text { do Projeto }\end{array}$ & $\begin{array}{l}\text { PB_INFORMAÇÕES_BÁSICAS_DO_P } \\
\text { ROJETO 458638.pdf }\end{array}$ & $\begin{array}{c}20 / 03 / 2015 \\
16: 28: 49 \\
\end{array}$ & & Aceito \\
\hline $\begin{array}{l}\text { TCLE / Termos de } \\
\text { Assentimento / } \\
\text { Justificativa de } \\
\text { Ausência }\end{array}$ & TCLE v1 30 março de 2015.docx & $\begin{array}{c}31 / 03 / 2015 \\
15: 10: 38\end{array}$ & & Aceito \\
\hline $\begin{array}{l}\text { Projeto Detalhado / } \\
\text { Brochura } \\
\text { Investigador }\end{array}$ & Projeto v1 30 março 2015 (1).docx & $\begin{array}{l}31 / 03 / 2015 \\
15: 11: 06\end{array}$ & & Aceito \\
\hline Outros & Carta de Acordo UPC_Erica.pdf & $\begin{array}{c}01 / 04 / 2015 \\
17: 02: 25 \\
\end{array}$ & & Aceito \\
\hline $\begin{array}{l}\text { Informações Básicas } \\
\text { do Projeto }\end{array}$ & $\begin{array}{l}\text { PB_INFORMAÇÕES_BÁSICAS_DO_P } \\
\text { ROJETO 458638.pdf }\end{array}$ & $\begin{array}{c}01 / 04 / 2015 \\
17: 10: 08 \\
\end{array}$ & & Aceito \\
\hline $\begin{array}{l}\text { TCLE / Termos de } \\
\text { Assentimento / } \\
\text { Justificativa de } \\
\text { Ausência }\end{array}$ & TCLE v2 10 de julho de 2015.docx & $\begin{array}{c}12 / 07 / 2015 \\
23: 31: 31\end{array}$ & & Aceito \\
\hline $\begin{array}{l}\text { Projeto Detalhado / } \\
\text { Brochura } \\
\text { Investigador }\end{array}$ & Projeto v2 10 julho 2015.docx & $\begin{array}{c}12 / 07 / 2015 \\
23: 32: 31\end{array}$ & & Aceito \\
\hline Outros & CEP HCFMRP- Projeto gabap.docx & $12 / 07 / 2015$ & & Aceito \\
\hline
\end{tabular}

Endereço: CAMPUS UNIVERSITÁRIO

Bairro: MONTE ALEGRE

CEP: $14.048-900$

UF: SP Município: RIBEIRAO PRETO

Telefone: (16)3602-2228 Fax: (16)3633-1144 E-mail: cep@hcrp.usp.br 


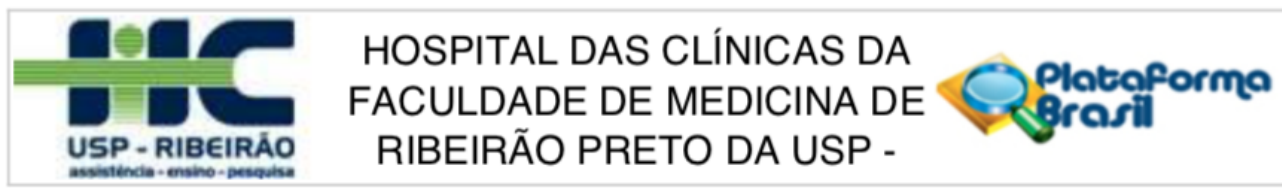

Continuação do Parecer: 1.190 .720

\begin{tabular}{|l|l|l|l|l|}
\hline Outros & CEP HCFMRP- Projeto gabap.docx & $23: 33: 15$ & & Aceito \\
\hline
\end{tabular}

Situação do Parecer:

Aprovado

Necessita Apreciação da CONEP:

Não

RIBEIRAO PRETO, 24 de Agosto de 2015

Assinado por:

MARCIA GUIMARÃES VILLANOVA

(Coordenador)

Endereço: CAMPUS UNIVERSITÁRIO

Bairro: MONTE ALEGRE

CEP: $14.048-900$

UF: SP Município: RIBEIRAO PRETO

Telefone: (16)3602-2228 Fax: (16)3633-1144 E-mail: cep@hcrp.usp.br 


\section{APÊNDICE B - Termo de Consentimento Livre e Esclarecido}

TERMO DE CONSENTIMENTO LIVRE E ESCLARECIDO

Versão 2 de 10/7/2015

(Pesquisa Científica em Seres Humanos, Resolução CNS 466/12)

\section{Identificação do voluntário}

Nome. Sexo

Identidade Data nascimento Idade

Endereço

Telefone fixo Celular

\section{Informações sobre a pesquisa}

Título: Avaliação clínica e por neuroimagem funcional da eficácia do uso da gabapentina na dor crônica neuropática

Pesquisadores envolvidos: Erica Negrini Lia (pesquisadora principal, aluna de pós-doutorado FMRP-USP), cel (16) 98136-7075; Lauro Wichert-Ana (docente FMRP-USP), cel (16) 981743300; Eduardo Barbosa Coelho (docente FMRP-USP) cel 98136-7075; Gabriela Rocha Lauretti (docente FMRP-USP), fone 3602-2211; Vera Lúcia Lanchote (responsável pela etapa de farmacocinética) fone 3602-4699, Priscila Colavite Papassidero cel (16) 98112-6343; Fabiola Dach Eckeli cel (16) 991731816. O telefone do Comitê de Ética em Pesquisa (CEP) do HC/FMRPUSP é (16) 3602-2228.

\section{Justificativa e objetivos da pesquisa}

A gabapentina é um remédio utilizado no tratamento das crises convulsivas ou ataques epilépticos, mas que também pode tratar a dor crônica. Este estudo deseja comparar a quantidade desse remédio no sangue com a quantidade que chega ao cérebro, em doses diferentes, utilizadas normalmente para o tratamento médico da dor em casos semelhantes ao seu. Para isso, todas as pessoas que irão participar deste estudo são aquelas que sofrem de dor crônica e que irão começar a tomar o remédio gabapentina.

\section{Procedimentos}

O estudo será realizado em duas fases. Na primeira fase, nós vamos pedir para você desenhar em um pedaço de papel o tamanho da sua dor e também vamos avaliar o tamanho da sua dor apenas olhando para você. Nesta primeira fase, você também receberá um remédio na veia e 
fazer uma tomografia cerebral, um exame que fornece imagens semelhantes a fotos do cérebro. Este remédio possui pequena quantidade de radiação, equivalente à metade da radiação de um Raio X de tórax e é importante para que o exame possa ser feito. Raramente este remédio pode causar alguns sintomas, tais como febre, dor de cabeça, dor no peito, vermelhidão na pele, tontura e enjoo. Na segunda fase, você iniciará um tratamento com a gabapentina, com a dose de $600 \mathrm{mg}$ ( 2 comprimidos) à noite. Depois de 7 dias usando a gabapentina nesta dose, se você estiver sem dor, deverá comparecer em jejum de 12 horas ao Hospital das Clínicas da Faculdade de Medicina de Ribeirão Preto as 7 horas da manhã para ser internado na Unidade de Pesquisa Clínica por um dia (24h). Durante esta internação você vai fazer mais uma tomografia cerebral e receber novamente o remédio para fazer o exame na veia. Além disso, durante a internação, serão feitas 16 coletas de sangue da sua veia (de aproximadamente 1 colher de sopa por vez) até $12 \mathrm{~h}$ após a tomada do remédio. Se a sua dor não passar com $600 \mathrm{mg}$ (2 comprimidos) de gabapentina após sete dias de uso, a dose poderá ser aumentada a cada sete dias para $900 \mathrm{mg}$ (3 comprimidos) ou até 1200mg (4 comprimidos) e a internação para a segunda fase somente será feita quando você não tiver mais dor ou se você receber a dose máxima (1200 mg, 4 comprimidos) e mesmo assim permanecer com a dor. Para realizar este estudo você precisa ser internado uma única vez. Para colhermos o sangue, você será picado uma só vez, sendo mantida um tubinho de plástico na sua veia para as retiradas posteriores de sangue, num volume total equivalente a três colheres das de sopa. Caso você receba $1200 \mathrm{mg}$ de gabapentina (4 comprimidos) e mantenha a dor, você será reavaliado no ambulatório de dor e um novo tratamento será proposto pelos médicos da clínica.

\section{Riscos}

Durante o estudo você pode ter algumas reações relacionados ao uso da gabapentina, tais como como sonolência, dores de cabeça, tontura, visão dupla, enjoo, vômito e sensação de cansaço ou fraqueza. Neste caso, procure imediatamente o Pesquisador. Além disso, pode ser que a dor que você sente não passe com as doses mais baixas de gabapentina. Durante o uso do remédio para fazer o exame do cérebro, a tomografia, pode acontecer tonturas, ansiedade ou até sensação de agonia. Durante a coleta de sangue, algumas pessoas podem sentir fraqueza e até mesmo desmaiar; também podem surgir hematomas e dor no local da picada da agulha. Por esse motivo os exames serão feitos com você internado e caso você passe mal, um médico poderá atendêlo, além de esclarecer qualquer dúvida. Esclarecemos que é a chance que você passe mal é bem pequena.

\section{Benefícios}


Você poderá se beneficiar do tratamento com a gabapentina para a sua dor. A sua colaboração permitirá entender melhor como a gabapentina se distribui no cérebro, possibilitando no futuro descobrir se a área do cérebro afetada pelo remédio depende da quantidade que é tomada e em quais pacientes a gabapentina pode funcionar melhor.

\section{Forma de acompanhamento e assistência}

Os pesquisadores estarão à sua disposição para quaisquer esclarecimentos no telefone(16) 98136-7075 / 3602-2543 Erica Negrini Lia / Eduardo Barbosa Coelho. Mesmo após o encerramento da pesquisa, você continuará seu acompanhamento no Ambulatório de Dor do Hospital das Clínicas.

\section{Garantia de liberdade em participar da pesquisa}

Você pode desistir de continuar da pesquisa a qualquer momento, sem nenhum tipo de prejuízo. Seu tratamento no Hospital será o mesmo se você desistir da pesquisa.

\section{Garantia de sigilo}

O pesquisador se compromete a manter segredo da sua participação e você será identificado apenas por um número, e de divulgar os resultados da pesquisa para os demais colegas médicos e pesquisadores

\section{Ressarcimento de despesas}

Você receberá ressarcimento financeiro para cobrir despesas da sua participação na pesquisa. O valor do ressarcimento é para utilização com transportes e lanche, já que você deverá vir ao hospital em jejum. Para cada retorno de consulta médica, você receberá $\mathrm{R} \$ 20,00$ (vinte reais) e para cada dia em que você permanecer internado no hospital para a coleta de sangue e realização da tomografia cerebral, você receberá $\mathrm{R} \$ 150,00$ (cento e cinquenta reais).

\section{Indenização}

Caso você tenha qualquer dano causado pela sua participação direta na pesquisa você terá direito a indenização por parte dos pesquisadores de acordo com a lei.

\section{Outros esclarecimentos}

Você tem a garantia de receber a resposta a qualquer pergunta ou esclarecimento a qualquer dúvida acerca dos procedimentos, riscos, benefícios e outros assuntos relacionados com a pesquisa e o tratamento a que será submetido. O pesquisador tem o compromisso de lhe dar informação atualizada durante o estudo, mesmo que possa afetar sua vontade em continuar participando. Você receberá uma via deste Termo de Consentimento Livre e Esclarecido, que será assinado e rubricado em todas as páginas pelo pesquisador e por você. 
Nome do participante

assinatura

Data

Nome do pesquisador

assinatura

Data 


\section{APÊNDICE C - Case Report Form (CRF)}

CRF

PROJETO DOR LOMBAR x SPECT x GABAPENTINA

IDENTIFICAÇÃO DO PACIENTE

Nome:

Endereço:

Telefone de contato:

Raça/cor:

Gênero:

Coletou TCLE? ( ) S ( ) N Data da coleta

V0- Triagem

CRITÉRIOS DE INCLUSÃO

Idade $^{3} 18$ anos ( )S ( )N

Dor lombar neuropática ( ) S ( )N

Já utilizou algum tratamento farmacológico para o tratamento da dor $(\quad) \mathrm{S} \quad($ )N Qual?

CRITÉRIOS DE EXCLUSÃO

Obesidade ( )S ( )N

Diabetes ( ) S ( )N

Hipertensão arterial ( )S ( )N

Hepatopatia ( )S ( )N

Nefropatia ( )S ( )N

Anemia ( )S ( )N

Cardiopatia ( )S ( )N

Doença neurológica neuropática ( )S ( )N

Alcoolismo crônico ( )S ( )N

Tabagismo ( )S ( )N

Obs: excluir o paciente do estudo caso a(s) resposta(s) acima seja(m) afirmativa(s)

DADOS DE SAÚDE

Lista de problemas:

Medicamentos em uso:

Exames bioquímicos

$\mathrm{Hb}=\quad \mathrm{Ht}=\quad \mathrm{Plq}=$ 
BT e frações $=$

Creatinina: $\mathrm{mg} / \mathrm{dL}$

TGO: $\quad \mathrm{U} / \mathrm{L}$

Gama GT: $\quad$ U/L

Glicemia: $\quad \mathrm{mg} / \mathrm{dL}$

Avaliação cardiológica

$\mathrm{ECG}=\quad \mathrm{FC}=\mathrm{bpm}$

( ) Incluído ( ) Excluído

V1 - Avaliação Inicial

$\mathrm{EVN}=$

REPOS $=$

$\mathrm{DN} 4=$

HADS-A =

HADS-D =

WHOQOL-bref =

$\mathrm{EPCD}=$

EPWORTH $=$

$1^{\circ}$. SPECT cerebral: data

Prescrever gabapentina (iniciar após o SPECT cerebral) na dose inicial de 600mg e marcar retorno em 7 dias (V2)

V2- Retorno: data

Utilizou corretamente a gabapentina? ( ) S ( ) N

Número de cápsulas tomadas $=$

Eventos adversos:

$\mathrm{EVN}=\quad \mathrm{REPOS}=$

EPWORTH $=$

EVN 4 pontos inferior à basal?

( ) $\mathrm{N}$---------Prescrever 900mg gabapentina e marcar retorno para 7 dias (continuar em V3)

( ) $\mathrm{S}$-------- 20. SPECT cerebral (mesmo dia preferencialmente)

HADS-A $=$

HADS-D =

WHOQOL-bref $=$

$\mathrm{EPCD}=$

Veio em jejum de $12 \mathrm{~h}$ ? ( ) S ( ) N

Instalado cateter intravenoso heparinizado ( ) $\mathrm{S} \quad(\quad) \mathrm{N}$ 
Coleta de sangue - Horário: $1^{\circ}$ (vale) $; 2^{\circ}($ pico $)$

Realizou 20. SPECT cerebral ? S( ) N( )

$(\quad) \mathrm{S}$---------------- Encerrar

( ) N -------------- Continuar em V3

V3 - Retorno: data

Utilizou corretamente a gabapentina? ( ) S ( ) N

Número de cápsulas tomadas $=$

Eventos adversos:

$\mathrm{EVN}=\quad \mathrm{REPOS}=$

EPWORTH $=$

EVN 4 pontos inferior à basal?

( ) $\mathrm{N}$-------Prescrever 1200mg gabapentina e marcar retorno para 7 dias (continuar em V4)

( ) S-------- 2 ${ }^{\circ}$ SPECT cerebral (mesmo dia preferencialmente)

HADS-A =
HADS-D =
WHOQOL-bref =

$\mathrm{EPCD}=$

Veio em jejum de $12 \mathrm{~h}$ ? ( ) S ( ) N

Instalado cateter intravenoso heparinizado ( ) $\mathrm{S}$ () $\mathrm{N}$

Coleta de sangue - Horário: $1^{\circ}$ (vale) $; 2^{\circ}$ (pico)

Realizou 20. SPECT cerebral ? S( ) N( )

( ) $\mathrm{S}$--------------- Encerrar

( ) N -------------- Continuar em V4

V4 - Retorno: data

Utilizou corretamente a gabapentina? ( ) S ( ) N

Número de cápsulas tomadas $=$

Eventos adversos:

$\mathrm{EVN}=$

REPOS $=$

HADS-A =

HADS-D $=$

$\mathrm{EPCD}=$

EPWORTH $=$

WHOQOL-bref

EVN 4 pontos inferior à basal?

( ) $\mathrm{N}$

( ) $\mathrm{S}$

Veio em jejum de $12 \mathrm{~h}$ ? ( ) S ( ) N 
Instalado cateter intravenoso heparinizado ( ) $\mathrm{S}$ () $\mathrm{N}$

Coleta de sangue - Horário: $1^{\circ}$ (vale) $; 2^{\circ}$ (pico)

Realizar obrigatoriamente $2^{\circ}$. SPECT cerebral (mesmo dia preferencialmente)

Realizou $2^{\circ}$. SPECT cerebral ? S( ) N( )

$(\quad) \mathrm{S}$--------------- Encerrar

( ) $\mathrm{N}$-------------- agendado para o dia e encerrar após

Desligamento do protocolo de pesquisa?

$\mathrm{S}($ ) $\mathrm{N}($ )

Em que etapa?

Motivo: ( ) intolerância ao medicamento ( ) falta do paciente ao retorno ( ) o paciente desejou descontinuar ( ) outro

Responsáveis pelo preenchimento: 
APÊNDICE D - Correlação entre alterações individuais do FSCr com escala EVN

\begin{tabular}{|c|c|c|c|c|}
\hline Paciente & $\begin{array}{l}\text { Cluster } 1 \\
\text { Hiperperfusão }\end{array}$ & $\begin{array}{l}\text { Cluster } 2 \\
\text { Hiperperfusão }\end{array}$ & $\begin{array}{l}\text { Cluster } 3 \\
\text { Hipoperfusão }\end{array}$ & $\overline{E V N}$ \\
\hline 1 & 3193,57 & 2955,77 & 2835,19 & 6 \\
\hline 2 & 2937,39 & 2968,07 & 2747,25 & 7 \\
\hline 3 & 3189,93 & 2978,79 & 2796,52 & 5 \\
\hline 4 & 3054,53 & 3124,16 & 2826,39 & 6 \\
\hline 5 & 3203,44 & 2937,76 & 2804,74 & 7 \\
\hline 6 & 3288,88 & 2976,96 & 2817,65 & 5 \\
\hline 7 & 3144,52 & 3097,09 & 2778,34 & 3 \\
\hline 8 & 3096,13 & 3050,18 & 2773,34 & 4 \\
\hline 9 & 3152,95 & 3050,84 & 2757,04 & 4 \\
\hline 10 & 3220,76 & 3023,11 & 2727,28 & 4 \\
\hline 11 & 3355,50 & 3020,13 & 2632,55 & 10 \\
\hline 12 & 3036,08 & 3075,75 & 2755,31 & 4 \\
\hline 13 & 3069,31 & 3112,38 & 2705,10 & 6 \\
\hline 14 & 2855,60 & 2835,26 & 2537,44 & 9 \\
\hline Média & 3128,47 & 3014,73 & 2749,58 & \\
\hline (DP) & 132,95 & 79,00 & 81,23 & \\
\hline
\end{tabular}

Abreviações: EVN, escala visual numérica. 
ANEXO A - ESCALA VISUAL NUMÉRICA (EVN)

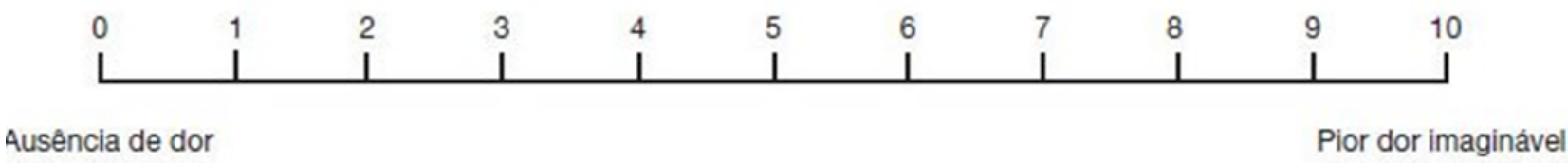

Katz J. e Melzack R., 1999 (10) 


\section{Questionário Para diagnóstico De Dor Neuropática - DN4}

\section{QUESTIONÁRIO PARA DIAGNÓSTICO DE DOR NEU ROPÁTICA - DN4}

Por favor, nas quatro perguntas abaixo, complete o questionánio marcando uma resposta para cada número:

\section{ENTREVISTA DO PACIENTE}

Questāo 1: A sua dor tem uma ou mais das seguintes características?

1- Queimaçăo

2- Sensação de frio dolorosa

3- Choque elétrico
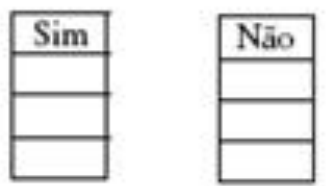

Questão 2: Há presenç̧a de um ou mais dos seguintes sintomas na mesma área da sua dor?

4- Formigamento

5- Alfinetada e agulhada

6- Adormocimento

7-Coceira
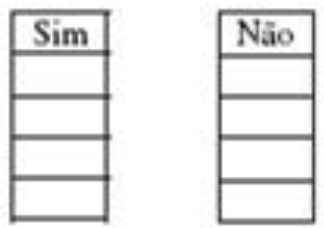

\section{EXAME DO PACIENTE}

Questāo 3: A dor está localizada numa área onde o exame físico pode revelar uma ou mais das seguintes caracteristicas?

8- Hipoestesia ao toque

9- Hipoestesia a picada de agulha

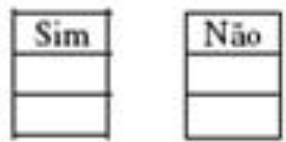

Questão 4: Na área dolorosa a dor pode ser causada ou aumentada por:

10. Escovapaño

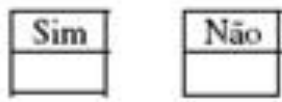

ESCORE

0 - Para cada item negativo 1 - Para cada item positivo

Dor Neuropáticar Escore total a partir de 4/10.

( ) Dor Nociceptiva

( ) Dor Neuropática

Bouhassira D. et al., 2005 (19) 


\section{ANEXO C - Escala Hospitalar de Ansiedade e Depressão (HAD)}

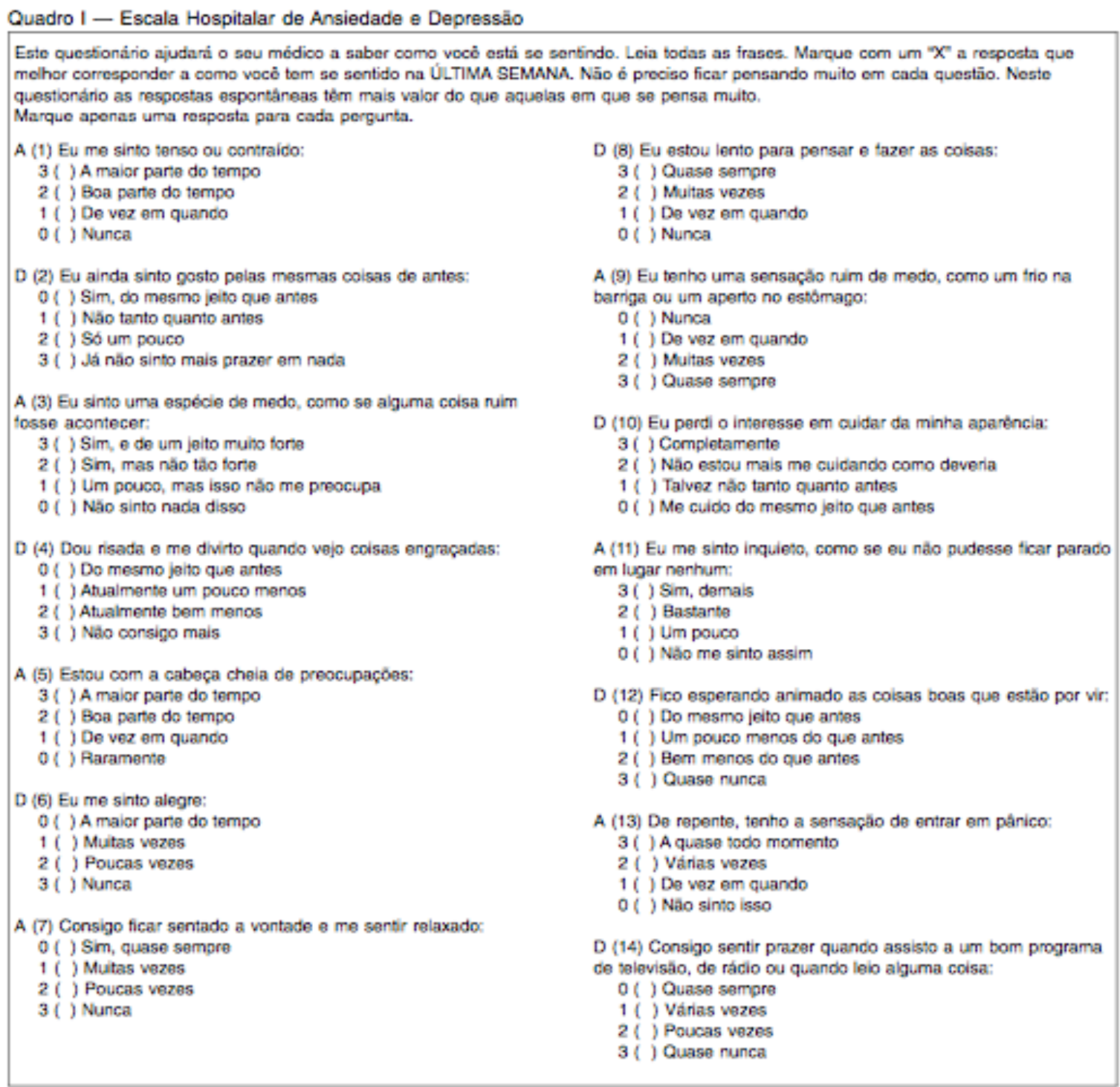


ANEXO D - Escala de Pensamentos Catastróficos Sobre Dor (EPCD)

Na maior parte do tempo, nós dizemos coisas. Por exemplo: nos encorajamos a fazer coisas, nos culpamos quando cometemos um erro ou nos recompensamos por algo que fizemos com sucesso. Quando estamos com dor, frequentemente dizemos coisas que são diferentes do que dizemos quando estamos nos sentindo bem. Abaixo existe uma lista de pensamentos típicos de pessoas que estão com dor. Por favor, leia cada uma dessas frases e marque com que frequência você tem estes pensamentos quando sua dor está forte. Por favor, assinale o número que melhor descreve a sua situação utilizando esta escala: $0=$ quase nunca até $5=$ quase sempre.

Quase nunca

Quase sempre

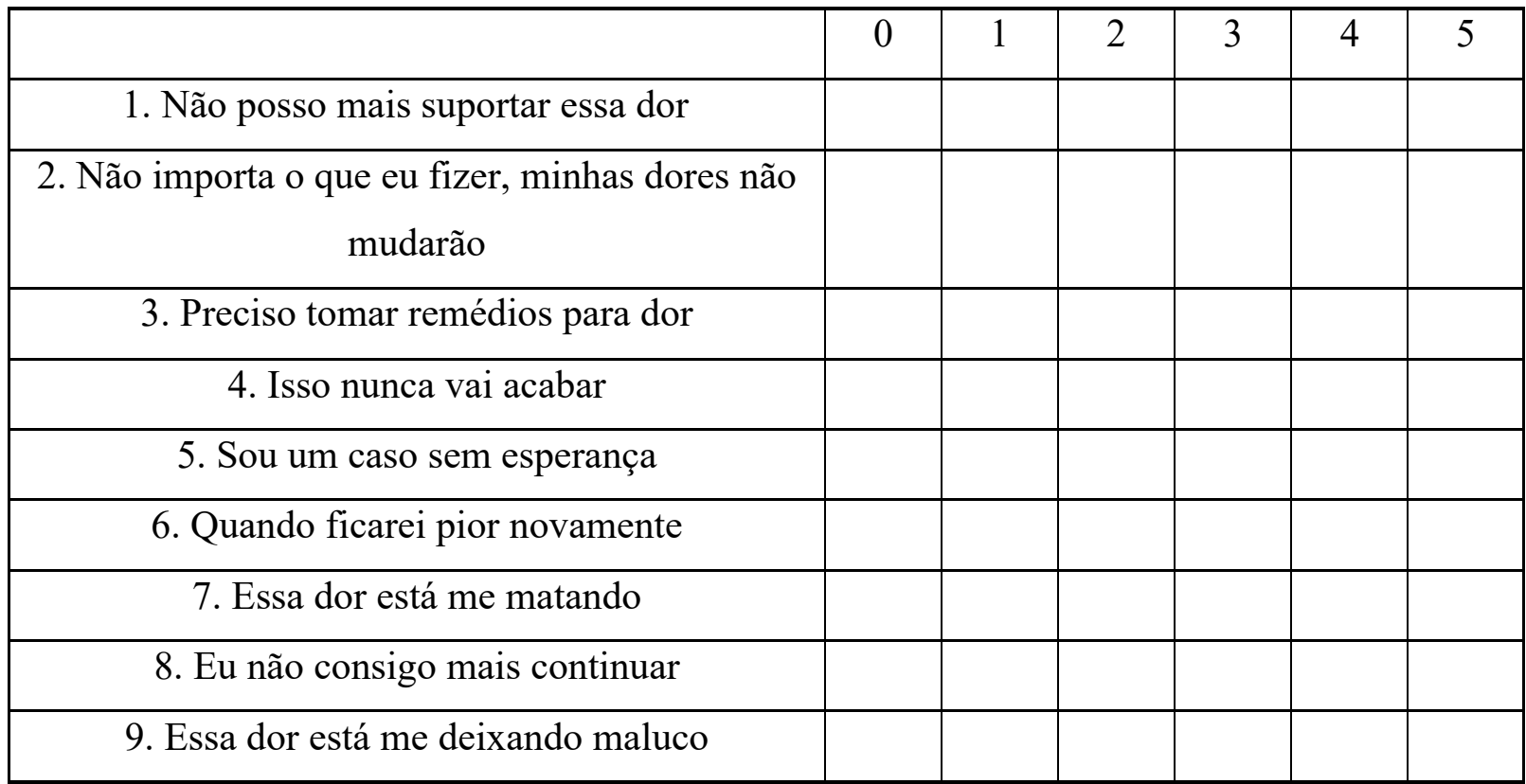

Flor H. et al., 1993 (49) 


\section{ANEXO E - Instrumento Abreviado de Avaliação da Qualidade de Vida \\ (WHOQOL-bref)}

\section{Instruções}

Este questionário é sobre como você se sente a respeito de sua qualidade de vida, saúde e outras áreas de sua vida. Por favor, responda a todas as questões. Se você não tem certeza sobre que resposta dar em uma questão, por favor, escolha entre as altemativas a que the parece mais apropriada. Esta, muitas vezes, poderá ser sua primeira escolha.

Por favor, tenha em mente seus valores, aspiraçốes, prazeres e preocupaçōes. Nós estamos perguntando o que você acha de sua vida, tomando como referência as duas últimas semanas. Por exemplo, pensando nas últimas duas semanas, uma questão poderia ser.

\begin{tabular}{||l|c|c|c|c|c|}
\hline & nada & $\begin{array}{l}\text { muito } \\
\text { pouco }\end{array}$ & médio & muito & completamente \\
\hline $\begin{array}{l}\text { Você recebe dos outros o apoio de que } \\
\text { necessita? }\end{array}$ & 1 & 2 & 3 & 4 & 5 \\
\hline
\end{tabular}

Você deve circular o número que melhor corresponde ao quanto você recebe dos outros o apoio de que necessita nestas últimas duas semanas. Portanto, você deve circular o número 4 se você recebeu "muito" apoio como abaixo.

\begin{tabular}{||l|c|c|c|c|c|}
\hline & nada & $\begin{array}{c}\text { muito } \\
\text { pouco }\end{array}$ & mídio & muito & completamente \\
\hline $\begin{array}{l}\text { Você recebe dos outros o apoio de que } \\
\text { necessita? }\end{array}$ & 1 & 2 & 3 & 4 & 5 \\
\hline
\end{tabular}

Você deve circular o número 1 se você não recebeu "nada" de apoio. 
Por favor, leia cada questïo, veja o que você acha e circule no número e lhe parece a melhor resposta.

\begin{tabular}{||l|l|c|c|c|c|c||}
\hline & & $\begin{array}{c}\text { muito } \\
\text { nuim }\end{array}$ & ruim & $\begin{array}{c}\text { nem ruim } \\
\text { nem boa }\end{array}$ & boa & $\begin{array}{c}\text { muito } \\
\text { boa }\end{array}$ \\
\hline 1 & $\begin{array}{l}\text { Como você avaliaria sua qualidade de } \\
\text { vida? }\end{array}$ & 1 & 2 & 3 & 4 & 5 \\
\hline
\end{tabular}

\begin{tabular}{||l|l|l|l|c|c|c||}
\hline & $\begin{array}{l}\text { muito } \\
\text { insatisfeito }\end{array}$ & insatisfeito & $\begin{array}{c}\text { nem satisfeito } \\
\text { nem insatisfeito }\end{array}$ & satisfeito & $\begin{array}{c}\text { muito } \\
\text { satisfeit } \\
0\end{array}$ \\
\hline 2 & $\begin{array}{l}\text { Quăo satisfeito(a) vocé está } \\
\text { com a sua saúde? }\end{array}$ & 1 & 2 & 3 & 4 & 5 \\
\hline
\end{tabular}

As questōes seguintes são sobre o quanto vocễ tem sentido algumas coisas nas últimas duas semanas.

\begin{tabular}{|c|c|c|c|c|c|c|}
\hline & & nada & $\begin{array}{l}\text { muito } \\
\text { pouco }\end{array}$ & $\begin{array}{l}\text { mais ou } \\
\text { menos }\end{array}$ & bastant & extremamente \\
\hline 3 & $\begin{array}{l}\text { Em que medida você acha que sua dor } \\
\text { (física) impede vocé de facrer o que você } \\
\text { precisa? }\end{array}$ & 1 & 2 & 3 & 4 & $s$ \\
\hline 4 & $\begin{array}{l}\text { O quanto você precisa de algum } \\
\text { tratamento médico para levar sua vida } \\
\text { điária? }\end{array}$ & 1 & 2 & 3 & 4 & 5 \\
\hline 5 & O quuanto você aproveita a vida? & 1 & 2 & 3 & 4 & 5 \\
\hline 6 & $\begin{array}{l}\text { Em que medida você acha que a sua vida } \\
\text { tem sentido? }\end{array}$ & 1 & 2 & 3 & 4 & 5 \\
\hline 7 & O quanto você consegue se concentrar? & 1 & 2 & 3 & 4 & 5 \\
\hline 8 & $\begin{array}{l}\text { Quão seguro(a) você se sente em sua vida } \\
\text { điária? }\end{array}$ & 1 & 2 & 3 & 4 & 5 \\
\hline 9 & $\begin{array}{l}\text { Quão saudável é o seu ambiente fisico } \\
\text { (clima, barulho, poluição, atrativos)? }\end{array}$ & 1 & 2 & 3 & 4 & 5 \\
\hline
\end{tabular}

As questōes seguintes perguntam sobre

quão completamente vocẻ tem sentido ou é capaz de fazer certas coisas nestas ültimas duas semanas.

\begin{tabular}{|c|c|c|c|c|c|c|}
\hline & & nada & $\begin{array}{l}\text { muito } \\
\text { pouco }\end{array}$ & médio & muito & completamente \\
\hline 10 & Vocé tem energia suficiente para seu dis-a-dia? & 1 & 2 & 3 & 4 & 5 \\
\hline 11 & Vocé é capaz de aceitar sua aparéncia fisica? & 1 & 2 & 3 & 4 & 5 \\
\hline 12 & $\begin{array}{l}\text { Você tem dinheiro suficiente para satisfazer suas } \\
\text { necessidades? }\end{array}$ & 1 & 2 & 3 & 4 & $s$ \\
\hline 13 & $\begin{array}{l}\text { Quão disponiveis para vocẻ estão as } \\
\text { informap̧ōes que precisa no seu đia-a-dia? }\end{array}$ & 1 & 2 & 3 & 4 & 5 \\
\hline 14 & $\begin{array}{l}\text { Em que medida você tem oportunidades de } \\
\text { atividade de lazer? }\end{array}$ & 1 & 2 & 3 & 4 & $s$ \\
\hline
\end{tabular}


As questōes seguintes perguntam sobre quảo bem ou satisfeito você se sentiu a respeito de vários aspectos de sua vida nas últimas duas semanas.

\begin{tabular}{|c|c|c|c|c|c|c|}
\hline & & $\begin{array}{l}\text { muito } \\
\text { nuim }\end{array}$ & nuim & $\begin{array}{l}\text { nem ruim } \\
\text { nem bom }\end{array}$ & bom & $\begin{array}{l}\text { muito } \\
\text { bom }\end{array}$ \\
\hline 15 & Quگ̃o bem vocé é capaz de se locomover? & 1 & 2 & 3 & 4 & 5 \\
\hline
\end{tabular}

\begin{tabular}{|c|c|c|c|c|c|c|}
\hline & & $\begin{array}{c}\text { mito } \\
\text { inswivitib }\end{array}$ & intivatio & $\begin{array}{l}\text { ter utived } \\
\text { teri inusivedo }\end{array}$ & sutsfeito & $\begin{array}{l}\text { mito } \\
\text { matifition }\end{array}$ \\
\hline 16 & $\begin{array}{l}\text { Quão satisfeito(a) você está com o seu } \\
\text { sono? }\end{array}$ & 1 & 2 & 3 & 4 & 5 \\
\hline 17 & $\begin{array}{l}\text { Quão satisfeito(a) você está com sua } \\
\text { capacidade de desempenhar as atividades } \\
\text { đo seu dia-a-dia? }\end{array}$ & 1 & 2 & 3 & 4 & 5 \\
\hline 18 & $\begin{array}{l}\text { Quão satisfeito(a) você está com sua } \\
\text { capacidade para o trabalho? }\end{array}$ & 1 & 2 & 3 & 4 & 5 \\
\hline 19 & $\begin{array}{l}\text { Quão satisfeito(a) você está consigo } \\
\text { mesmo? }\end{array}$ & 1 & 2 & 3 & 4 & 5 \\
\hline 20 & $\begin{array}{l}\text { Quão satisfeito(a) vocé está com suas } \\
\text { relaçōes pessoais (amigos, parentes, } \\
\text { conhecidos, colegas)? }\end{array}$ & 1 & 2 & 3 & 4 & 5 \\
\hline 21 & $\begin{array}{l}\text { Quão satisfeito(a) você está com sua vida } \\
\text { sexual? }\end{array}$ & 1 & 2 & 3 & 4 & 5 \\
\hline 22 & $\begin{array}{l}\text { Quão satisfeito(a) você está com o apoio } \\
\text { que você receb̀e de seus amigos? }\end{array}$ & 1 & 2 & 3 & 4 & 5 \\
\hline 23 & $\begin{array}{l}\text { Quão satisfeito(a) voeê está com as } \\
\text { condiçūes do local onde mora? }\end{array}$ & 1 & 2 & 3 & 4 & 5 \\
\hline 24 & $\begin{array}{l}\text { Quão satisfeito(a) você está com o seu } \\
\text { acesso aos serviços đe saúde? }\end{array}$ & 1 & 2 & 3 & 4 & 5 \\
\hline 25 & $\begin{array}{l}\text { Quão satisfeito(a) você está com o seu } \\
\text { meio de transporte? }\end{array}$ & 1 & 2 & 3 & 4 & 5 \\
\hline
\end{tabular}

As questōes seguintes referem-se a com que freqü̈̇ncia você sentìu ou experimentou certas coisas nas útimas duas semanas.

\begin{tabular}{|c|c|c|c|c|c|c|}
\hline & & nume & $\begin{array}{l}\text { dymss } \\
\text { seos }\end{array}$ & feqpertemertix & $\begin{array}{c}\text { mato } \\
\text { fogientureste }\end{array}$ & senpre \\
\hline 26 & $\begin{array}{l}\text { Com que frequẻencia você tem } \\
\text { sentimentos negativos tais como mau } \\
\text { humor, desespero, ansiedade, } \\
\text { đepressão? }\end{array}$ & 1 & 2 & 3 & 4 & 5 \\
\hline
\end{tabular}

The WHOQOL group, 1998 (54) 
ANEXO F - Escala de Sonolência de Epworth

Escala de Sonolência de Epworth - validação brasileira.

Nome:

Data:__ Idade (anos):

Sexo:

Qual a probabilidade de você cochilar ou dormir, e não apenas se sentir cansado nas seguintes situações? Considere o modo de vida que você tem levado recentemente. Mesmo que você tenha feito algumas destas coisas recentemente, tente imaginar como elas o afetariam. Escolha o número mais apropriado para responder cada questão:

$0=$ nunca cochilaria

$1=$ pequena probabilidade de cochilar

2 = média probabilidade de cochilar

3 = grande probabilidade de cochilar

\section{Situação}

Sentado e claro

Assistindo TV

Sentado, quieto, em ligar público (por exemplo, em um teatro, reunião ou palestra)

Andando de carro por uma hora sem parar como passageiro

Ao deitar-se à tarde para descansar, quando possível

Sentado conversando com alguém

Sentado quieto após o almoço sem bebida de álcool

Em um carro parado no trânsito por alguns minutos

Probabilidade de cochilar

$\begin{array}{llll}0 & 1 & 2 & 3\end{array}$

$\begin{array}{llll}0 & 1 & 2 & 3\end{array}$

$\begin{array}{llll}0 & 1 & 2 & 3\end{array}$

$\begin{array}{llll}0 & 1 & 2 & 3 \\ 0 & 1 & 2 & 3\end{array}$

$\begin{array}{llll}0 & 1 & 2 & 3\end{array}$

$\begin{array}{llll}0 & 1 & 2 & 3\end{array}$

Obrigado por sua cooperação

Bertolazi AN et al., 2009 (64) 